UC-NRLF

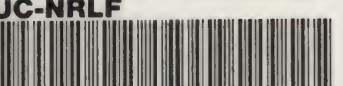

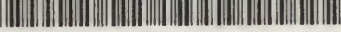

B 3 키 494 


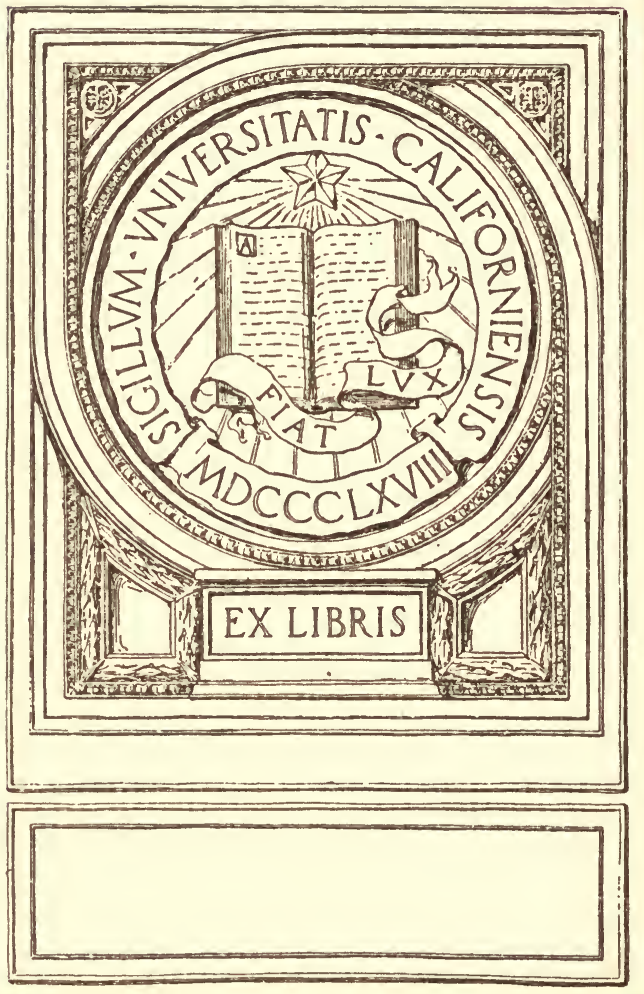







\section{SKELETAL REMAINS}

SUGGESTING OR ATTRIBUTED TO EARLY MAN

\section{IN NOR'TH AMERICA}

BY

\section{ALE HRILIČKA}

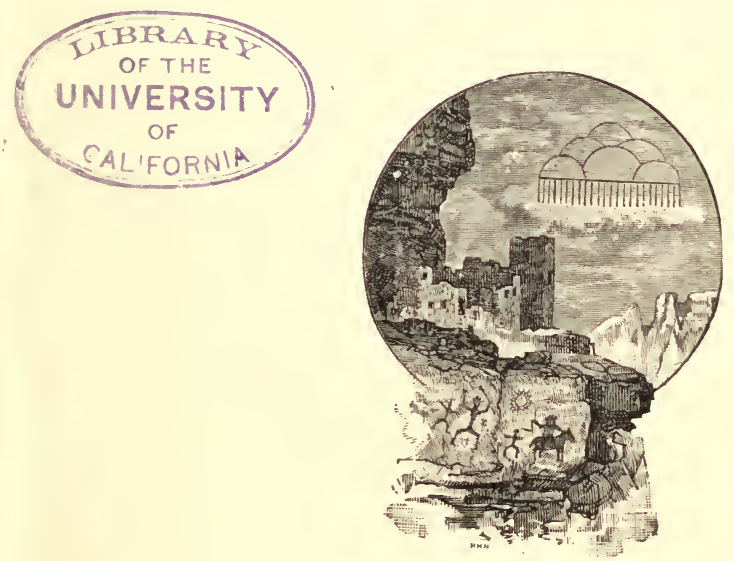

\section{W A S H I N G'TON}

GOVIR M E T P R I T I NG OFFICE 1907 
$\sum_{n^{5}}^{5}=3$

h 


\section{PREFATORY NOTE}

The Bureau of American Ethnology from its foundation has taken a deep interest in all researches relating to the antiquity of man in America, and its attitude in considering the various questions that have arisen has been conservative. In the earlier years of the investigation there existed a rather marked tendency on the part of students, and especially on the part of amateurs and the general public, hastily to accept any testimony that seemed to favor antiquity, and the conservative attitude of the Bureau was emphasized by a desire to counteract and correct this tendency. Evidence of the great antiquity of man in the Old World is abundant and convincing, and the assumption that like conditions exist in America seemed reasonable and was perhaps justifiable, although it led to the general acceptance of much that was without satisfactory rerification.

It has been the practice of the Bureau when discoveries believed to have an important bearing on the question of human antiquity in North America have been announced to seek to determine their just value. In pursuance of this plan its representatives have been sent on occasion to New Jersey, to the Ohio valley, to sites on the Potomac, to Minnesota, to California, to Florida, and to Kansas, to make the necessary investigations. On receipt of reports of the discovery in Nebraska of human crania of low type and possibly of great geological antiquity, prompt action was taken. Doctor Hrdlička, an accomplished student of human osseous remains, was sent to Lincoln to examine the peculiar remains and to make such investigations regarding the conditions under which they were discovered as he might find possible at that season of the year. When this discovery was announced, the Bureau was about to send to press a paper by Doctor IIrdlička embodying descriptions of all the known American human remains for which geological antiquity had been claimed. This paper was withheld from publication, however, until the Nebraska specimens could be examined, so that the present bulletin inchudes; descriptions of these as well as of all kindred remains brought to light in North America up to the present time.

W. H. Hownes, Chief. 



\section{CONTENTS}

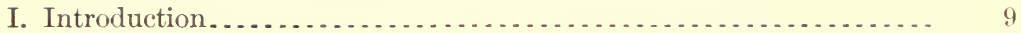

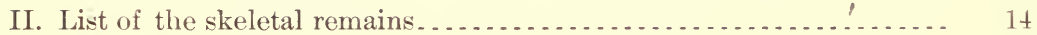

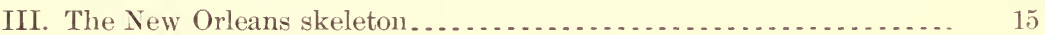

IV. The Quebec skeleton . . . . . . . . . . . . . . . . . . . . . . . . . . 16

V. The Natchez pelvic bone. . . . . . . . . . . . . . . . . . . . . . . . . . 16

VI. The Lake Monroe (Florida) bones . . . . . . . . . . . . . . . . . . . . . . . 19

VII. The Soda Creek skeleton . . . . . . . . . . . . . . . . . . . . . . . . . 20

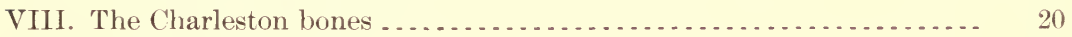

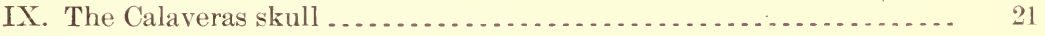

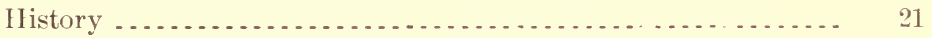

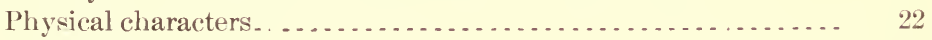

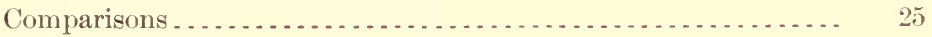

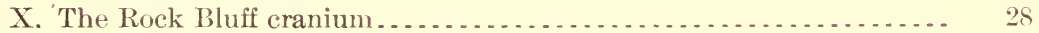

XI. The Man of Peñon . . . . . . . . . . . . . . . . . . . . . . . . . . . . . 32

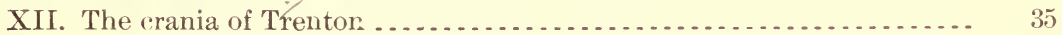

The Burlington County skull ....................... . 36

The Riverview Cemetery skull . . . . . . . . . . . . . . . . . . . 36

Racial affinities of the Burlington County and Riverview Ceme-

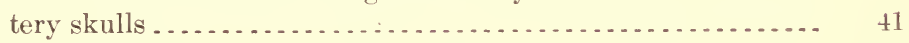

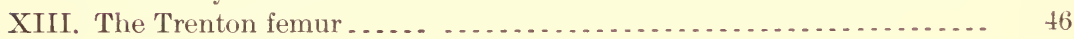

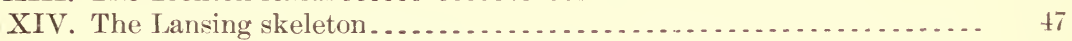

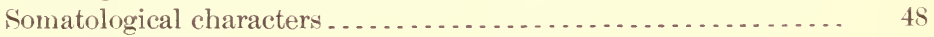

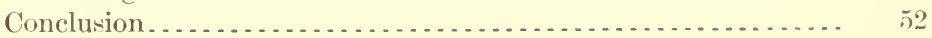

XV. The fossil man of western Florida . . . . . . . . . . . . . . . . . 53

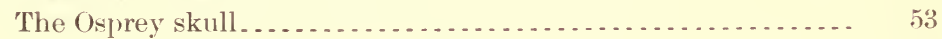

The North Osprey bones. . . . . . . . . . . . . . . . . . . . . 54

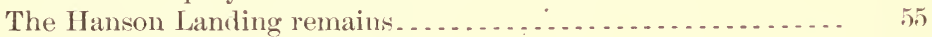

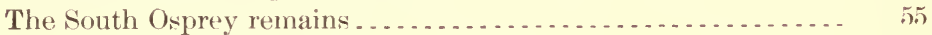

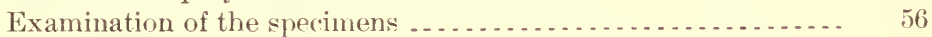

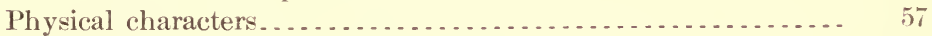

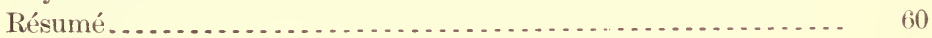

Report of Dr. T. Wayland Vaughan ................. 64

XVI. Mound crania (Florida) . . . . . . . . . . . . . . . . . . . . . 66

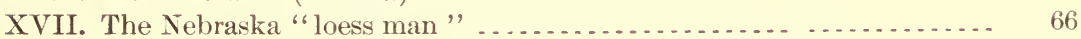

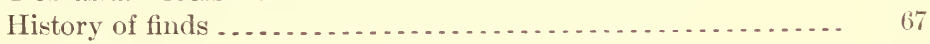

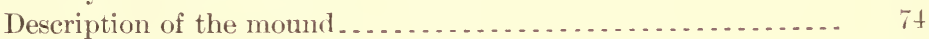

Examination of the bones. . . . . . . . . .

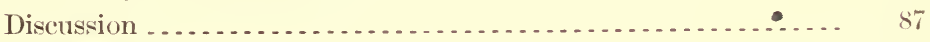

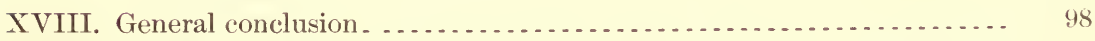

XIX. Appendix: Recent Indian skulls of low type in the U. S. National

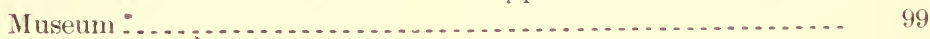

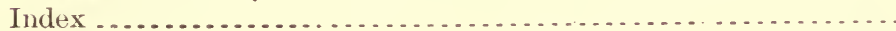





\section{TLLUSTRA'TIONS}

Puate I The Calaveras (California) skull as it was in 1902 .

II. Skulls from Illinois

III. Skull from Burlington county, New Jersey .................... 37

IV. Skull from Riverview cemetery, Trenton, New Jersey .... . . . . . . . 37

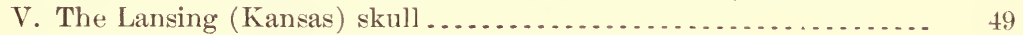

VI. Skulls from Florida ........................................ 57

VII. The North Osprey (Florida) femur and tibia................. 59

VIII. The South Osprey (Florida) skeleton...................... 59

IX. Osseous remains in process of silicification, found at Sonth Osprey, Florida ...................................................... 64

X. Skulls from Gilder mound ............................. 80

XI. Skulls from Gilder mound . ............................... 80

XII. Skulls with low foreheads (Davenport Academy of Sciences) . . . . . 95

XIII. Mound-builder skulls (Davenport Academy of Sciences) .......... 95

XIV. Skull from mound in North Dakota (I. S. National Museum no.

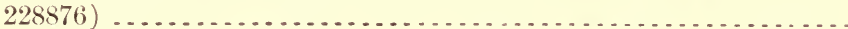

XV. Skull of Piegan from Montana (U. S. National Museum no. 243673).

XVI. Skull irom mound near Browning, Schuyler county, Illinois (I. S.

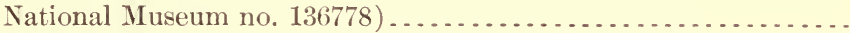

XVII. Skulls with low foreheads, from Illinois and Nevada.............

XVIII. Skulls with low foreheads, from California....................

XIX. Skull from Santa Cruz island, California (I. S. National Museum no. 241927 )

XX. Skulls with low foreheads, from California and Wisconsin ........

XXI. Skull from mound in Orange county, Incliana (U. S. National Museum no. 243855) . . . . . . . . . . . . . . . . . . . . . . . . . . . . . .

Fig. 1. Geological formations concerned in human history ...............

2. The Natchez pelvic bone (after Leidy) . . . . . . . . . . . . . . . . . . . .

3. Cave skull, Calaveras county, California; sicle view .............. . .

4. Remnant of the skull of the "Hombre del Peñon" (after Barcena, in

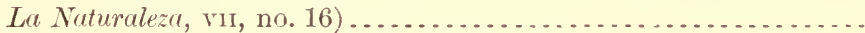

5. Front view of two of the Bremen chamæcephals ................

6. Side and top views of one of the Bremen chamæcephals...........

7. Comparison of the nasion-opisthion ares, geometrically constructed, of the Lansing skull and three modern Indian crania.......... .

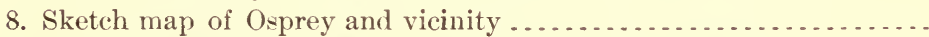

9. Section of deposits showing position of the Osprey skull .........

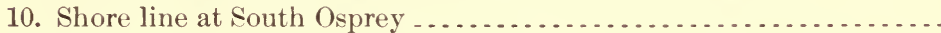

11. Section of the layers at the locality of the South Osprey find.......

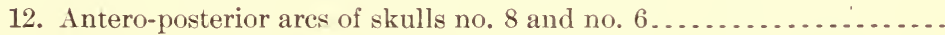

13. Antero-posterior ares of skulls no. 4402, Davenport Academy of

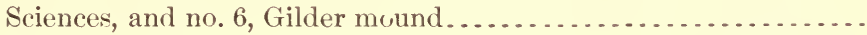

14. Antero-posterior ares of skulls no. 4402, Davenport Academy of

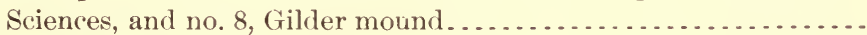

15. Antero-posterior ares of skulls no. 242982, U. S. National Museum,

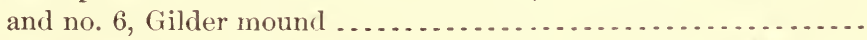

16. Antero-posterior ares of skulls no. 242982, U. S. National Museum, and no. 8, Gilder mound 



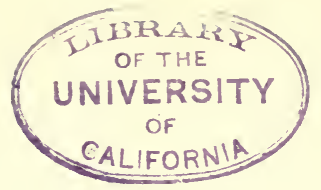

\title{
SKELETAL REMAINS SUGGESTING OR ATTRIBUTED TO EARLY MAN IN NORTH AMERICA
}

\author{
By Aleš HrdiččKa
}

\section{I.-INTRODUCTION}

According to current classification of geological time, the Cenozoic era (the era of modern life) is divided into two periods, the Tertiary and the Quaternary. The former, which is the older, comprises three subdivisions, Eocene. Miocene, and Pliocene, and the latter two subdivisions, Pleistocene and Recent. These periods are indicated in figure 1 in the order of the formations representing them.

Man made his appearance in the Old World probably during the Tertiary period through differentiation from the primates, the class of animals to which he presents the closest structural analogies. Primates of the higher forms were not found in America; they existed only in the warmer parts of Asia, Africa, and Europe, and it is there that we must look for the first traces of man's appearance. Accepting this view, it follow: that America was peopled by immigration from the Old World,

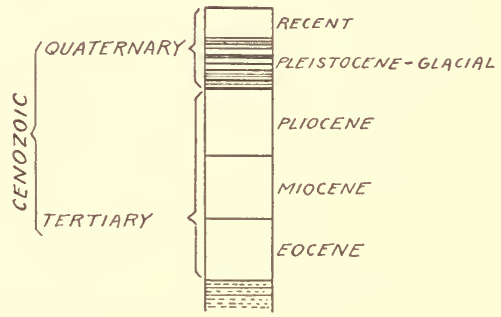

Fif. 1.-Geological formations concerned in human history.

which could not have taken place until after great multiplication and wide distribution of the human species and the development of some degree of culture. This implies a vastly later date than that which must be assigned to man's origin. A wide dispersion of the race over the earth could hardly have taken place before the later stages of the Cenozoic era.

In considering the question of the appearance of man in America, special interest attaches to the Pleistocene, during several phases of which period man is known to have existed in central and western Europe; there is absolutely no indication that he reached the American continent before that time. The American Pleistocene, which is. synchronous with the Glacial period, is marked by certain well-known geological deposits, which are particularly abundant and character- 
istic in the regions over which the glaciers extended. These formations include especially the so-called glacial gravels which have received particular attention at the hands of students of early ${ }^{a}$ man in this country.

The several irregular ice invasions extended at their maximum as far south on the Atlantic coast as Long Island. In the Delaware valley they reached Easton, Pennsylvania; in the Ohio valley, Cincinnati, Ohio; and in the Missouri valley, the vicinity of St. Louis. Beginning with the earliest subdivision, the several successive stages of this period, with the few and uncertain chronological approximations that have been made, are thus given by leading American geologists : ${ }^{b}$

I. The Sub-Aftonian, or Jerseyan, the earliest known invasion

Time in years since climax was reached

II. The Aftonian, the first known interglacial interval

III. The Kansan, or second invasion now recognized-_

300,000 to $1,020,000$

IV. The Yarmouth, or Buchanan, the second interglacial interval

T. The Illinoian, the third invasion

140, 000 to 540,000

VI. The Sangamon, the third interglacial interval

60,000 to 300,000

VIII. The Peorian, the fourth interglacial interval

40,000 to 150,000

$\mathrm{X}$. The fifth interval of deglaciation, as yet unnamed

20,000 to $(60,000$

XI. The Later Wisconsin, the sixth advance_.........

XII. The Glacio-Lacustrine substage.

XIII. The Champlain substage.

The glacial invasion closed apparently with a gradual recession of the ice, and thus terminated considerably earlier in southern than in northern latitudes; this should be kept in mind in considering the date of the ultimate disappearance of 'the ice in any limited region. The precise date of the final recession of ice in any locality must always remain in a large degree conjectural. The climax of the final, or Champlain substage, in the latitude of the St. Lawrence river, was apparently reached considerably more than ten thousand years ago. ${ }^{c}$

Should it be assumed that man existed on the North American continent before the present geological period, and taking into account his osseous remains only, two important questions arise, namely, where

a The term early, as employed in this paper, applies only to the Pleistocene and older geological periods.

${ }^{b}$ After 'Thomas C. Chamberlin and R. D. Salisbury's Geology, III, 383, 420, New York, 1906 ; reversed in arrangement. See also Salisbury's The Glacial Geology of New Jersey, Geological Survey of New Jersey, v, Trenton, 1902. It should not be understood that all of the given divisions apply to the entire vast glaciated area; some of the terms relate only to somewhat localized phases of the period.

c A summary of the whole question of estimates by years is given in the chapter on the Glacial period in volume III of Chamberiln and Salisbury's Geology. 
are such remains likely to oceur and how is their antiquity to be determined. The first of these queries is answered with comparative ease. Man's greatest necessities are food and water, and unrestrained settlement of primitive peoples was guided everywhere to a large extent by facilities for obtaining these requisites. The only other strong motives which generally influenced the choice of dwelling sites were the requirements of comfort (including primarily a farorable climate) and of safety. It may be assumed, therefore, that the habitations of the earliest Americans were established on defensible sites along the seashore and larger streams where the food supply, consisting of mollusks, fish, and game animals, as well as of fruits, was particularly abundant, and in regions free from the extremes of climate. Thus it is mainly on and about elevated sites along the sea coasts and in the valleys of the temperate zones of the periods of occupation that bones of early man should first be looked for. If there are contemporaneous rock recesses, especially caves, these should receive attention, for such shelters were utilized by all primitive peoples for both dwelling and burial. Bog deposits, which naturally offer favorable conditions for the preservation of the bones of those who perished in such places, also deserve examination.

Proper identification of human bones as those of early man is of the first importance, and at the same time is fraught with exceptional difficulties. Finds of osseous remains suggesting man of other than the recent period should be photographed in situ, and should be examined by more than one man of science, including especially a geologist familiar with the particular formations involved; and the chemical and somatological characters of the bones should receive the closest attention with the view of determining their bearing on questions involving the antiquity of the remains. The history of a majority of archeological finds suggestive of early man in this country is particularly instructive in this connection, ${ }^{a}$ illustrating as it roes many of the difficulties attending efforts at chronological identification.

A point requiring especial attention is that of the possibility of intrusive burials. Men of recent times have inhabited many of the sites that may have been occupied by early man, and it will be readily appreciated that human remains of different periods might often be closely associated or even intermingled. Where such an occurrence is suspected, chemical and somatological tests are of particular value,

${ }^{a}$ See especially the papers of W. II. Holmes on Traces of Glacial Man in Ohio, Journal of Geology, I, 147-163, February-March, 1893: Vestiges of Early Man in Minnesota, American Geologist, xI, 219-240, April, 1893; Are there Traces of Man in the Trenton Gravels? Journal of Geology, I, 15-37, January-February, 1893; Primitive Man in the Delaware Valley, Scienee, n. s., vi, 824-829, 1897; and Review of the Evidence relating to Auriferous Gravel Man in California. Smithsonian Report for 1899, 419-472, Washington. 1901. 
although their application may prove ardnous and is not certain of affording satisfactory results.

A geologically ancient bone may be safely expected to show some? degree of infiltration and replacement of its constituents by mineral matter, while modern bones are generally little changed; yet there exist in some localities conditions which greatly retard or facilitate the processes of mineralization, so that ancient bones may show but little evidence of fossilization, while, on the other hand, undoubtedly recent bones may have undergone decided change. The latter condition is far more frequent. There is a possibility that the kind or the degree of the change may make it practicable to distinguish between recent and ancient fossilization; but there are as yet no satisfactory means of testing this matter.

Somatologically, the bones, and particularly the skull, of early man may be confidently expected to show some differences from those of modern man, especially in the direction of lesser differentiation. Unfortunately the knowledge of the osseous structures of early man in other parts of the world is still meager, and this lack of information is felt very keenly. We do not know as yet whether the human beings of the geological period just before the recent differed so from the present man that even the extreme individual variations in the two periods (the most advanced evolutionally in the old and the least advanced among modern individuals) would stand appreciably apart. Very likely they overlap and dovetail considerably.

Yet the difficulties which may attend the separation on the morphological basis of ancient from recent man should not be insuperable. If a find should consist of a series of well-preserved skulls or skeletons geologically ancient and of a similarly well-preserved series of skulls or skeletons of recent man, it is the firm conviction of the writer that in a large majority, if not in all, of the cases, their separation would be practicable. 'The greater the number of male adult normal, and in no way deformed, crania in each find, the easier it would become to make the necessary distinctions; and it may be safely assumed also that the greater the separation of the two groups in time the more distinct would be the somatological differences.

There is no such thing as absolute stability in any human structure. Every organic feature, of whatever consistency or importance, is the result of all the factors by which it was affected. With the skeletal parts by far the strongest of these factors, in itself a very composite one, is the potentiality of heredity, next to which in importance comes habitual muscular action, particularly muscular use due to long-established habits of whole groups of people Heredity, however, especially in so far as it applies to the latest acquired characteristics of the skeleton, is subject to incidental irregularities as well as to gradual modifications. Habits of muscle action, on the other 
hand, change with environment and culture; such changes in activities may take place much more slowly in some localities than in others, yet they are bound to manifest themselves everywhere in the course of ages and to be followed by corresponding and recurring structural alterations. The great skeletal diversity of mankind to-day can be accounted for in no other manner. The alterations in the skull or bones need not be general or even of prime importance, and may require for their discovery detailed study and extended comparisons; but in the case of an individual from the earlier stages of the period immediately preceding the recent they should be pronounced enough to be easily apprehended. ${ }^{a}$ 'The geologically ancient crania of Europe may be cited in support of this statement. In the case of single features, however, or with scanty material, all far-reaching conclusions must be avoided, for in such cases we can not be certain that we are outside of the territory of semipathological occurrences, and features of reversion, degeneration, or purely accidental variation limited to individuals or small numbers of persons.

In this connection it is necessary to bear in mind also human migrations, resulting in a replacement of physical types. While the stability of the same stock of people is much greater in some localities than is generally appreciated, it is probable that in a large majority of places one or more replacements of population have occurred even during recent geological time. On this account alone the explorer is very likely to find in recent burials racial types distinct from those found in older burials. The greater the difference in age between two sets of osseous human remains the greater the improbability, for the reason just given above, that they belong to one physical variety.

To summarize, identification of human bones as those of early man-that is, man of geological antiquity-demands indisputable siratigraphical evidence, some degree of fossilization of the bones, and marked serial somatological distinctions in the more important osseous parts. A skeleton or a skull not fossilized or one (whether fossilized or not) agreeing in most of the more essential features

${ }^{a}$ It has been stated on good authority (A. Thompson and D. Randall-MacIver, The Ancient Races of the Thebaid, Oxford, 1905; and chas. S. Myers, Contributions to Egyptian Anthropometry, Journal of the Anthropological Institute, xxxy, 80-91, 1905) that the most ancient known inhabitants of Egypt, dating from about seven thousand to elght thousand years ago, show no important difference of type from certain Egyptian natives of the present day. If definitely settled, the fact would be of much importance; it does not appear, however, that much attention was paid to numerous features of the skulls such as do not enter ordinarily into anthropometric determinations, but which may play a large part in making distinctions. It is often possible to detect just such secondary or less commonly studied characteristics in different localities among the Indians, even though these belong to the same general type, and it may be confidently asserted thai they would be found to differentiate recent from ancient man in any locality. It should be borne in mind also in connection with the Egyptian crania that seven thousand or eight thousand years is really but a short period geologically, equaling probably less than half of the recent era. See on this subject also E. Schmidt, in the Arch. f. Anthrop., XVII, 189 et seq., 1888. 
with a skeleton or a skull of recent, or not very ancient, man in the same locality, can not be accepted as geologically ancient, unless the geological evidence should be absolutely decisive. Features characteristic of inferior stages of human development, though to be expected in all geologically ancient skeletal parts of man, are not of themselves necessarily proofs' of antiquity; their presence only strengthens the case if associated with other evidence of great age of the specimens.

\section{II.-LIST OF THE SKELETAL REMAINS}

Interest in man's antiquity in this country began to manifest itself at about the same time as the growth of interest in man's natural history in general, and with the rise of the science of anthropology during the earlier part of the nineteenth century. The work of Morton in this country and of Prichard in England doubtless had great influence in this direction; Morton's Crania Americana ${ }^{a}$ particularly drew attention to the remains of the human skeleton. 'The first find of importance of bones that seemed to indicate the presence of early man was made in 1844, and similar discoveries followed from time to time. The finds so far made include fourteen specimens or groups of specimens, the majority of which call for careful consideration. They are as follows:

A. The New Orleans (Louisiana) bones, discovered in_-__-_____-_- $18+4$

B. The Quebec (Canada) skeleton, discovered in

C. The Natchez (Mississippi) pelvic bone, discovered in__________ 1846

D. The Lake Monroe (Florida) bones, discovered in____________ 18.22 or 1853

L. The Soda Creek (Colorado) skeleton, discovered in $\ldots \ldots+1860$

I. The Charleston (South Carolina) remains, discovered in

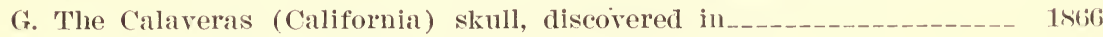

II. The Rock Bluff (Illinois) skull, discovered in_________. 1866;

I. The Peñon (Mexico) skeleton, discovered in______ 1884

J. The Trenton (New Jersey) skulls, discovered in________ 1879-1897

K. The Western Florida skull and bones, discovered in _-_ 1571-1588

L. The Trenton (New Jersey) femur, discovererl in ______ 1899

M. The Lansing (Kansas) skeleton, discovered in

N. The Nebraska "loess man," discovered in_____________ 1594-1900;

A majority of these specimens have been previonsly examined and reported upon, ${ }^{b}$ and within the last few years the writer has reexamined and compared all the more important available material and besides has been able to visit the localities of the heretofore undescribed western Florida skeletons. The crania and other remains are dealt with according to chronological sequence of discovery, with the exception of those from Florida, which are placed near the last for the reason that, although brought to light some years ago, they had

${ }^{a}$ Philadelphia, 1839.

${ }^{b}$ For bibliographical references, see the reports in this paper on the several finds. 
not been studied until the last year. The whole investigation has been carried on without preconceived opinions in regard to either the presence in or the absence from northern America of early man and is in the main a simple anatomical comparison.

\section{III.-THE NEW ORLEANS SKELETON}

In a number of the older writings touching on the subject of man's antiquity in North America, particularly in Nott and Gliddon, ${ }^{a}$ are found references to the discovery of an apparently ancient skeleton at New Orleans, Louisiana. The original report on this find, usually credited to D. B. Dowler, ${ }^{b}$ is by Prof. D. Drake, ${ }^{c}$ and reads as follows:

In 1844 I visited two gas tanks, each 60 feet in diameter and 16 feet deep, recently sunk in the back part of the city [i. e., New Orleans], and received from the intelligent superintendent, Doctor Rogers, an account of what was met with in excavating them. At first they encountered soil and soft river mud, then harder laminated blue alluvion, then deep black mold resting on wet bluish quicksand. . . . The roots and the basis or stumps of no ferer than four successive growths of trees, apparently cypress, were found standing at different elerations. The first had a diameter of 2 feet 6 inches, the second of 6 feet, the third of 4 feet, and the fourth of 12 feet, at al short distance up, with a base of 28 feet for the roots. It is embedded in a soft deep-black mold. When cut with the spade much of this wood resembled cheese in texture, but hardened on drying. . . . At the depth of $\tau$ and 16 feet burnt wood was met with. No shells or bones of land animals or fish were observed, but in a tank previously excarated, at the depth of 16 feet the skeleton of a man was found. 'The cranium lay between the roots of a tree and was in a tolerable state of preservation, but most of the other bones crumbled on pressure. A small os ilium, which I saw, indicated the female sex. A low and narrow forehead, moderate facial angle, and prominent widely separated cheek bones seemed to prove the skull of the same race with our present Indians. No charcoal, ashes, or ornaments, of any kind were found around it.

On the basis of the foregoing rather defective data and calculations as to the probable age of the stumps, Doctor Dowler concluded (page 17) that the "human race existed in the delta more than fifty-seven thousand years ago." On a little reflection this estimate shows so many weak points that it can not be accepted for anything more than an individual opinion. The notes concerning the skull, so far as they go, indicate that the specimen resembled in the main the skull of an ordinary Indian, but this conclusion has little value. It is nowhere stated what became of the skeleton. Drake's remark that " most of the other bones crumbled on pressure" makes it probable that few, if any, parts of it have been preserved, and also clearly indicates that the bones were in no degree fossilized.

\footnotetext{
a Types of Mankind, chap. xi, numerous editions, Philadelphia.

${ }^{b}$ Tableaux of New Orleans, 8-9, New Orleans, no date (published in the early fifties).

c A Systematic Treatise on the Principal Diseases of the Interior Valley of North America, etc., 76-77, Cincinnati, 1850.
} 


\section{IV.-THE QUEBEC SKELE'TON}

According to Doctor Usher ${ }^{a}$ a fossil human skeleton, "which was dug out of the solid schist-rock on which the citadel stands," was preserved in the museum at Quebec. There are no particulars in print concerning the find; the skeleton is not preserved in the Laval University Museum, the only museum in the city containing objects of natural history, and nothing could be learned concerning it during the writer's recent visit to Quebec. The absurdity of the statement that a human skeleton was " $\operatorname{dug}$ out of the solid schistrock" will be apparent when it is remembered that the rock is Silurian.

\section{V.-TIEE NATCHE/ PELVIC BONE}

In $18 \pm 6$ Dr. M. Wr. Dickeson exhibited at the Academy of Natural Sciences at Philadelphia a collection of fossil bones obtained by him in the vicinity of Natchez, Mississippi, among which was a piece of a human pelvis. An account of this specimen, which appeared in the Proceedings of the Academy in 1846 (page 107), reads as follows:

This ancient relic of our species is that of a young man of about 16 years of age, as determined by its size and form, and by the fact that the epiphyses have separated from the tuberosity of the ischium and from the erista of the ilimu. Nearly all the os pubis is wanting, the upper posterior part of the ilinum is broken away, and but half the acetabulum remains. That this bone is strictly in the fossil state is manifest from its physical characters, in which it accords in every respect of color, density, etc., with those of the Megalonyx and other associated bones. That it could not have drifted into the position in which it was found is manifest from several racts: 1 . That the plateau of blue rlay $b$ is not appreciably acted on by those causes that produce raivines in the superincumbent diluvial; 2 . That the human bone was found at least 2 feet below three associated skeletons of the Megalonyx, all of which, judging trom the apposition or proximity of their several parts, had been quietly deposited in this locality, independently of any active current or other displacing power; and lastly, because there was no admixture of diluvial drift with the blue clay, which latter retains its homogeneous character equally in the higher part that furnished the extinct quadrupeds, and its lower part that contained the remains of man.

The find obtained a wide publicity and received the particular' attention of Sir Charles Lyell on the occasion of his visit to this country in 1846. Lyell examined the locality and in his reportc thereon took a rather skeptical view as to the antiquity of the

${ }^{a}$ W. Usher, Geology and Paleontology in Connection with Human Origins, chap. xi, in Nott and Gliddon's Types of Mankind.

${ }^{b}$ The stratum that contained this and the megalonyx bones "is a tenacious blue clay that underlies the diluvial drift of Natchez, and which diluvial deposit abounds in bones and teeth of the Mastodon giganteum" (p. 106).

- Second Visit to America, II, 191 et seq., 1846. 
remains. In a subsequent work $^{a}$ he states that the pelvic bone was taken from a comparatively recent channel known as the Mammoth ravine, at the base of a high cliff.

The cliff consists of a Cretaceous base, a layer of Eocene material, and a surface deposit of loam or loess.

From a clayey deposit immediately below the yellow loam, bones of the Mastodon ohioticus, a species of Megalonyx, bones of the genera Equus, Bos, and others, some of extinct and other presumed to be of living species, had been detached, falling to the base of the cliff. Mingled with the rest, the pelvic bone of man-os imnominatum-was obtained by Doctor Dickeson, of Natchez, in whose collection I saw it. It appeared to be quite in the same state of preservation, and was of the same black color as the other fossils, and was believed to have come, like them, from a depth of about 30 feet from the surface [of the cliff].

In my second Visit to America (II, 197, 1846) I suggested, as" a possible explanation of this association of a human bone with remains of a Mastodon and Megalonyx, that the former may possibly have been derived from the vegetable soil at the top of the cliff, whereas the remains of extinct mammalia were dislodged from a lower position, and both may have fallen into the same heap or talus at the bottom of the ravine. The pelvic bone might, I conceived, have acquired its black color by having lain for years or centuries in a dark, superficial, peaty soil, common in that region. I was informed that there were many human bones, in old Indian graves in the same district, stained of as black a dye. . . . No doubt, had the pelvic bone belonged to any recent mammifer other than man, such a theory would never have been resorted to; but so long as we have only one isolated case, and are without the testimony of a geologist who was present to behold the bone when still engaged in the matrix, and to extract it with his own hands, it is allowable to suspend our judgment as to the high antiquity of the fossil.

The Natchez pelvic bone was described in detail and illustrated by E. Schmidt in 1872. ${ }^{b}$ This author takes issue with Doctor Dickeson's statement that the bone belonged to a young individual; he considers it that of an adult, but damaged in such a way that it resembles an immature specimen. He takes issue also with Sir Charles Lyell regarding the antiquity of the bone, declaring his belief that it is not recent, but dates from the Champlain epoch. ${ }^{c}$ Schmidt does not furnish any new important facts concerning the find, but attempts to substantiate his view by a different interpretation of the known conditions. Lyell apparently did not accept Schmidt's conclusions, for the last edition of the former's Geological Evidences of the Antiquity of Man contains exactly the same statement concerning the Natchez bone as those published previously; and, as he was a geologist and visited the locality a short time after the find had

a 'The Geological Evidences of the Antiquity of Man, 3d ed., 200 et seq., London, 1863 ; 4th ed., 236 et seq., London, 1873.

${ }^{b}$ Zur Urgeschichte Nordamerikas, Arch. f. Anthrop., v, 244 et seq., 1871-72.

c The references of Schmidt to the "Champlain epoch" indicate a different notion of this period and a greater antiquity than that now accepted by American geologists. See particularly page 233 of his paper.

$3453-$ No. $33-07-2$ 
been made, it seems that his opinion should carry, more weight than that of Doctor Dickeson.

Examination and measurements of the specimen gave Schmidt nothing extraordinary, and racial identification of the bone was justly declared by him to be wholly impossible.

The Natchez pelric bone came eventually to the attention of Prof. Joseph Leidy, and he reported on it in the Transactions of the Wagner Free Institute of Science, 1889 (II, 9-10). According to this authority-

the collection of fossils, yet contained in the museum of the academy, are well preserved, firm in texture, and stained chocolate brown from ferruginous infiltration. The fossils consist of a nearly entire skull and other bones of Megalonyx Jeffersoni, teeth of Hegalonyx dissimilis and Ereptodon priscus, bones of Mylodon Marlani, bones and teeth of Mastodon americanus, and teeth of Equus major and of Bison latifrons. 'The human innominatum, somewhat mutilated, presents the same condition of preservation and color as the other fossils with which it was found associated. . . It differs in no respect

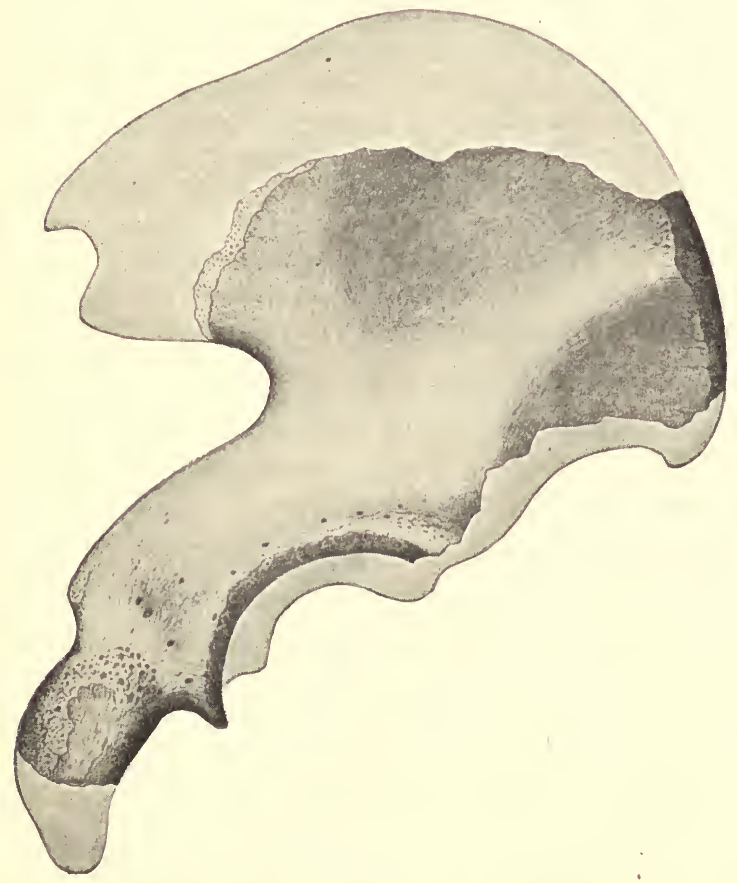

Fig. 2.-The Natchez pelvic bone. (After Leidy.) from an ordinary average specimen of the corresponding recent bone of man.

Sir Charles Lyell, in an interview with Professor Leidy-

expressed the opinion that, although the human bone may have be e $n$ contemporaneous with those of the extinct a $\mathrm{nim}$ a ls witl which it had been found, he thought it mole probable it had fallen from one of the Indian glaves and liad become mingled with the older fossils which were dislodged from the deeper part of the cliff. - At the time of making his communication Doctor Dickeson intimated that the human bone was found at a lower level, beneath bones of the Megalonyx, etc., but this would not prove its age to be greater than or contemporaneous with the latter. In the wear of the cliff the upper portion, with the Indian graves and human bones, would be likely to fall first and the deeper portion with the older fossils subsequently on the latter. 
Professor Leidy gave the accompanying illustration (figure 2) of the pelvic bone in question. It is seen to be a defective right os innominatum, which, on comparison with a similar recent Indian bone, shows nothing peculiar. This is really all that can be said regarding it, and it would be quite useless to speculate as to its antiquity. Had the geological evidence been conclusive in referring the find to the Champlain or another late geological period, the somatological features of the bone would not form an insuperable objection to this disposition of it.

\section{VI.-THE LAKE MONROE (FLORIDA) BONES}

In W. Usher's chapter on Geology and Paleontology in connection with human origins, in Nott and Gliddon's Types of Mankind, ${ }^{a}$ we find an account by Professor Agassiz of fossilized and supposedly ancient human "jaws with perfect teeth and portions of a foot," discovered apparently about 1852 or 1853 by Count F. de Pourtales "in a bluff upon the shores of Lake Monroe," Florida. "The mass in which they were found is a conglomerate of rotten coral-reef limestone and shells, mostly ampularias of the same species now found in the St. John River, which drains Lake Monroe." The deposit is of lacustrine origin and contains remains of animal forms that are still in existence. Its age Agassiz conld not give with precision; it was considered certain by him, however, that "the whole of the southern extremity of Florida, with the Everglades, has been added to that part of the continent since the basin has been in existence, in which the conglomerate with human bones has been accumulating." Calculations based on the growth of the peninsula and its duration in a desert state left Professor" Agassiz still "ten thousand years, cluring which it should be admitted that the mainland was inhabited by man."

The foregoing, unfortunately, seems to be the only account of the specimen. It is mentioned by Lyell ${ }^{b}$ without any further particulars. It is not stated at what depth the human bones were liscovered or in what association. There is, finally, nothing known as to the physical characteristics of the specimens beyond the fact that "the teeth were perfect," and nothing as to their fate. On the whole, the claim to antiquity of this particular find is not a strong one. Fossilization itself means in Florida but little, as the process is even now going on in many portions of the peninsula. There is but one possible conclusion regarding the Lake Monroe bones, which is that they can not, on the existing evidence, be accepted as proofs of the presence of early man on this continent.

${ }^{a}$ Excerpts here given are from 10th ed., 352-353, 1871.

${ }^{b}$ The Geologlcal Evidences of the Antiquity of Man, 3d ed., 44-45, London, 1863. 


\section{VII.-THE SODA CREEK SKELETON}

Soda creek is situated in Colorado, in longitude $105^{\circ} 40^{\prime}$, latitude $39^{\circ} 35^{\prime}$, at an altitude of about 6,570 feet. There are numerous springs in the locality, some hot and some cold, the water of which deposits mineral substances. In September, 1860, according to a report by E. L. Berthoud, C. E. ${ }^{a}$

'Two miners, who had been for two months and a half opening a mining claim about 200 yards sonthwest of the springs and at the foot of the hill marked on the map of Soda hill, reached at last in the gravel, bowlders, and focky deposits of Sodal bar a depth of 22 feet; here at this depth and about $: 3$ yards from the foot of the hill slope they found a hmun skeleton lying on its face and embedted in a deposit of gravel, sand, small bowlders, and fragments of the adjacent rock in situ. .. . . The skeleton, all whose larger bones, though very light and porous, were yet intact, and whose sliull was also entire, was in a very tolerable state of preservation. Inder the skeleton and about 2 feet lower down they found upon the surtace of what the miners call " red rock," the trunk, limbs, and roots of a small pine tree, identical in all respects with the red pine ( $P$. variabilis) of the adjacent slopes. The bark appeared charred and blackened, the wood was light, yellow, and apparently sound.

On exposure to air, however, it soon became soft and crumbled, more like rotten or water-soaked wood. The roots and limbs appeared as if violently compressed or forced in the seams of the underlying rock. There, then, was a point conclusively shown-namely, that prior to the cause which covered Soda hill, Soda bar, and Dry Diggings hill with its enormous beds of gravel, sand, and bowlders, and its native gold . . . man roved and dwelt in this region. . . Whatever cataclysm buried this member of the human family. be he Aztec, Indian, Esquimaux, or Mound-builder, he is for the region above mentioned "homo diluvii testis."

Berthoud's account leaves much to be desired from the standpoint of geology. It gives the impression that the material covering the human remains and the pine may have been talus of no great antiquity. The skeleton represented undoubtedly an intentional burial, otherwise the bones would have been crushed. It did not seem to present anything very extraordinary and was not fossilized. There is no report of a scientific examination of the bones, and no clew is given as to what became of them. Under these circumstances it is impossible to arrive at any definite conclusion regarding the antiquity of the find. What evidence there is speaks more against than for any considerable geological age of the skeleton.

\section{VIII.-THE CHARLESTON BONES}

Emil Schmidt, in his Zur Urgeschichte Nordamerikas, ${ }^{b}$ gives nearly all that is known concerning these specimens. It appears that Prof. F. S. Holmes, geologist and paleontologist, of Charleston, while ex-

${ }^{a}$ Description of the Hot Springs of Soda Creek . . . together with the remarkable discovery of a human skeleton and a fossil pine tree in the bowlder and gravel formation of Soda bar, Oct. 13, 1860, Proccedings of Academy of Natural Sciences, Philadelphia, xviII, 342-345, 1866.

${ }^{\natural}$ Arch. f. Anthrop., v, 250 et seq., 1871-72. 
ploring the banks of the Ashley river about 10 miles above the city, discovered human bones, fragments of pottery, etc., together with the bones of the mastodon. Professor Leidy, who was sent by the Philadelphia Academy of Sciences to examine the locality, actually found human bones associated with those of the mastodon, but there appeared in the same connection also a fragment of porcelain.

Later, in following his investigations in the same region, Professor Holmes discovered further evidences of the coexistence of man with extinct animals; these were particularly a human lower jaw, a tibia, a femur, some stone implements, and potsherds, which were dug out personally from an undisturbed old deposit. The lower jaw was that of an adolescent, and showed a prominent chin and strong muscular impressions; the teeth were normal. The femur also showed strong derelopment.

It seems that Professor Holmes has never published his account of the finds just mentioned, and there is consequently but little to aid us in the effort to reach a conclusion. Schmidt was inclined to accede to the opinion that the bones were geologically ancient, and suggested that they belonged to a man of the Champlain period. This view can not be sustained in the absence of more definite information. Chemical and detailed physical characteristics of the skeletal parts are wanting, and the fate of the bones is unknown. They are not in the Charleston Museum.

\section{IX.-THE CALAVERAS SKULL}

The specimen known as the Calaveras skull is a portion of a somewhat fossilized human cranium preserved in the Peabody Museum at Cambridge. Prof. F. W. Putnam, director of this museum, kindly permitted the writer to examine the specimen thoroughly and furnished the two photographs which accompany this section.

\section{History}

It is not necessary to review in this place all that has been written about the skull in question; the original detailed account of it will be found in J. D. Whitney's Auriferous Gravels of the Sierra Nevada of California, ${ }^{a}$ and a résumé of this, with addlitional information and critical remarks, is contained in W. H. Holmes's thorough Review of the Evidence relating to Auriferous Gravel Man in California. published in the Report of the Smithsonian Institution for $1899 .^{b}$ It suffices to say that the skull was reported as having been found in 1866, in Bald hill, near Altaville, Calaveras county, California, by a mine operator, in a shaft which he had sunk, at the depth of 
about 130 feet from the surface, where there was a layer of gravel. ${ }^{a}$ This gravel lay beneath seven alternate layers of lava and gravel, and clates from about the middle Tertiary period. The skull had adhering to it, or at least to the lower part of its face and to its base, a "conglomerate mass of ferruginous earth, water-worn pebbles of much altered volcanic rock, calcareous tufa, and fragments of bones," and "a thin calcareous incrustation appears to have covered the whole skull when found." (Whitney, page 268.) On chemical examination by Mr. Sharples, the specimen was found to " have lost nearly all its organic matter," and "a large portion of the phosphate of lime had been replaced by the carbonate (phosphate of lime 33.79, carbonate of lime 62.03 parts in 100$)$. In other words, it was in a fossilized conclition."

After the lapse of more than two years from the clate of its discovery the skull came indirectly into the possession of Professor Whitney, at that time State (xeologist of California, and was finally placed in the Peabody Museum. The specimen has received much attention in the press. 'The archeological aspect of the find has been realt with by Prof. IV. II. Holmes in two reports, which give accounts not only of the skull, but of all the reported California gravel finds indicating the presence of early man, and their well-substantiated conclusions should be consulted in this connection. As to the physical characteristics of the skull, the only original data extant are those of Professor Wyman, included in the report of J. D. Whitney. There are three subsequent accounts, by E. Schmidt, ${ }^{c}$ J. Kollmann, ${ }^{\text {}}$ and George A. Dorsey, ${ }^{e}$ respectively; but all of these are based on Wyman's measurements and on study of the illustrations of the skull, not on personal examination of the specimen. This deficiency will be remedied in this paper so far as possible.

\section{Physical Characters}

The specimen (plate I) is rather heavy ( $15 \frac{3}{4}$ ounces $=446$ grams), though its weight is due mainly to adhering mineral matter. It is a very defective skull, lacking nearly the whole occipital, both parictals, the right temporal, parts of the left temporal, sphenoid, and superior

${ }^{a}$ It is nowhere stated on the authority of the finder or of Professor Whitney that the skull was actually dug out from the gravel. Mr. Mattison, who found it in the mine, states simply (Whitney, p. 268) that "he took the skull from his shaft, in February, 1866 , with some pieces of wood found near it."

${ }^{b}$ Treliminary Revision of the Evidence relating to Auriferous Gravel Man in California, Amcrican Anthropologist, n. s., I, 107-121, 614-645, 1899 ; Review of the Evidence relating to Auriferous Gravel Man in California, Smithsonian Report for 1899, 419-472, Washington, 1901.

c Zur Urgeschichte Nordamerikas, Arch. f. Anthrop., v, 253-259, 1871-72; also in Die ältesten Spuren des Menschen in Nordamerika, 43 et seq., Hamburg, 1887.

${ }^{d}$ Hohes Alter der Menschenrassen, Zcitschr. f. Ethnol., xvi, 185-191, 1884.

$e$ In IIolmes's Review of the Evidence relating to Auriferous Gravel Man in California. $465-466$. 


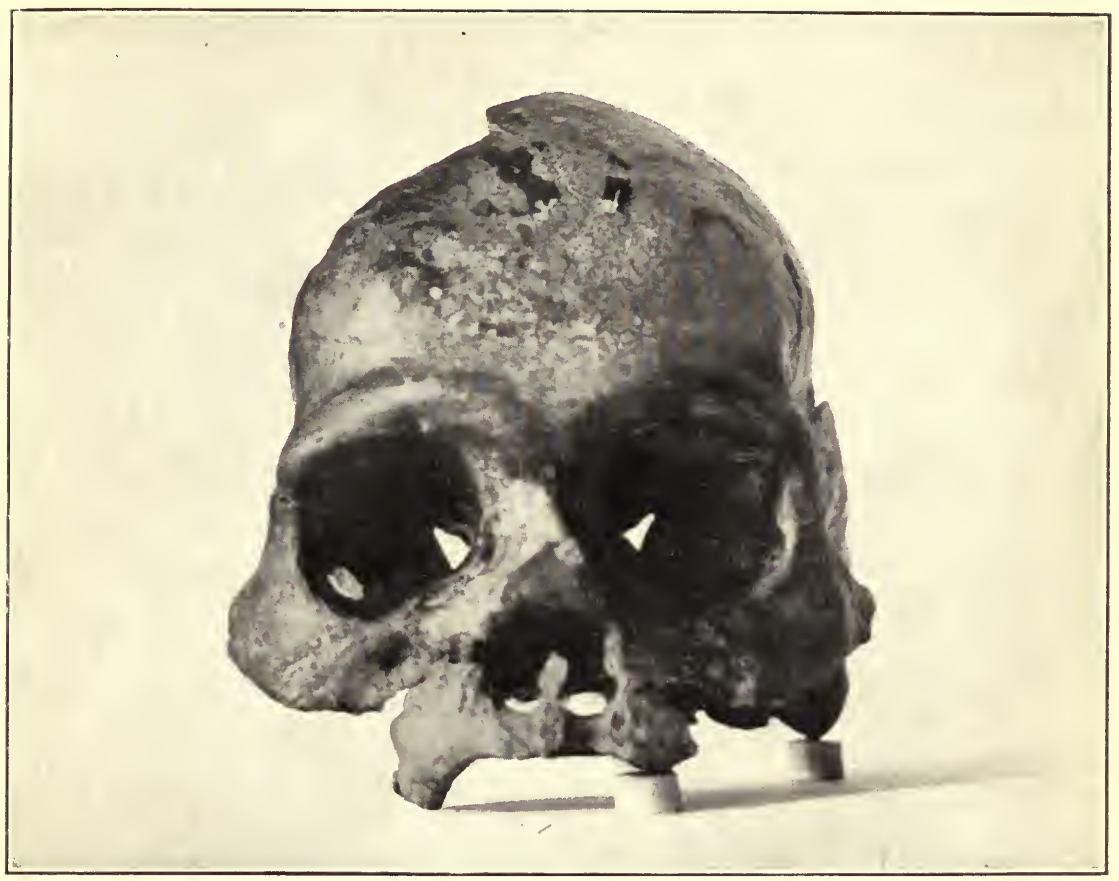

$a$

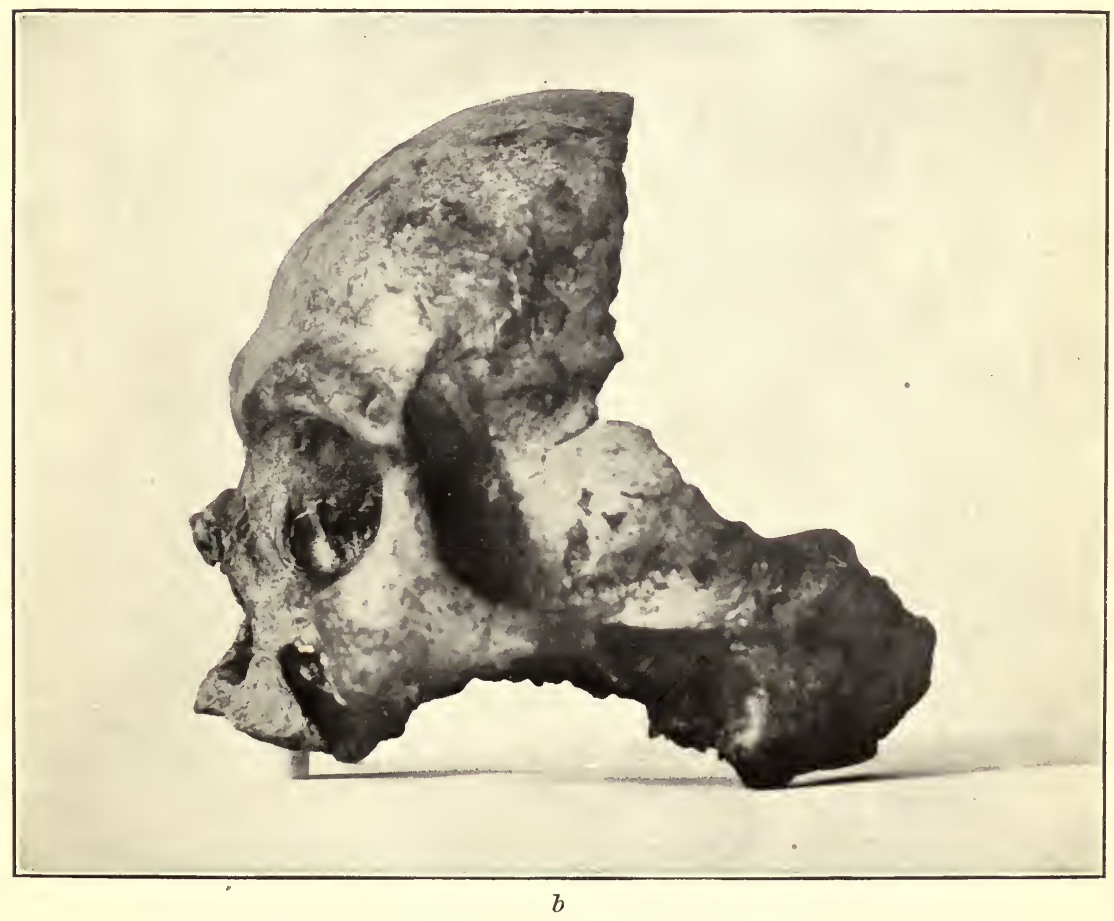

THE CALAVERAS (CALIFORNIA) SKULL AS IT WAS IN 1902

$a$ Front view; $b$ side view 


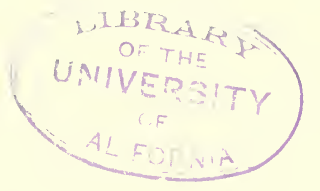

¿

5
$i$ 
maxilla, and the lower jaw. 'The basilar process and the antra of Highmore show some firmly adhering material referred to as gravel, and in many places the specimen has remnants of a coating (0.25 to $1.5 \mathrm{~mm}$. thick) of apparently calcareous stalagmite.

The general somatological aspect of the skull is in no way extraordinary. It is plainly a male skull and belonged to an individual of advanced years, but not of extreme age. In form it was in all probability mesocephalic, and of medium height. The face was only moderately broad for a male; its height can not be ascertained on account of an advanced absorption of the upper alreolar process, but was apparently in no respect unusual. The nose is very slightly platyrhynic (nasal index 53.5), a form that occurs quite commonly among Indian crania; and the orbits (with breadth measured from dacryon) are megaseme (index of right 95, of left 91), a condition not infrequent among Indians. Facial prognathism was insignificant; a veolar prognathism can not be determined.

The forehead is of medium height and prominence, showing no sloping such as might be expected in a male skull of a low form. The temporal ridges are not pronounced or high. The supraorbital ridges are strong, but not more so than in some modern masculine Indian crania; they extenc, however, along the whole superior border of the orbits, a much less common form. The glabella is a little less prominent than the ridges; as a result of this formation there is between the latter a shallow depression.

The face is somewhat damaged, but permits of a number of desirable determinations. The nasion depression is pronounced; there is nothing peculiar about the nasal bridge or bones; the nasal aperture is pyriform, with the left notch somewhat lower than the right; there are shallow nasal gutters (not rare in the Indian); and the spine was well developed. The orbits are slightly ovoid in shape. their distal part being higher than the proximal, and deep: their borders are not sharp. The malars are of ordinary form and moderate size, not unusually protruding; the marginal process is not large; the zygomx are strong; the submalar ("canine") fossx are fairly well hollowed. The upper alveolar border shows a loss of all the teeth and in front an advanced alveolar absorption (to within $11 \mathrm{~mm}$. of the nasal notch on the right, and to within even a shorter distance on the left, side); but as an indication of age these conditions do not agree with the state of the sutures, and are therefore probably of pathological origin. The palate offers nothing exceptional.

What remains of the temporal bones presents ordinary features, with a medium-sized masculine mastoid.

As for the base, the glenoid cavities are deep and rather narrow antero-posteriorly; there are high spinous, and quite high vaginal, 
processes, but the styloids were apparently not much developed, a condition often observed in the Indian. The petrous portions are seen in a moderate depression between the basilar process and the sphenoid, about as in the average Indian. ${ }^{a}$

Tentrally may be seen a moderately high metopic crest; impressions of brain convolutions are perceptible, especially over the orbital roof, but are not pronounced; the sella turcica is normal, the clinoids are rather stont, the anterior and posterior being united on the left; the dorsum sellae shows in its superior border a deep $(4 \mathrm{~mm}$.) median notch.

The thickness of the frontal bone is not greater than in many Indian crania (see measurements).

There are traces of the nasal suture, but its exact state can not be determined; the naso-maxillary and the naso-frontal articulations seem to be patent on both sides; the malo-frontals show no obliteration; there is no trace of metopic separation; the spheno-frontal, which can be seen on the left, seems to show some synostosis, but the spheno-malar and the spheno-temporal sutures appear open; there are no signs of obliteration in the coronal and in the right sphenoparietal suture, and the same statement applies to what remains of the right temporo-parietal and the temporo-occipital articulations.

Trrespective of its large defecis, the specimen shows remarkably few injuries, and it is wholly inconceivable that it should have been rolled about in a stream bed or subjected to pressure in gravel deposits.

The measurements permitted by the condition of the skull are as follows:

Diameter frontal minimum centimeters_- 10.1

Diameter frontal maximum, about__-__-

Nasion-bregma arc _______ Nose:

Ieight (nasion to lowest point of notch border) -

Right side do___ 4.9

Ieft side. do

Breadth, maximum Orbits :

Height-

Right do 3. 8

reft do 3. 55

Breadth (from dacryon)-

Right do_.--

Ieft do millimeters 5 to 6 Maximum thickness of frontal bone, near bregma. do_._- \& Diameter bizygomatic maximum, about centimeters_- 14.3

\footnotetext{
${ }^{a}$ In undeveloped and low-form crania the inferior surface of the petrous bones is on a level with the neighboring surfaces, while in the best developed skulls of whites and other races the petrous portions appear deep in a depression.
} 


\section{Comparisons}

A study of the Calaveras skull as compared with other crania, particularly with those of California Indians, has been made by Dr. Jeffreys Wyman and Dr. George A. Dorsey. Doctor Wyman's conclusions are that-a

(1) The skull presents no signs of having belonged to an inferior race. In its breadth it agrees with the other crania from California, except those of the Diggers, but surpasses them in the other particulars in which comparisons have been made. This is esperially obvious in the greater prominence of the forehead and the (ap)acity of its chamber. (2) In so far as it differs in dimensions from the other ('rania from california, it approatches the Escumamx.

In this report there are two points to which exception must be taken. The skull lacks both parietals and one whole temporal; therefore a measurement of its breadth (given by Wyman as $1.5 \mathrm{~cm}$. ) is impossible, and even an approximation to it must remain uncertain; and there is absolutely nothing about the specimen which approaches the high and narrow-nosed, broad and flat-faced, and narrow, keelvaulted Eskimo. Doctor Dorsey's account ${ }^{b}$ is more circumstantial, but unfortunately is based on a comparion of the Calaveras skull as known from Whitney's account and measurements, including the slightly misleading illustrations, and not from the specimen itself, with a skull of a Digger Indian from Calaveras county. Doctor Dorsey recognizes the skull as that of a male, and in summarizing states that-

While the comparison of an actual skull with the drawings of a fragment of another must be unsatisfactory, ret the conclusion is necessary that the two skulls have the same general features and may easily be pronounced of one and the same type.

The National Museum collection includes two crania and some fragments of skulls from cares in Calaveras county, collected and donated in 1857 by J. S. Hittell, of San Francisco. All these specimens had, and most of them still retain, inside and outside, a coating of grayish calcareous, stalagmitic deposit, much like that which partially covers the Calaveras skull; in fact, on fracture, the deposit in the two cases, so far as the maided eye can perceive, is identical in character. None of the cave skulls or fragments show any adhesion of gravel. Both the entire specimens are male adult skulls, but one (cat. no. 225171) does not appear entirely normal, and its orbits are affected in form and size by very heary supraorbital ridges, so that only one of the specimens (cat. no. 22.5172) appears fit for comparison with the Calaveras skull. It is a mesocephalic cranium (cephalic index 75.5) of moderate height (basion-bregma $13.6 \mathrm{~cm}$.) and general good development; it belonged to a person of abont fifty-five years of

a J. D. Whitney, Auriferous Gravels of the Sierra Nevada, 273. Cambridge, Mass.. 1879.

${ }^{b}$ In William H. Holmes's Review of the lividence relating to Auriferous Gravel Man in California, Smithsonian Report for 1899, 465-466, Washington, 1901. 
age. It is not a fresh skull; the bones are quite brittle and seem to be largely devoid of animal matter, but no claim is made that it is very ancient, and there is no probability that it is so.

This cave skull (figure 3 ) is in all essential features closely related to the Calaveras specimen. It has similarly strongly developed supraorbital ridges, extending along the entire superior border of the orbits; similar depression between the ridges, over the glabella; similarly marked nasal depression below the glabella, and about the same development of the marginal process of the malar, of this bone itself, of the zygoma, and of the nasal spine. There seem to have been pres-

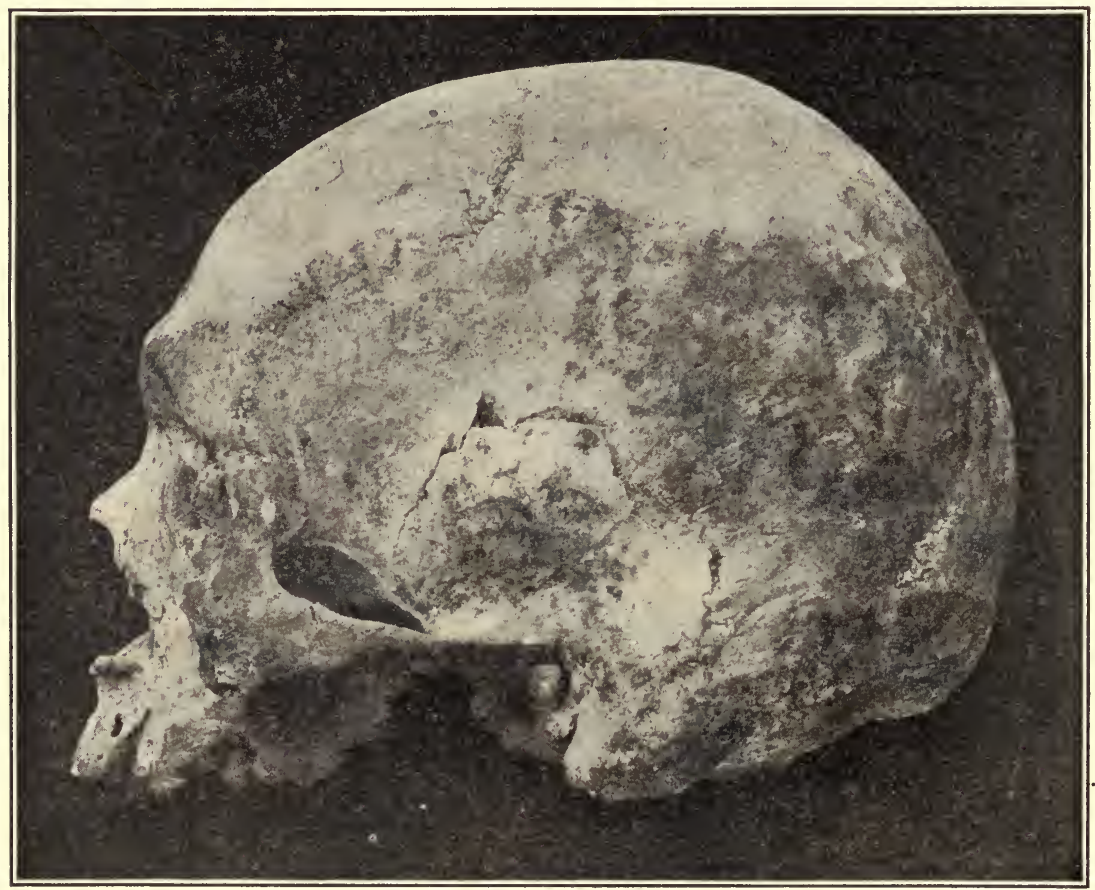

Frg. 3.-Cave skull, Calaveras county, California; side view.

ent also slight nasal gutters. The orbits in the specimen catalogued as no. 225172 are slightly more quadrangular, but otherwise are nearly like those in the Calaveras skull. The alveolar process in no. 225172 has suffered no absorption; owing to this fact and to the absence from the cave skull of injuries, the lower parts of the faces of the two specimens differ in appearance, but this dissimilarity is not morphological. The forehead in no. 225172, though slightly narrower than that in the Calaveras skull, is very nearly as well arched. On the whole, the structural resemblance between this cave skull and the Calaveras cranium are close enough not only for racial, but even for tribal, relationship. 
The measurements of both specimens which could be secured exactly or with a close degree of approximation are as follows:

\begin{tabular}{|c|c|c|}
\hline & $\begin{array}{l}\text { Calaveras } \\
\text { skull. }\end{array}$ & $\begin{array}{c}\text { Cave skull } \\
\text { (no. } \\
225172) .\end{array}$ \\
\hline & $\mathrm{cm}$. & $\mathrm{cm}$. \\
\hline Diameter frontal minimum... & 10.1 & 9.4 \\
\hline Diameter frontal maximum .. & $a 12.0$ & 11.8 \\
\hline Nasion-bregma are............. & 13.1 & 12.3 \\
\hline \multicolumn{3}{|l|}{ Nose: } \\
\hline Height, maximum... & 5.05 & 5.35 \\
\hline Breadth, maximum............ & 2.7 & 2.7 \\
\hline Index, maximum............... & 53.5 & 50.5 \\
\hline \multicolumn{3}{|l|}{ Orbits: } \\
\hline Mean height .............. & 3.67 & 3.67 \\
\hline Mean breadth..................... & 3.95 & 3.90 \\
\hline 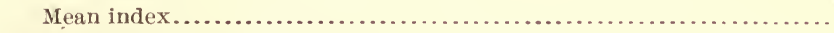 & 93.0 & 94.2 \\
\hline Interorbital diameter $\ldots \ldots \ldots \ldots \ldots \ldots \ldots$ & 2.5 & 2.7 \\
\hline Greatest surface length of left temporal (measured with a tape) ... & 9.95 & 9.9 \\
\hline Diameter bizygomatic maximum.......................... & a 14.3 & a14.3 \\
\hline
\end{tabular}

${ }^{a}$ Approximate.

The thickness of the frontal bone could not be measured in the cave skull on account of the stalagmitic deposit inside, but it is apparently very nearly the same as that in the Calaveras specimen.

The measurements show a somewhat smaller frontal bone in no. 225172, which probably indicates that the Calaveras skull as a whole was larger. At all events such differences are not outside of the scope of individual variation within a single people. The remaining measurements, particularly the important nasal and orbital indexes, are so much alike that on the basis of these and of the other resemblances it is impossible to do otherwise than to pronounce the two specimens of the same type, which necessarily leads to the implication that the Calaveras skull is geologically recent.

There is one feature connected with the Calaveras skull besides the scarcity of secondary injuries which may not have received the consideration it deserves; this is its calcareous coating, which, though colored on the surface, is white and crystalline on fracture, exactly like that of the cave skulls. How could such a coating have been formed, and formed with much uniformity, over the surfaces of a skull packed in sand or mud and gravel of an ancient river? It is probable that, under special circumstances, bones manifest some affinity for calcareous matter in solution, and it is known that animal fossils with somewhat similar coating have been recovered from ancient sands or gravels. This phenomenon is most commonly observed in caves or crevices into which water percolates, carrying lime in solution, and, in view of the presence of numerous such caves and crevices in the Calaveras region, the occurrence of typical cavern deposits on the surfaces of the 
Calaveras specimen must have great weight in favor of its cavern origin. A mass of gravel, bones, etc., adhered to the base of the skull when discovered, but this was not firmly solidified and could be removed without injury to the bone. It had very much the appearance of débris from some cave or crevice, cemented to the specimen while the latter was being coated with stalagmitic deposit. The infiltration or fossilization of the Calaveras skull furnishes no reliable test of its antiquity. It will be shown later in this paper that even siliceous fossilization of bones can take place near the surface of the ground, and in all probability has taken place within a geologically insignificant period. The process is regulated wholly by the local mineralogical conditions and the results are of little or no value as chronological criteria.

\section{X.-THE ROCK BLUFF CRANIUM}

The specimen known as the Rock Bluff skull was reported on by Meigs, ${ }^{a}$ Schmidt, ${ }^{b}$ and Kollmann, ${ }^{c}$ and its claim to geological antiquity is based mainly on certain remarks found in Schmidt's account. According to Meigs, the skull was found, with a lower jaw-

. . . in June, 1866, in a fissure of the rock, at Rock Pluff, on the Illinois river where it is crossed by the fortieth parallel. The fissure, which is 3 feet wide, was filled with the drift material of this region, consisting of clay, sand, and broken stone, the whole being covered with a stratum of surface soil. In this bed, which apparently had been undisturbed since the deposit, was found the skull under consideration, at the depth of 3 feet.

After giving a description of the specimen, which contains several inaccuracies, Meigs speaks of a number of Indian crania which show resemblances to that from Rock Bluff, and concludes as follows:

Bearing in mind the locality in which it was found, the skull under consideration is so far unique in its ethnical character, that I do not feel authorized to refer it to any of the aboriginal American cranial forms with which I am acquainted. If the position in which it was discorered be any evidence of its age, it belongs. in all probability, to an earlier inhabitant of the American continent than the present race of Indians.

At the time of Doctor Meigs's writing there was apparently extant no important evidence of the geological antiquity of the find, and had not the skull been of rather inferior type, it would hardly have attracted particular attention. Four years later, however, Schmidt gave a detailed description and measurements of the skull accompanied by the statement that he was in possession of a letter from

$a$ J. Aitken Meigs, Description of a IIuman Skull in the Collection of the Smithsonian Institution, Smithsonian Report for 1867, 412-415, Washington, 1868.

${ }^{b}$ E. Schmidt, Zur Udgeschichte Nordamerikas, Arch f. Anthrop., v, 237-244, 1871-7:2,

c J. Kollmann, Hohes Alter der Menschenrassen, Zeitschr. f. Ethnol., xvi, 191-193, 1884 . 
Professor Baird, at that time Assistant Secretary of the Smithsonian Institution, to the effect that the locality at which the Rock Bluff skull was discovered had been examined by "McConnell," who found that the drift in which the specimen lay was in no way disturbed and that, therefore, the skull was not intrusive, but coincided in age with the formation of the deposit. Schmidt ends his account with the opinion that the age of the two specimens (skull and lower jaw, the latter of which he considered as belonging to a different body), provided it is established that they were found in undisturbed drift, is very considerable and referable to "the Champlain, or even to the glacial, epoch."

A search in the archives of the Smithsonian Institution resulted in finding two letters from Mr. McConnell, of Jacksonville, Illinois, the donor of the skull. It is not disclosed who Mr. McConnell was; there appear to be no contributions under that name to the literature of either geology or anthropology. In his letter of June 4, 1866, addressed to Prof. Joseph Henry, is the following:

I have sent to you by express a small box containing a human skull of an unusual shape and formation. It is evidently not deformed, but a natural skull, and from its shape and the place where it was found it is believed not to have belonged to any race of men now known to exist, and it is conjectured it may have belonged to a preadamite race, if there was any such race.

I have never met with such a formed head, either living or dead, as this. ant for this reason I send it to you, supposing from your opportunities in this branch of science you might determine if I am right in supposing this specimen not to have belonged to any one of the present races no:w extant. I now will refer particularly to the place where this skull was found. The Illinois river - . has cut through the various stratas down to a level, and in many cases below the upper coal-deposits. Along the Illinois bluff the strata of rock covering this coal deposit crop out, and this rock is quarried for building purposes. In one of these quarries a few miles south of the fortieth degree of north latitude this skull was found, several feet of clay, sand, and broken stone were taken off of the strata, and, in quarrying, a rift or seam in the rock was found, about 3 feet wide, filled with the same material that covered the quarry, and in this rift or seam in the rock, firmly embedded in this clay, sand. and broken material, this skull was found. Examination showed that it had evidently been thrown, or washed, into that opening in the rock with the material that surrounded it.

In the neighborhood of this quarry and indeed all along the Illinois river are found many mounds, called in this country Indian mounds, but evidently (they) have no connection with the present race of Indians.

In an additional note to Professor Henry, of June 11, 1866, Mr. McConnell, besides enumerating various persons who would vouch for his character, says:

I have been a long time in the valley of the Mississippi and have traveled over most of it and have always had a passion for hunting up old relics and studying this and geology by actual personal examination. 
He remarks in closing that-

The only apparent doubt about the great antiquity of this skull is its perfect preservation, but this is owing to the material in which it was found. There are other instances in this sane locality of like preservation not petrified.

The foregoing excerpts constitute the total of extant records concerning the find. It is plain that Mr. McConnell was an amateur collector and geologist and that the Rock Bluff skull attracted his attention mainly by its unusual shape. His notes concerning the geology of the find are so meager that no important conclusion can be based on them. That Schmidt, and after him Kollmann, were inclined to class the skull as geologically ancient could have been due only to an imperfect acquaintance with these records and to the low forehead of the cranium. At the time of Schmidt's and Kollmann's writings sufficient osteological material from the valley of the Illinois river did not exist to enable them to determine the range of cranial variation in that region.

The skull itself (plate II, $a$ ) is now part of the National Museum collections. Though somewhat injured, especially about the face, it is remarkably well preserved, in no way deformed or affected by disease, and not at all fossilized. It is dirty yellowish-white in color and shows on the left side superficial injuries, which appear as if due partially to cutting with an edged implement and partially to the gnawing of rodents, but these are of.little significance. Morphologically, the skull is quite remarkable. Its most noteworthy feature, and that which gives it the appearance of a specimen of a low type, is its greatly developed supraorbital ridges. 'These are not in the form of arcs, however, as in anthropoids and in the human skulls of Spy, Neanderthal, and, to a less extent, in the two Calaveras specimens, but involve, as general among Indians, only about the median three-fifths of the supranasal and supraorbital portions of the frontal

- bone. They project greatly forward, however. The extent of projection amounts to $1.1 \mathrm{~cm}$. on the right and $1 \mathrm{~cm}$. on the left side in front of a plane passing through points situated on the dorsal side of the middle of the supraorbital borders, or $2.5 \mathrm{~cm}$. on the right and 2.4 $\mathrm{cm}$. on the left side, in front of a vertical plane touching on each side the anterior extremity of the malo-frontal suture. This great prominence of the ridges brings forward the whole supranasal region, making the forehead, naturally quite low, appear still lower and unusually sloping. It is this extraordinary development of the median part of the supraorbital ridges more than deficient development of the frontal part of the cranial cavity that gives this skull its aspect of inferiority. There is still another feature which points to mediocre development of the cranium, and that is the position of the petrous wedges ${ }^{a}$ in relation to the neighboring parts of the 


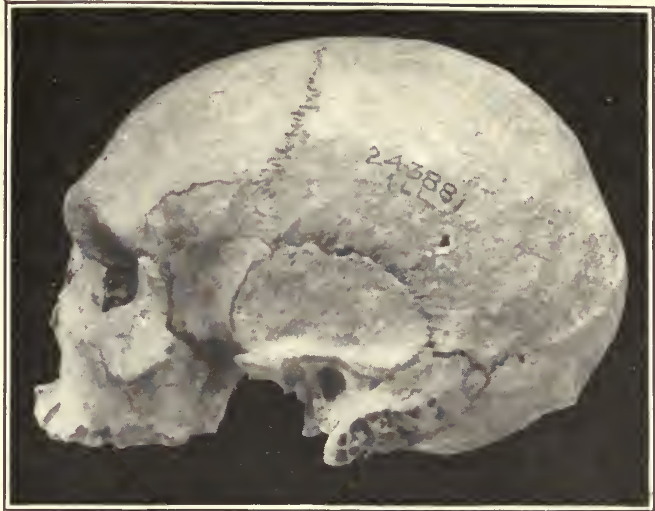

$a$

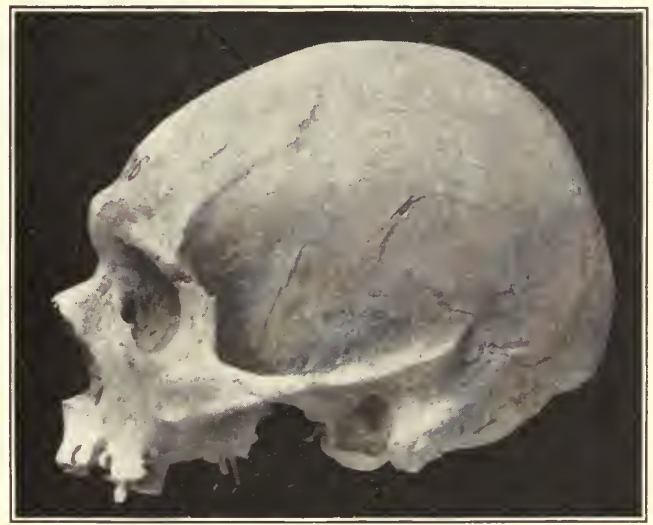

$b$

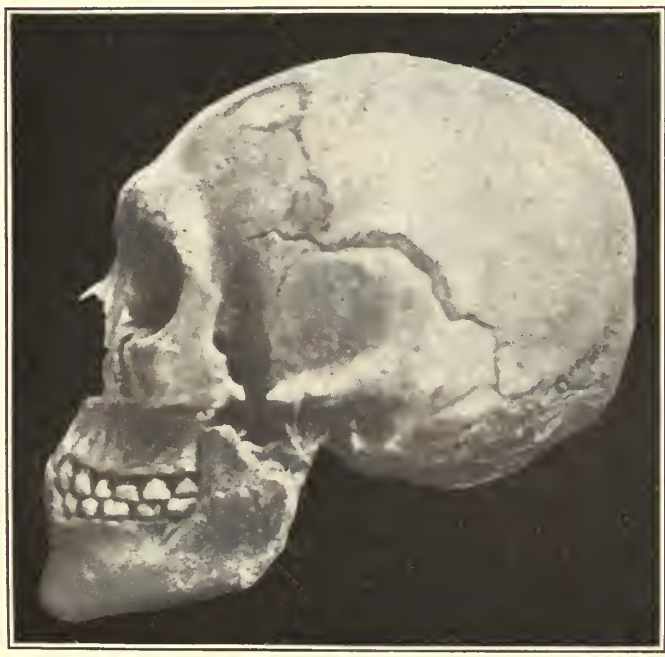

SKULLS FROM ILLINOIS

$a$ The Rock Bïuff skull, side view; $b$ skull from mound near Alton, side view; $c$ skull from mound near Albany, side view 
Eving 
base. When the base of the skull is viewed from above, it is seen that the inferior surface of the right petrous portion is but slightly depressed, while that of the left is on the level, and anteriorly even slightly above the level, of the neighboring parts-always a sign of rather deficient expansion of the cranial cavity, for in a well-expanded specimen the petrous portions are seen in a decided hollow. The skull shows large mastoids and a well-developed superior occipital crest, indicating a powerful musculature; but the temporal ridges are not pronounced and their nearest approach to the sagittal suture amounts on each side to nearly $6 \mathrm{~cm}$. The face was apparently but moderately prognathic, as is general in Indians, and the malars and the zygomæ were not above medium in strength. The nasal spine is low and not very prominent, but this feature constitutes no great exception among Indian crania. The palate, the dental arches, and the teeth were of only ordinary dimensions; the injured condition of the arches and absence of the teeth prevent the giving of measurements. The foramen magnum is large, indicating probably tall stature. The glenoid cavities are deep and spacious. The lower jaw, which was originally with the specimen, is wanting, but according to Meigs's illustration and Schmidt's account, it showed nothing that would be uncommon in the lower jaw of a modern Indian.

The National Museum collection contains a good series of Indian crania obtained from mounds along the Illinois river, with which the Rock Bluff skull can be compared; and there are several skulls from the Albany mounds, Illinois, in the Davenport Acarlemy of Sciences, which can also be utilized in this connection. These mound crania are certainly not geologically ancient, though they probably antedate the advent of whites into the valley. They show some variety, due possibly to tribal mixture, but the predominating type is dolichocephalic, having rather low orbits and, in males, strongly developed supraorbital ridges, with narrow, low, and occasionally very sloping, forehead. Mesocephalic forms appear occasionally. With most of these skulls the Rock Bluff specimen agrees fairly in every essential particular that goes to form a cranial type. Its supraorbital ridges alone are quite equaled by those of no. 4401, Davenport Academy (plate xir, $a$ ), and in several other specimens they are closely approached. Were the Rock Bluff skull mingled with the rest of the Illinois River male crania no observer would be likely to single it out as especially remarkable. It agrees with most of them even in color. The peculiarities it presents are well within the scope of individual variation. The following table and illustrations (plate II, $b, c$ ) show the resemblances, which are still further strengthened by an examination of the whole series of specimens from the Illinois valley.

In view of the above facts, and irrespective of the wholly unsatisfactory geological evidence, the Rock Bluff skull, though regarded 
as of a low type, must be classed with crania from the Illinois River mounds, with which it has much in common. The differences are not sufficient to indicate any distinct cranial variety, and the specimen can not properly be regarded as evidence of a geologically early man in North America.

Measurements of the Rock Bluff skull and of four masculine Indian cranir from mounds along the Illinois river."

\begin{tabular}{|c|c|c|c|c|c|}
\hline & $\begin{array}{l}\text { Rock } \\
\text { Bluff } \\
\text { skull. }\end{array}$ & $\begin{array}{l}\text { Cat. no. } \\
242966 \text {. }\end{array}$ & $\begin{array}{l}\text { Cat. no. } \\
136773 \text {. }\end{array}$ & $\begin{array}{c}\text { Cat. no. } \\
242982 \text {. }\end{array}$ & $\begin{array}{l}\text { Cat. no. } \\
4401 \text { ("no. } \\
\text { 3," Albany } \\
\text { mounds), } \\
\text { Davènport } \\
\text { Academy } \\
\text { of Sciences. }\end{array}$ \\
\hline 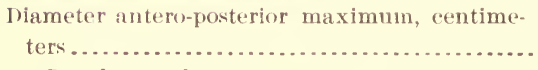 & 19.5 & 19.1 & 20.3 & 17.8 & 17.45 \\
\hline Do., from ophryon ............. . centimeters.. & 19.0 & 19.0 & 20.0 & 17.4 & ...... \\
\hline Diameter lateral maximum .................... & 13. 7 & 13.6 & 13.1 & 13.6 & 13.4 \\
\hline Cephalic index ..................... & 70.3 & 71.2 & 64.5 & 76.4 & 76.8 \\
\hline Basion-bregma height ...............eentimeters. . & 13.3 & 13.9 & $(?)$ & 13.4 & 13.4 \\
\hline Height of nose ............................... & 5.25 & 5.10 & 5.25 & 5.25 & 5.55 \\
\hline Maximum breadth of nose.................... & 2.65 & 2.80 & 2.80 & 2.50 & 2.40 \\
\hline 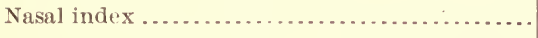 & 50.5 & 54.9 & 53.3 & 47.6 & 43.3 \\
\hline Height of right orbit................. centimeters.. & 3.3 & 3.3 & 3.2 & 3.4 & $(b)$ \\
\hline 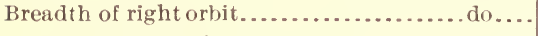 & 4.0 & 3.65 & 3.9 & 3.9 & 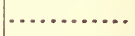 \\
\hline 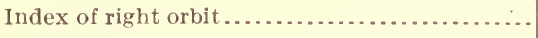 & 82.5 & 90.4 & 82.1 & 87.2 & ….... \\
\hline Diameter frontal minimum .........centimeters. . & 9.7 & 9.2 & 9.0 & 9.7 & 8.7 \\
\hline Thickness of left parietal............millimeters.. & $5-6$ & $6-8$ & $5-7$ & $5-6$ & $6-8$ \\
\hline 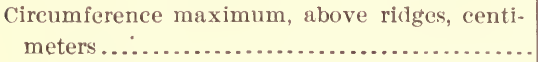 & 52.5 & 52.1 & 52.3 & 49.5 & \\
\hline Cranial capacity .............cubic centimeters.. & 1,430 & 1,425 & $(?)$ & 1,260 & .......... \\
\hline
\end{tabular}

a Several of Schmidt's measurements of the Rock Bluff skull, particularly that of the breadth of the specimen, are inaccurate, in all probability on account of a defective instrument.

$b$ Damaged.

\section{XI.-THE MAN OF PEÑON}

The remains of the so-called man of Peñon consist of a portion of the skull and of fragments of other parts of a skeleton, embedded in a variety of limestone, discovered accidentally in 1884 in the Valley of Mexico. It was reported on in the following year by Mariano Barcena, ${ }^{c}$ and in 1886 the find was described by Barcena and Antonio del Castillo in La Naturaleza, in Mexico. The essential

c Mariano Barcena, Notice of Some IIuman Remains Found near the City of Mexico, The American Naturalist, $\mathrm{x} 1 \mathrm{x}$, 739-744, August, 1885; also, by same author, The Fossil Man of Peñon, Mexico, ibid., xx, 633-635, July, 1886 ; Noticia acerca del hallazgo de-restos humanos prehistoricos en el Valle de Mexico, por Mariano Barcena y Antonio del Castillo, La Naturaleza, $\mathrm{VI}, 256-264$, entrega 16, Mexico, 1866 ; Nuevos datos acerca de la antiguedad del hombre, en el Valle de Mexico, por Mariano Barcena, ibid., 17, 265-270, Mexico, 1886; Discusiones acerca del hombre del Peñon: Carta del Prof. Newberry al editor de La Tribuna, ibid., 18, 284-285, Mexico, 1886; Contestacion a las observaciones de la carta anterior, por Mariano Barcena, ibid., 286-288. 
points concerning the specimen, according to these reports, are as follows:

In the month of January, 1884, some quarrying was being done by means of dynamite at the foot of the small hill known as "Peñon de los Baños," about $2 \frac{1}{2}$ miles east of the City of Mexico, and in the rocks of the uppermost layer loosened by the explosions a number of human bones were found. These were collected by Col. A. Obregon, who supervised the work, and were delivered by him to the minister of public works, who appointed Barcena to make a study of them. Several days afterwards Barcena and Castillo, the latter $\mathrm{a}^{\mathrm{a}}$ professor of geology, explored the locality of the find. It was seen that the human bones came from the uppermost layer of calcareous tufa (in another place called silicified calcareous rock), covered with a "recent formation of vegetable earth and marl," containing numerous fragments of pottery of Aztec and of modern origin. The calcareous rock was found not to constitute an uninterrupted layer and yielded no bones of animals or pieces of pottery. Some shells discovered in it belong to the Quaternary as well as to the present-day waters. Softer calcareous rocks were found in the neighborhood where were also remains of pottery and roots of plants clearly modern. In the eastern part of the hill there is a hot-water spring, which forms sediments somewhat similar to those containing the bones; but the formation of the rock from this source is very slow and not extensive. The conclusions of Barcena and Castillo were that the deposit containing the human bones was of lake origin and belonged to the "Upper Quaternary, or at least to the base of the present geological age." Professor Newberry's opinion, expressed in the Tribune (see bibliography, page 32), was that the rock is a comparatively recent travertine or sediment from the thermal waters of that locality.

The human bones are firmly embedded in and their cavities are filled with the rock, which is brownish gray in color and very hard. The exposed parts are portions of the skull, clavicle, vertebræ, ribs, and the bones from the upper and the lower limbs. They lie in disorder, but are apparently parts of the same skeleton. The bones are yellowish in color and present aspects of fossilization.

As to the anthropological characteristics of the bones, Barcena writes as follows: ${ }^{a}$

The greater part of the cranium haring been destroyed, it was not possible to determine its diameter and thus classify it. . . . The odontological characteristics indicate that this man belonged to an unmixed race, the teeth being set with regularity and corresponding perfectly the upper with the lower. They present the peculiarity, besides, that the canine teeth are not conical, but have

a The American Naturalist, xIx, 743, 1885.

$3453-$ No. $33-07-3$ 
the sime shape as the incisors. . . The size and shape of the bones of the limbs correspond to those of a man of ordinary stature, and from the appearance of the teeth the man must have been about 40 years old.

The writer saw the specimens in 1902. The illustrations in La Naturaleza (vir, no. 16) and in The American Naturalist (xix, no. 8,

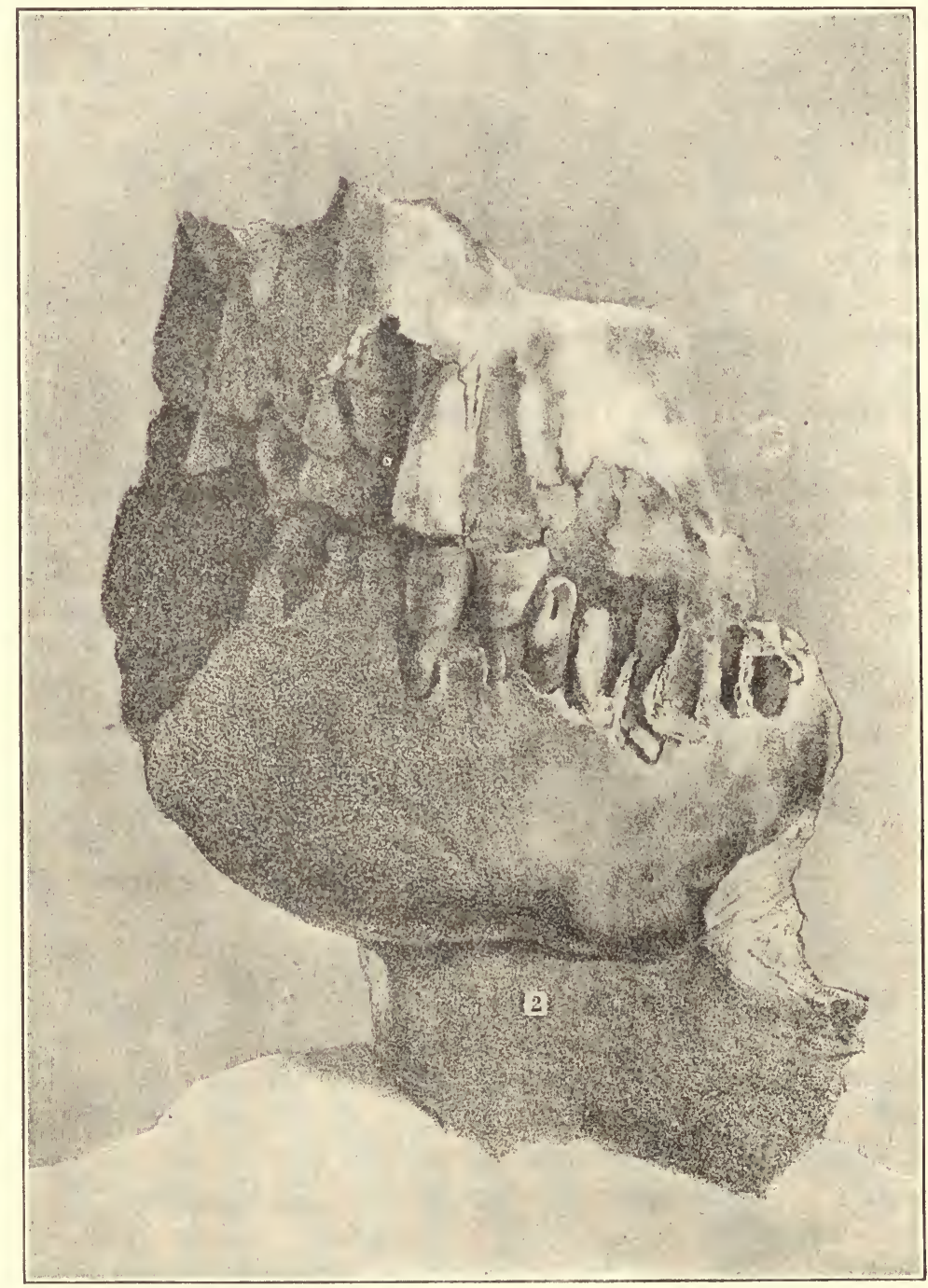

Fig. 4.-Remnant of the skull of the "Hombre del Peñon." (After Barcena, in La Naturaleza, viI, no. 16.)

1885), particularly the former, give a fair view of the mass containing the skull (figure 4). Altogether, there is not enough of the material to warrant any conclusion as to the race of the individual; what there is suggests the Indian. There is no excessive prognathism or 
receding lower jaw, such as might be expected in geologically ancient man. The teeth are of ordinary size; they are worn off to a quite marked extent, a condition which points to rather coarse vegetable diet, and is general among Indians after early middle age. The canines are in no way morphologically peculiar, but their points have been worn off to the level of the incisors; this happens invariably, unless the teeth are displaced, as the process of attrition advances.

There is, on the whole, nothing connected with the remnants of the Peñon skeleton which would indicate man of a type earlier than, or radically different from, the Indian.

\section{XII.-THE CRANIA OF TRENTON}

There is no other region on this continent that has been brought as conspicuously to the attention of archeologists and students of man's antiquity as that along the Delaware river in and about Trenton, New Jersey. This district is rich in deposits of glacial gravels, and for nearly thirty years these have been searched wherever exposed for the remains of early man and his art. For nearly twenty years, with a few intermissions, Prof. F. W. Putnam, of the Peabody Museum, Cambridge, Massachusetts, has carried on, principally through Mr. E. Volk, careful explorations of these gravels, with the view of determining the question of man's presence in the Delaware valley before the advent there of the Indian. The deposits in the valley have yielded many remains and relics of the Lenape (Delawares), who occupied it up to and even for some time after the appearance of the whites. They have yielded also implements which were thought to belong to an earlier culture, and parts of human skeletons of a seemingly earlier people. Unfortunately, the geological evidence of the presence of early man in the region is not conclusive, and the age of many of the remains is still unsettled. The idea that during postGlacial time or even before the close of the Glacial period man lived where Trenton now stands has found adherents, but the best-qualified students of the question, including Professor Putnam himself, maintain a careful reserve.

It was under these circumstances that the writer was invited by Professor Putnam, in 1898, to examine all the osteological material recovered in the Delaware valley and to determine what the anatomical features of the remains indicate as to the antiquity of the Trenton man. A detailed account of this examination was published in the Bulletin of the American Museum of Natural History, in 1902, and the essentials are here given, with additional observations based on the writer's more recent knowledge of certain reports on European crania. 
Most of the skulls and other bones examined were readily recognized as those of Indians, and the so-called "gasometer" skull could be referred to no other people. There were also a few morphologically insignificant fragments, the identity of which remained doubtful, ${ }^{a}$ but there were, in addition, two crania which, on account of their peculiar features, could not possibly be referred to the Delawares (Lenape) or to any other known American aborigines. These were the so-called Burlington County skull and another skull found on the site of the Riverview cemetery. These specimens proved to be of so much interest that the writer feels justified in repeating here their full history and the results of his examination.

\section{The Burlington County Sirull}

- This specimen was presented to the Peabody Museum, Cambridge, in 1879, by Dr. Charles C. Abbott, of Trenton, who at that time was actively interested in the archeology of the valley. The skull was discovered accidentally in a field near a small settlement known as Sykesville. It had rolled out of the bank of a brook running through a field. The geology of the locality is cretaceous, and here the green sand marls and stratified clay and sand are overlaid by the "southern-drift," as the white pebbles and yellow sand are called. Above is a rich alluvial deposit, but this is not a uniform covering, the drift often being exposed over considerable areas. It was in this drift, unassociated with other bones, that the skull lay.

\section{The Riverview Cemetery Skull}

This specimen, now also in the Peabody Museum, was procured in 1887 by Mr. Volk, whose account of the find is as follows:

A man with whom I was acquainted, employed in digging graves in the Riverview cemetery, told me of a skull he had found in a new plot in which no burials had been made before. On my arrival at the cemetery he showed me the place; it was an elevated part of the ground, and now there is one grave there. The man told me that when he dug that grave he struck with his spade, at the depth of about 3 feet, a human skull. There were no other bones there, but he noticed a few black lines in the soil.

The workman gave the skull to Mr. Volk, who in turn gave it to the Peabody Museum. On examining the deposits as disclosed in the grave, Mr. Volk found from " 6 to 10 inches of black soil, about 18 inches of yellow drift, and then stratified sand and gravel. This skull, according to the information of the man who found it, was in the apparently undisturbed sand and gravel."

a See original publication in Bulletin of American Museum of Natural History, XVI, $23-62,1902$. See the same paper for bibliography. 

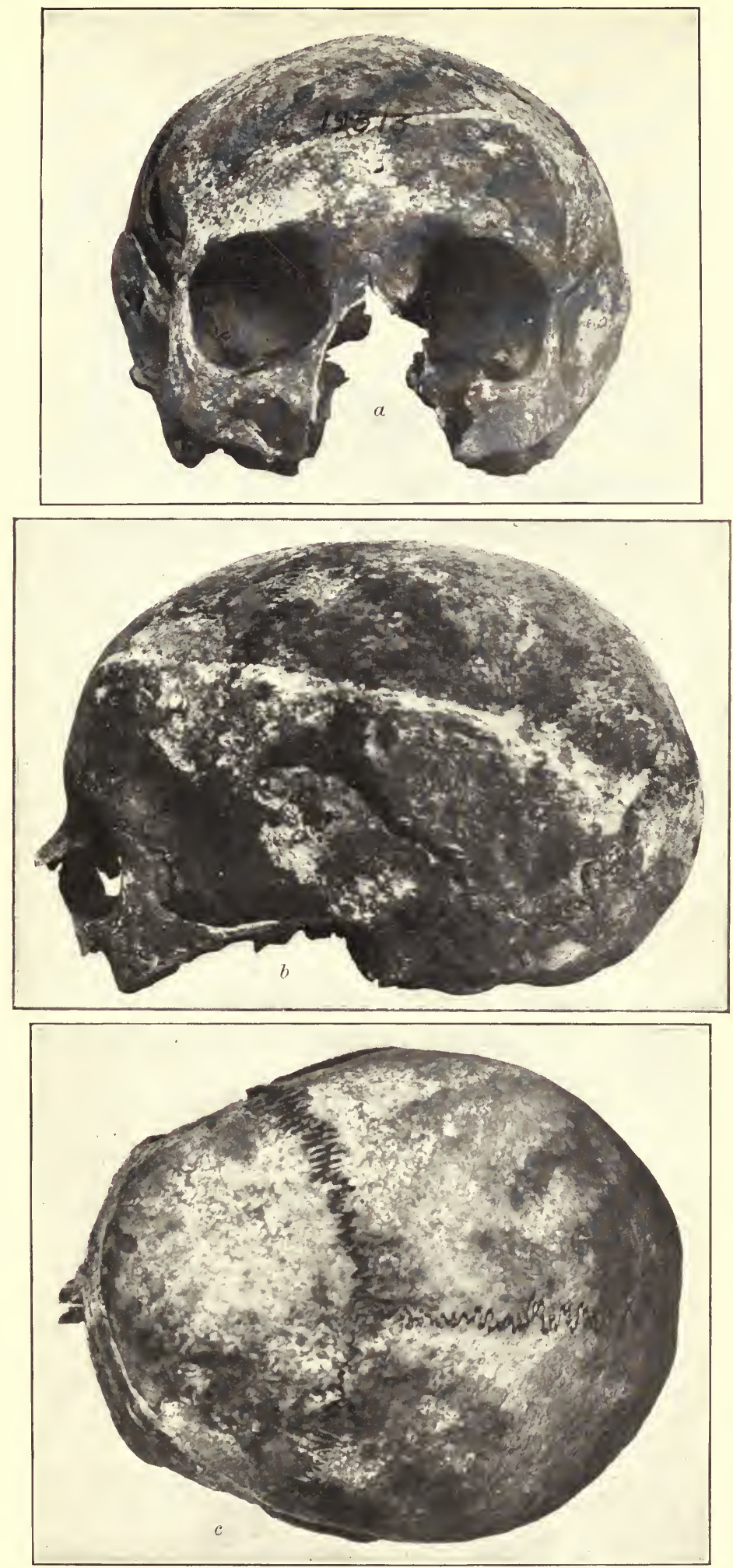

SKULL FROM BURLINGTON COUNTY, NEW JERSEY $a$ Front view; $b$ side view; $c$ top view 


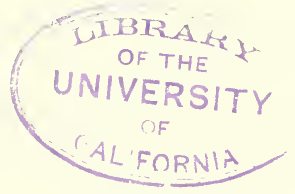




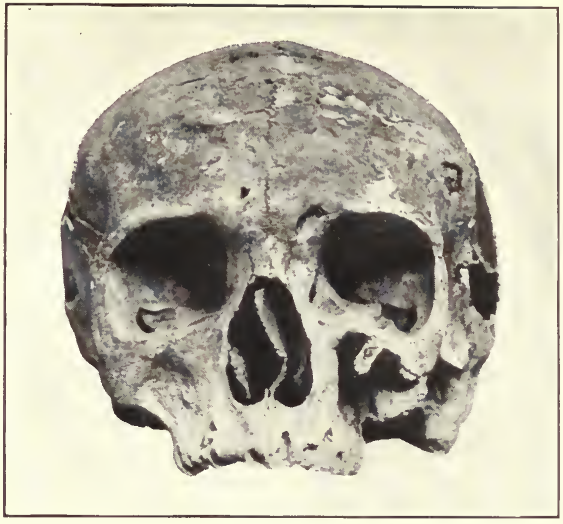

$a$

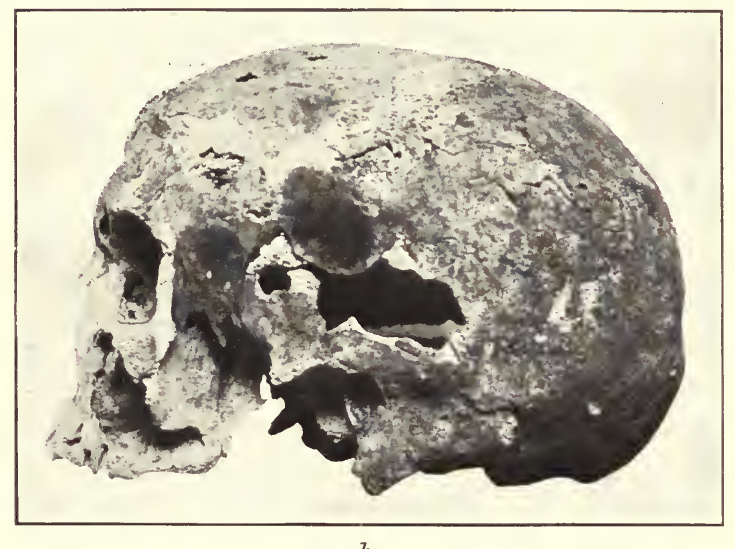

b

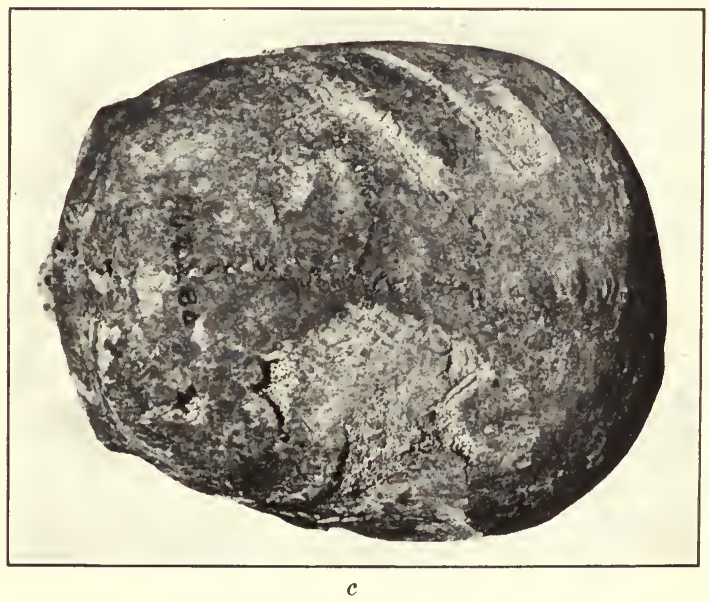

SKULL FROM RIVERVIEW CEMETERY, TRENTON, NEW JERSEY $a$ Front view; $b$ side view; $c$ top view 


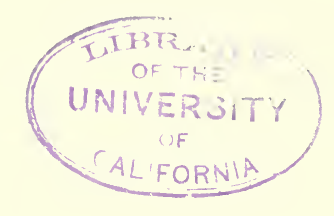


The Burlington County skull (no. 19513, Peabody Museum) is that of a female, fully adult but not of advanced age. This skull is symmetrical and not deformed or diseased. (Plate III.) The bones are thin, but of considerable hardness. A slight warping causes a partial opening of the right coronal and temporo-sphenoidal sutures. The bones apparently retain some animal matter. Their surface has suffered a considerable scaling off, but as yet the diploë is not visible. The facial parts are much damaged, the superior maxilla being almost entirely absent. The mastoids are broken, and the bone above them, particularly on the left side, shows numerous perforations; there is, however, no indication that these latter are the result of disease. The lower part of the occiput is damaged, and the sphenoid body is broken across in front of the basi-sphenoid articulation, but these injuries have not affected the form of the skull. There is no unnatural depression of the region about the foramen magnum. The right squama shows a small perforation, probably a recent injury; the bone exposed is scaly almost throughout. There are no scratches now visible on the surface of the skull, but such may have existed and disappeared with the outermost layer of the bones. There are no discolorations with the exception of a peculiar narrow, regular band, lighter than the neighboring bone, that obliquely encircles the whole cranium. It seems that a narrow firm band, or some contrivance provided with such a band, was applied to the head or skull and left its impression thereon. There is no metallic discoloration.

The skull has very marked peculiarities of form, visible at a glance. It is unusually low throughout its whole extent; the outlines of its planes are rounded, not angular, and the portion of the specimen behind a vertical plane passing through the auditory meati is quite markedly larger than the portion anterior to the plane.

Enough of the face is left to show that it was very narrow, and the malars, both preserved, are even less prominent than those which we find in an average white female skull. The orbits are megaseme, their borders quite sharp, their angles rounded; depth $4 \mathrm{~cm}$. The nasal bridge, well preserved, is of fair height, slightly concave in its upper half, and not very broad. Nasion depression moderate. Glabella large, of medium convexity. There are no supraorbital ridges proper, but an elevation appears on each side of and adjoining the glabella. The interorbital septum measures $2.4 \mathrm{~cm}$. (24.6 per cent of the line between the orbital ends of the malo-frontal sutures).

The forehead is very low, though not sloping. Diameter: Frontal minimum 9.3, frontal maximum 11.6; nasion-bregma are $11.6 \mathrm{~cm}$. (33.2 per cent of the total arc from nasion to opisthion).

The parietals show considerable quite uniform convexity from above downward and slightly less so from before backward. The 
sagittal region is but very slightly elevated. The bregma-lambda arc measures $11.8 \mathrm{~cm}$. (33.8 per cent of the arc from nasion to opisthion). 'There is only one parietal foramen (right), of moderate size. Temporal ridges were not high in position and are barely perceptible.

The occipital region is quite full, not protruding; the right side is very little more prominent than the left. Occipital ridges and depressions are very faint. The temporal regions show moderate bulging. The squamæ are low. The zygomæ are quite slender. Pterions are of II form, rather narrow.

The sutures show as yet no traces of ossification. Their serration is superior to that in any of the Lenape skulls. A distinct serration is seen in the posterior third of the temporo-parietal sutures, a condition which is uncommon. There are no Wormian bones.

The base of the skull is rather flat. 'The foramen magnum is quite large, measuring $3.8 \mathrm{~cm}$. in its antero-posterior and about 2.9 $\mathrm{cm}$. in its maximum lateral diameter. The plane of the opening, if extended forward, would pass only about $1 \mathrm{~cm}$. beneath the nasion. The processes are low, the foramina of moderate size except the foramina ovale, which are smaller than the average in female crania. The styloids are broken; they were, particularly the left, very slender. The glenoid fossæ are of fair depth, the right being slightly more spacious than the left.

The ventral surface of the skull shows but few and shallow impressions of the convolutions; it is scaling off similarly to the outer surface. Thickness of the left parietal 3 to $4 \mathrm{~mm}$.

The differences between this specimen and the various Lenape and eastern crania, as shown by the inspection, are even more plainly indicated by the principal measurements and indices (see tables, page 41). The most characteristic features of the specimen are its considerable breadth coupled with extreme narrowness of the face; its extremely small height, which is noticeable even if we compare the auriculo-bregmatic instead of the basi-bregmatic heights, and which gives rise to very low height-length and height-breadth indices, and the megaseme character of its orbits. Differences of such nature and so great in number are entirely beyond the scope of individual variation. When found in a normal skull, as this is, they can represent only racial characters. In this case they effectually differentiate the Burlington County cranium from all those crania recognized as Indian.

The Riverview Cemetery cranium (no. 44280, Peabody Museum) is that of a male about fifty years of age. It is somewhat damaged, but enough of the face as well as of the vault is preserved for almost all of the more important measurements. (Plate Iv.) The skull 
is normal with the following exceptions: There is a slight depression behind the left lower portion of the face, and the angle between the plane of the posterior nares and the basilar process is somewhat more acute than usual; the left border of the foramen magnum is slightly irregular, and on the left side the upper half of the border of the occipital is situated somewhat higher than that of the parietal bone. The left mastoid also is situated a little more posteriorly than the right. All of the features indicate some disturbance in the development of the inferior portion of the left side of the skull. These defects were not of a serious enough character, however, to affect the general conformation of the skull, and the vault together with other parts is symmetrical.

The surface of the skull shows a large abrasion on the left parietal, and several cuts, such as could be made with the edge of a not very sharp shovel, on the left parietal bone; considerable and deep scaling, particularly over the frontal and left parietal regions; and two darkgreenish (copper or brass) discolorations of oval shape about $2 \mathrm{~cm}$. in the longer diameter, situated one on the left squama behind the pterion, the other near the middle of the right squama, on the parietal bone adjoining. Both squamæ and the occipital bone give evidence of defects caused by injuries.

Inspection as well as measurements show the Riverview skull to be very closely allied to that from Burlington county and in common with the latter to differ radically from all other crania described in this paper. The Riverview skull presents similar rounded outlines of its planes, similar small height, narrow face, and megaseme orbits, in comparison with that from Burlington county. The differences between the two are only slight, such as are commonly met with in the two sexes. ${ }^{a}$

The face in the Riverview skull is orthognathic, but this character is undoubtedly due in part to the previously mentioned backward depression of the facial parts. The alveolar process, fairly well preserved, presents also but little slanting. The alveolar arch is regular and massive; it is rather low (alveolar point to nasal border $1.85 \mathrm{~cm}$.), but not very narrow (maximum external width

$a$ The peculiar features of these crania were well recognized by Prof. F. W. Putnam as early as 1888, and are also acknowledged by Ioctor Russell in his paper on the Human Remains from the Trenton Gravels $(148-150)$. Doctor Russell wrote under the difficulty of lacking sufficient material, a circumstance which undoubtedly influenced his incorrect final conclusions. Professor Putnam's remarks, made after the presentation by Mr. Volk of the Riverview Cemetery specimen to the Peabody Museum, are as follows (Peabody Muscum Report, Iv, no. 2, 35, 1888): "This human skull (the Riverview specimen) is small and of a remarkable form, and agrees with two other's (Burlington County and 'Gasometer' skulls) which we have from New Jersey, one of which was certainly from the gravel. These three skulls are not of the Delaware Indian type," etc. The only error in these remarks relates to the gasometer skull which, after all, was shown to be closely similar to the crania of the Lenape (see The Crania of Trenton, Bulletin of American Museum of Natural History, xvi, 23, New York, 1902). 
$5.6 \mathrm{~cm}$.). The alveoli of the second incisors and those of all the molars are largely obliterated. Judging from the size of the remaining alveoli, the teeth must have been of somewhat submedium size; their number and position were normal. The palate is symmetrical and presents nothing extraordinary; its length, from the alveolar point to the end of the spine (which is small) is $4.8 \mathrm{~cm}$., its maximum width $4.1 \mathrm{~cm}$., height, in front of the first molars, where the bone has suffered but little change, $1.45 \mathrm{~cm}$. Posterior nares regular, slightly wider near the palate than above; height in middle 2.9, width in middle $2.6 \mathrm{~cm}$.

The nasal aperture is regular, of pyriform shape, with sharp borders; there are two small subnasal fossa. The nasal index shows a low mesorhyny.

The.submalar fossæ are well marked. The malars are not massive and show no prominence except directly above the fossæe just named.

The orbits are of moderate size and megaseme index; they approach the quadrangular shape; borders quite sharp, depth $4.4 \mathrm{~cm}$., interorbital septum $2.65 \mathrm{~cm}$. (27.5 per cent of the line between the orbital ends of the malo-frontal sutures).

Nasal bridge slightly submedium in height, moderately wide. Glabella quite prominent; the same is true of the ridges which extend above the median halves of the orbits.

The forehead is low, but not sloping. Above the supraorbital ridges the frontal bone shows a moderate depression which, in the present state of the specimen, is accentuated by the scaling of the outer table of the bone. Frontal eminences ordinary. There is a persistence of the metopic suture. Diameter frontal minimum 9.6, diameter frontal maximum $12.6 \mathrm{~cm}$.; nasion-bregma are $12.1 \mathrm{~cm}$. (32.1 per cent of the total nasion-opisthion arc).

The parietal bones show nothing unusual. The eminences are not prominent. Temporal ridges low, scarcely traceable. No parietal foramen. Bregma-lambda are $14 \mathrm{~cm}$. (36.8 per cent of the nasionopisthion arc), showing considerable antero-posterior development of the bones.

The occipital bone shows on the left side above the superior ridge a moderate bulging, which produces the before-mentioned somewhat greater elevation of the superior half of the occipital over the adjoining parietal border on that side. The superior occipital ridge and inion elevation are well marked.

The temporal regions show moderate bulging. The squamæ are quite low. The zygomæ were apparently of only moderate strength. Styloids masculine, not very massive.

Base of the skull: The foramen magnum is, as already stated, slightly irregular; its size is moderate (diameter antero-posterior 3.65 , diameter lateral maximum $3.2 \mathrm{~cm}$.). There is no depression of 
the bones about the foramen. The plane of the foramen, prolonged forward, passes $1.2 \mathrm{~cm}$. beneath the nasion. The posterior condyloid foramina are obliterated; the remaining openings in the base present nothing unusual. The processes, including the styloids, are all well developed. The petrous portions are but slightly sunken below the level of the surrounding parts; the middle lacerated foramina are smaller than in average whites. Glenoid fossæ fairly deep.

The sutures of the skull show a fine, not very deep serration. Obliteration is noticeable only in the sagittal suture, at vertex and about obelion, and at a point in front of the pterion, on the left side in the coronal suture. The pterions are of the $H$ form, but quite narrow. There are no Wormian bones.

Measurements of the Burlington County and Riverview Cemetery skulls, with minima and maxima of measurements of Lenape and other eastern Indian erania of the same general type.

Capacity (Flower's method). Diameter antero-posterior (glabella-occipital) Diameter lateral maximum Height (basion-bregma) . Cephalic index ...

Height-breadth index

Nasion-alveon height.

Diameter byzigomatic maximum.

Facial index .

Orbital height, average

Orbital breadth, average

Orbital index, average.

Height of nasal aperture.

Breadth of nasal aperture

Nasal index.

Basion-alveon line.

Basion-nasion line.

Gnathic index (Flower)
Height-length index.

\begin{tabular}{|c|c|c|c|}
\hline $\begin{array}{l}\text { The Burling- } \\
\text { ton County } \\
\text { skull (no. } \\
\text { 19513, Pea- } \\
\text { body Muse- } \\
\text { um)-fe- } \\
\text { male. }\end{array}$ & \begin{tabular}{|c} 
The River- \\
view Ceme- \\
tery skull \\
(no. 44280, \\
Peabody Mu- \\
seum)- \\
male.
\end{tabular} & $\begin{array}{c}\text { Minima and } \\
\text { maxima } 0,47 \\
\text { eastern In- } \\
\text { dian skulls- } \\
\text { females. }\end{array}$ & $\begin{array}{c}\text { Minima and } \\
\text { maxima of } 21 \\
\text { eastern In- } \\
\text { dian skulls- } \\
\text { males. }\end{array}$ \\
\hline $\begin{array}{l}c m . \\
(a)\end{array}$ & $\begin{array}{l}c m . \\
(b)\end{array}$ & $\begin{array}{l}\mathrm{cm} . \\
(?)\end{array}$ & $\begin{array}{r}c m . \\
\ldots . . .\end{array}$ \\
\hline 17.7 & 18.4 & $16.9-18.5$ & $17.1-19.7$ \\
\hline 14.5 & 14.6 & $12.1-13.9$ & $13.0-14.6$ \\
\hline 11.5 & 11.6 & $12.4 \overline{5}-13.5$ & $13.7-14.6$ \\
\hline 81.9 & 79.3 & $66.1-80.8$ & $67.4-83.8$ \\
\hline 65.0 & 63.0 & $68.9-79.4$ & $71.5-83.8$ \\
\hline 79.3 & 79.5 & $89.9-108.0$ & $98.6-109.8$ \\
\hline (?) & 6.9 & $6.2-7.2$ & $7.1-8.4$ \\
\hline$c 12.0$ & $c 12.1$ & $11.9-13.75$ & $13.5-14.7$ \\
\hline (?) & c 57.0 & $48.8-56.3$ & $50.0-57.9$ \\
\hline 3.5 & 3.25 & $2.87-\quad 3.7$ & $3.2-3.5$ \\
\hline 3.7 & 3.55 & $3.6-4.25$ & $3.85-4.15$ \\
\hline 94.6 & 91.6 & $79.7-92.5$ & $79.5-88.6$ \\
\hline (?) & 5.0 & $4.5-5.2$ & $4.7-6.1$ \\
\hline (?) & 2.4 & $2.2-2.65$ & $2.2-3.0$ \\
\hline (?) & 48.0 & $45.1-56.7$ & $42.9-63.8$ \\
\hline (?) & 7.9 & $9.2-10.5$ & $10.1-11.0$ \\
\hline 9.5 & 7.0 & $9.26-10.5$ & $10.35-11.45$ \\
\hline (?) & 92.9 & $95.2-104.0$ & $93.6-104.4$ \\
\hline
\end{tabular}

a Approximately 1,275 cubic centimeters. ${ }^{b}$ Between 1,300 and 1,400 cubic centimeters. c Approximate.

\section{Racial Affinities of the Burlington County and Riverview Cenetery Sikulls}

The inevitable conclusions are that the Burlington County skull and that from the Riverview cemetery at Trenton are of a type totally different from that of the Lenape, or of any other Indian crania from the East or elsewhere of which we have thus far any knowledge. 
They are skulls of people of a different race with which no further acquaintance has yet been made in this country. What this race was, the writer was not able to show at the time of the publication of the report in 1902. Two possibilities suggested themselves at that time: One, that the crania represented some non-Indian people who preceded the Lenape about Trenton; the other, that they might be crania of later intruders-or immigrants-into that region. The former theory could not be accepted without further proof, and the immigrant idea seemed hardly plansible, for the Delaware valley had been settled largely by Swedes, whose cranial type is radically different. On the whole, there are very few localities known, in Europe or elsewhere, where normally very low skulls had been observed.

The problem was slowly followed up, a search being made in the American collections for examples and in European literature for reports of crania similar to the two skulls under consideration. As to other specimens on this continent, it was found that in very rare instances a low skull occurs normally among the Indians, but none of the few examples seen were of the type of the two Trenton crania, the faces especially differing therefrom. The whole research strengthened the conclusion that the Burlington County and Riverview Cemetery skulls are not Indian. The quest in literature, however, had a result which may come very near a definite explanation of the enigma. In 1874 Virchow $^{a}$ reported a number of extraordinarily low skulls mainly from northwestern Germany, from the Elbe to the coast of Holland, drawing attention at the same time to several "Batavian" specimens and others of the same nature from the islands in the Zuyder Zee that had been pictured or described previously. ${ }^{b}$ All of these skulls were comparatively recent, the oldest not dating beyond about the ninth century of our era. The majority ranged in form from mesocephaly to brachycephaly; in capacity, from 1,215 to 1,700 c. c.; and in rertical height, ${ }^{c}$ from 12 to $12.85 \mathrm{~cm}$. Several of the skulls showed a depression of the base; the majority were free from any indication of a pathological condition. Virchow recognized these skulls as constituting a distinct cranial form and called the type chamocephaly. He thought he recognized it in some Dutch paintings. As to its significance, he was undecided.

A year later J. W. Sprengel published an account ${ }^{d}$ of some Zuyder

${ }^{a}$ R. Virchow, Über eine niedrige Schädelform in Norddeutschland, Zeitschr. f. Ethnol., vi, 239-251, taf. xvil, 1874. See also Zcitschr. f. Ethnol., Ix, 41, 1877, and consult in this connection 11 is and Rutimeyer's Crania Helvetica.

'Particularly in Blumenbach's Decades craniorum, pl. Ixiii, and in v. d. Hoeven's Catalogue craniorum.

$c$ Virchow measured this height from basion to the highest point of the skulls anterior to the middle of the sagittal suture. This measurement exceeds that of basion-bregma by from 1 to $5 \mathrm{~mm}$.

${ }^{d}$ Schädel von Neanderthal Typus, Arch. f. Anthrop., viri, 49-66, pl. v-viii, 1875. 
Zee Islands ${ }^{a}$ skulls, in lowness and in other features approximating to the type of the Neanderthal cranium. One of these specimens, a female skull from the Marken island, showed a height (German method) of only $12 \mathrm{~cm}$.

Finally, toward the end of $1875 \mathrm{~J}$. Gildemeister published a very interesting account of a series of remarkably low skulls, from burials in the dune under the Bremen cathedral. ${ }^{b}$ The burials, about 30 in number, were all of comparatively modern date, the oldest being from the ninth or tenth century of the present era. The majority of the crania belonged to the ordinary type, showing a fair height; thirteen of the skulls, however, presented chamæcephaly, six of them to a most extraordinary degree (see appended measurements). Gildemeister regards these specimens as representative of a distinct physical and hence ethnic type, persisting along parts of the northwestern coast of Europe to modern times. The resemblance of this type to that of the Neanderthal skull is striking, though the lowness of the forehead of the latter and its great supraorbital ridges are not approached.

Gildemeister's measurements of the six most pronounced of the Bremen low skulls follow:

\begin{tabular}{|c|c|c|c|c|c|c|}
\hline Characters. & No. 1. & No. 2. & No. 3. & No. 4. & No. 5 . & No. 6. \\
\hline Sex $\ldots . . . .$. & Male. & Male. & Male. & Irale. & Female. & Female. \\
\hline 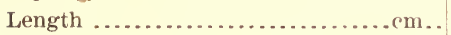 & 20.0 & 19.0 & 21.0 & 18.5 & 18.0 & 18.6 \\
\hline 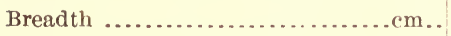 & 15.0 & 14.5 & 16.3 & 12.0 & 14.0 & 13.7 \\
\hline Height (vertically above basion) ....cm.. & 11.9 & (11.9) & 13.2 & 12.0 & 11.0 & 11.5 \\
\hline 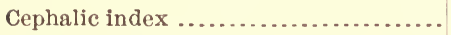 & 75.0 & 76.3 & 77.6 & 70.3 & 73.0 & 73.7 \\
\hline 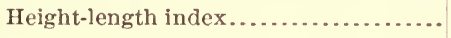 & 59.5 & $(62.7)$ & 62.8 & 64.8 & 61.0 & 61.8 \\
\hline Height-breadth index . . . . . . . . . . . . . . & 79.1 & $(82.0)$ & 81.0 & 92.0 & 78.0 & 83.9 \\
\hline
\end{tabular}

The specimens, it is seen, are dolichocephalic to mesocephalic, differ greatly in size, and are extremely low. The height-length indices are the lowest recorded from any part of the world. ${ }^{c}$ None of the skulls is reported as in any way pathological.

The foregoing accounts, which do not seem to have been followed by any additional observations of importance on similar material,

a'That is, Marken, Schokland, Urk. The account includes reexamination and illustration of Blumenbach's "Batavus genuinus," Decades craniorum, pl. Ixiii. See also II. Welcker, Craniologische Mittheilungen, Arch. f. Anthrop., I, 153, 1866, footnote; reports on 15 skulls from Urk and Marken, with the average height of $12.7 \mathrm{~cm}$.

- ${ }^{b}$ Ueber einlge niedrige Schädel aus der Domsdüne zu Bremen, Abhandl. naturw. Vereine Bremen, Iv, 513-524, taf. xii-xiv, 1875. Also Neue Schädelfunde am Domberge zu Bremen, Verhandl. der Berliner Gesellsch. f. Anthrop., Ethnol., and Urgesch., 120, Berlin, 1875.

${ }^{c}$ 'The height-length index, based on the vertical, or maxlmum, height, averages in whites near 75 and is generally above 70 . 
establish the presence in parts of northwestern Germany and Holland in or up to recent times of a cranial type characterized by precisely the feature which renders so extraordinary the skulls from Burlington county and Riverview cemetery, namely, very low height. 'The cephalic index and the capacity of the European chamæcephals show a wide range, which easily includes the same characteristics of the Trenton specimens. The facial measurements are lacking in the German reports, but Gildemeister speaks of a narrow face. a feature

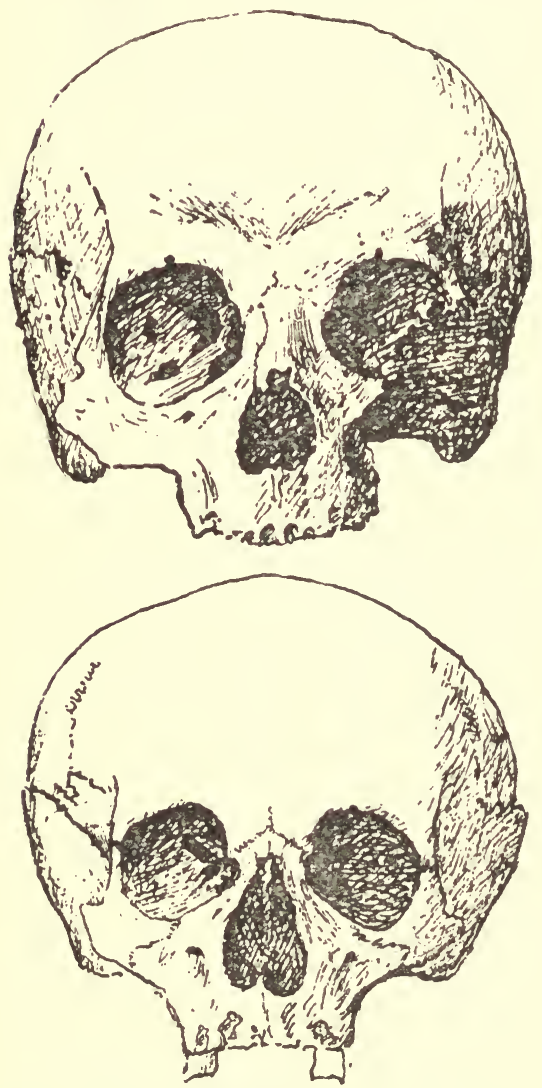

Fig. 5.-Front view of two of the Bremen chamæeephals. marked also in the two skulls from New Jersey; and one of the latter, it will be remembered, shows a trace of basal depression, such as noticed in a more pronounced degree in some of Virchow's low crania. The illustrations of the European chamæcephals (see figures 5 and 6) show remarkable general resemblances to the two Trenton skulls-there are the same rounded outline, without sagittal elevation, of the anterior and the posterior plane, similar shape of the superior plane, and similar aspect of the face. There can be no doubt of the relationship of the two forms, and it now remains to account for the occurrence of identical forms in regions so remote from each other.

That such marked similarity of any two normal, important, extreme, and repeated forms in cranial morphology could be of accidental origin has never been demonstrated, and, in fact, is not conceivable.

Similarity of skull form due to pathological conditions is rather common; furthermore, the same pathological agency, such as premature closure of a suture, affects all skulls in similar manner, giving rise to typical forms, the best known of which are plagiocephaly and scaphocephaly. A depression of the base, such as was noticed by Virchow in several of his low crania and is present to a slight degree in the Riverview Cemetery skull, is due to abnormal softness of the bones at some period during development, and causes a diminution 
in height. But this condition, easily perceivable, affects the rest of the skull irregularly and can not possibly account for the large number of the low crania, including that from Burlington county, in which there is nothing abnormal, and for the chamxcephalic type as a whole. This type, though not as yet known with all the detail desirable,
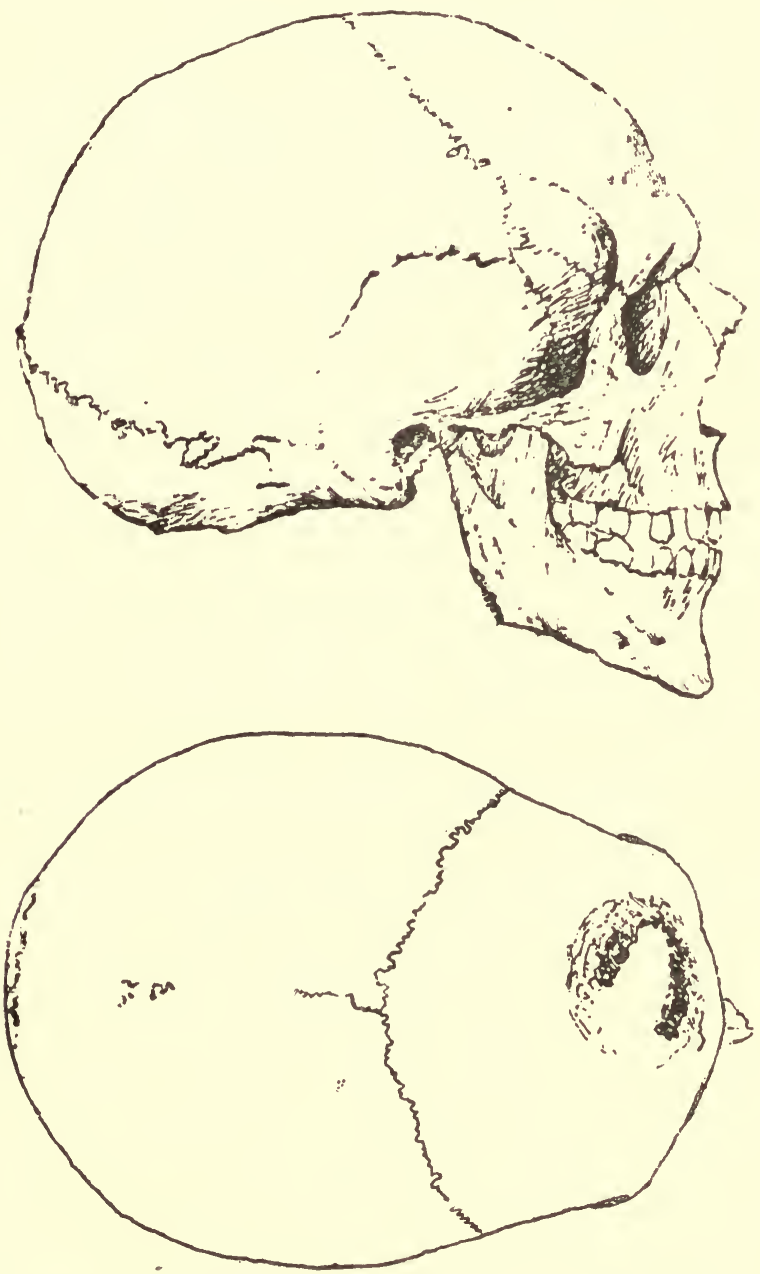

FIG. 6.-Side and top views of one of the Bremen chamæcephals.

appears to represent a racial or tribal form, which in some instances may naturally be modified, or enhanced in some particular, by pathological conditions.

There remains, then, only the question of racial affinity, and this narrows down to the following limits: The European and the Delaware Valley chamæcephals are palpably alike, and both differ greatly 
in at least one important character, from the rest of the whites on one side, and in all features from all the Indians of whom there is any knowledge, on the other. In view of these facts, the conclusion is unavoidable that close kinship exists between the European and the New Jersey specimens.

Granted that the western European and the Trenton skulls referred to proceed from practically the same people, we have not yet solved their chronological relation. A type of so pronounced characteristics is probably old, and may be very ancient; and as its representatives have been found on opposite sides of the Atlantic ocean, which might have been traversed accidentally or otherwise thousands of years ago, the possibility that the American representatives of that type may be much more ancient than those found in European burials can not be excluded. However, the probabilities are against the ancient origin of the crania. The detailed records of New Jersey show that, while the Delaware valley was settled to a large extent by Swedes, there were also some immigrants from Holland, among whom were very likely individuals of the low cranial type. The deposits in which the Burlington County and the Riverview Cemetery skulls were found do not preclude comparatively recent burials. On the whole, it seems safer and more in line with the known evidence to regard the two low Trenton crania as of relatively modern and European origin than as representatives of Quaternary Americans.

\section{XIII.-THE TREN'TON FEMUR}

The specimen known as the Trenton femur is a portion of a human thigh bone discovered in December, 1899, by Mr. E. Volk, under the employ of Prof. F. W. Putnam, in a railroad cut within the limits of the city of Trenton. The bone lay $7 \frac{1}{2}$ feet ( 2.286 meters) below the surface, in sand, under an apparently undisturbed deposit of glacial gravel, and was photographed in situ. Shortly after its discovery Professor Putnam kindly submitted the specimen to the writer for examination, and soon thereafter reported on it in a preliminary way before section $\mathrm{H}$ of the American Association for the Advancement of Science. ${ }^{a}$ The detailed account of the find, which Professor Putnam has been preparing, has not yet been published. The antiquity of this specimen must rest on the geological evidence alone. The bone is undoubtedly part of a human femur, from a little below the trochanters. It shows ordinary dimensions, with a flattening at its upper end such as occurs with especial frequency in Indians, but

a Winter meeting of the section, at New Haven; there is no pubilished report of this meeting. 
there is no possibility of definite racial determination. The specimen bears evidence of what appear to be traces of human workmanship; the details of these, however, as well as the details of the physical examination and the archeology of the find, will be dealt with by Professor Putnam.

\section{XIV.-THE LANSING SKELETON}

The skeleton of an adult and a portion of the lower jaw of an infant were discovered in February, 1902, by the sons of Mr. M. Concannon, a farmer near Lansing, Kansas, in digging a tunnel which was to serve for storing apples and other farm products. This tunnel enters horizontally into a low bench or terrace situated at the base of the Missouri river bluffs at the entrance to a small side valley. The child's jaw lay about 60 feet, the adult skeleton about 70 feet, from the entrance of the tunnel and 20 feet below the surface. The deposit in which the bones were embedded and which forms the bulk of the bench is an undisturbed loess-like silt, through which at all levels are scattered fragments of limestone and shale, the whole presenting great variety of composition and considerable irregularity of accumulation.

The find became known to men of science through Mr. M. C. Long, curator of the museum of Kansas City, who, on reading of the discovery in a local paper, immediately visited the locality in company with Mr. E. Butts, a civil engineer. Before the end of 1902 the locality had been visited and examined by many prominent geologists, and a deep exploratory trench was sunk near the tumnel by Mr. G. Fowke, under the direction of Professor Holmes of the Bureau of American Ethnology. Scientific reports concerning the find were published by Williston, ${ }^{a}$ Upham, ${ }^{b}$ Winchell, ${ }^{c}$ Chamberlin, ${ }^{d}$ Holmes,${ }^{e}$ and Fowke. ${ }^{f}$ It appears that no question has been raised as to the correctness of the accounts regarding the location of the human bones; but there are important differences of opinion concerning the geological age of the deposits and consequently the antiquity of the skeleton. Without going into details, it may be said that Professors Williston, Upham, and Winchell favored a considerable antiquity for both the deposits and the specimens, regarding the former as true loess, while Professors Chamberlin, Calvin, Salisbury, and Iolmes, with Fowke, judged the deposits to be not true loess but of a much more recent formation.

\footnotetext{
${ }^{a}$ Seicnee, August 1, 1902.

${ }^{b}$ Seience, August 29, 1902; American Geologist, September, 1902; American Anthropologist, n. s., IV, no. 3, 566, 1902.

c Amcrican Geologist, September, 1902.

¿Journal of Geology, October-November, 1902; also notes by Calvin and Salisbury in ibid.

e Ameriean Anthropologist, n. S., Iv, no. 4, 743-752, 1902.

1Bulletin 30 of the Burcau of American Ethnology, pt. 1, 1907.
} 
In the words of Professor Holmes, ${ }^{a}$ whose opinion agrees closely with that of the other opponents of the geological antiquity of the find-

The preferred interpretation of the phenomena is that the relic-bearing deposits of the Concannon bench were not laid down in glacial times by the silt-charged waters of the Missouri, but that they are a remnant of delta-like accumulations formed in comparatively recent times within and about the mouth of the tributary valley by local subaerial agencies, all save the more protected portions having been removed by late encroachments of the ever-changing river.

The importance of the find made it very desirable to consult the testimony of the bones themselves. In October, 1902, the writer therefore visited the locality of the find ${ }^{b}$ and by the courtesy of $\mathbf{M r}$. Iong and Prof. E. Haworth ${ }^{c}$ was enabled to examine all of the bones recovered. A report of the results of this examination and of a subsequent study of the skull at the National Museum was read before the International Congress of Americanists at its New York meeting in the fall of 1902 and was subsequently published. ${ }^{d}$ In order to avoid double reference, the essential portions of the report are herein reprinted with a few minor modifications in the text.

\section{Somatologicar, Characters}

The skeleton is fairly complete, but many of the constituent parts are damaged and many fragments are wanting.

All the parts of the skeleton show a nearly uniform yellowishwhite color and all are of similar consistency. Portions of the bones show adhering soil, which now, in its dry state, is uniformly gray. In addition there are spots at which is a closely adhering, hard, brittle, grayish, apparently calcareous concretion. ${ }^{e}$

The bones are quite hard and not very brittle; they are not sufficiently chalky to mark a blackboard. They fully preserve their structure and exhibit no perceptible traces of fossilization.

The skeletal parts are all entirely normal - that is, free from anomalies or disease-with one exception; a few of the articular surfaces are surrounded by moderate marginal exostoses, such as occur frequently in older individuals or in certain forms of arthritis.

The skeleton is distinctly that of a male of about fifty-five years of age. The man was of medium stature (about $1.65 \mathrm{~m}$. ) and of ordinary strength. The bones of the lower extremities indicate better development than those of the upper, showing relatively greater use of the former.

a American Anthropologist, n. S., IV, no. 4, 751, 1902.

${ }^{b}$ In examining the site where the skeleton was said to have lain, a piece of bone, in all probability a portion of a human phalanx, was found in situ in the wall of the tunnel.

${ }^{c}$ By this time the skull only was in Mr. Long's keeping, the rest of the bones being in the care of Professor Haworth at the State University, Lawrence, Kansas. Since then the skull has been deposited in the National Museum.

dAmerican Anthropologist, n. s., v, no. 2, 1903.

$e$ Some of this concretion covers the edges of breaks, as in the humerus and femur, showing these breaks to be ancient, while more adheres to the occipital and parietals within the cranium. 
(UNiversity 


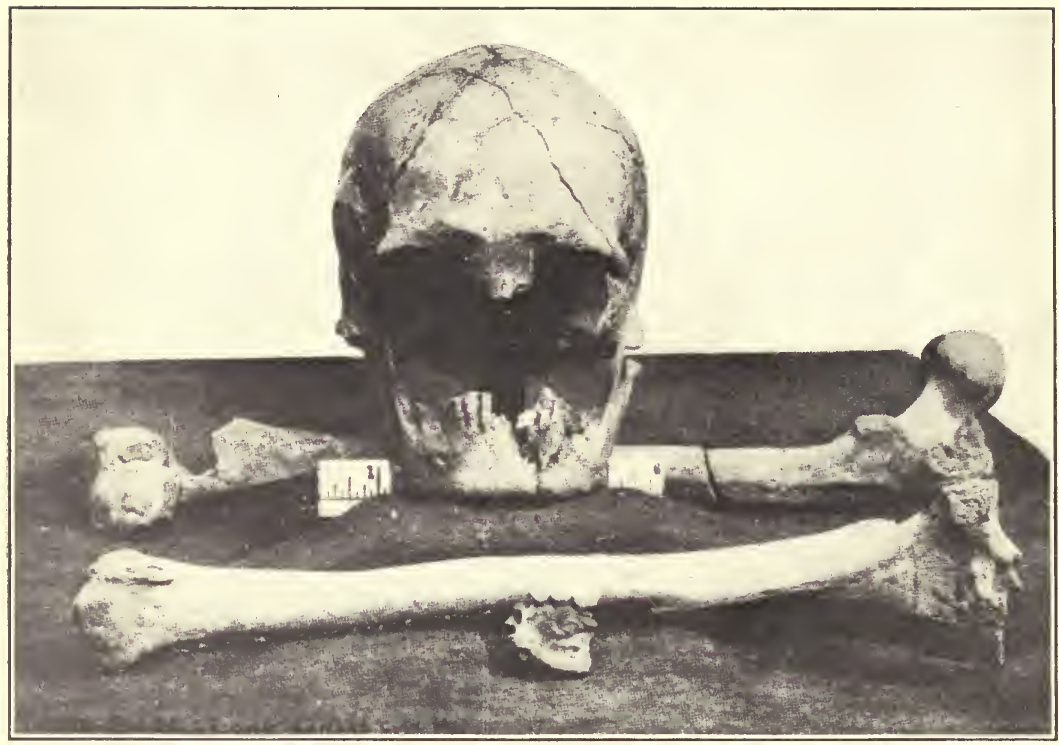

$a$

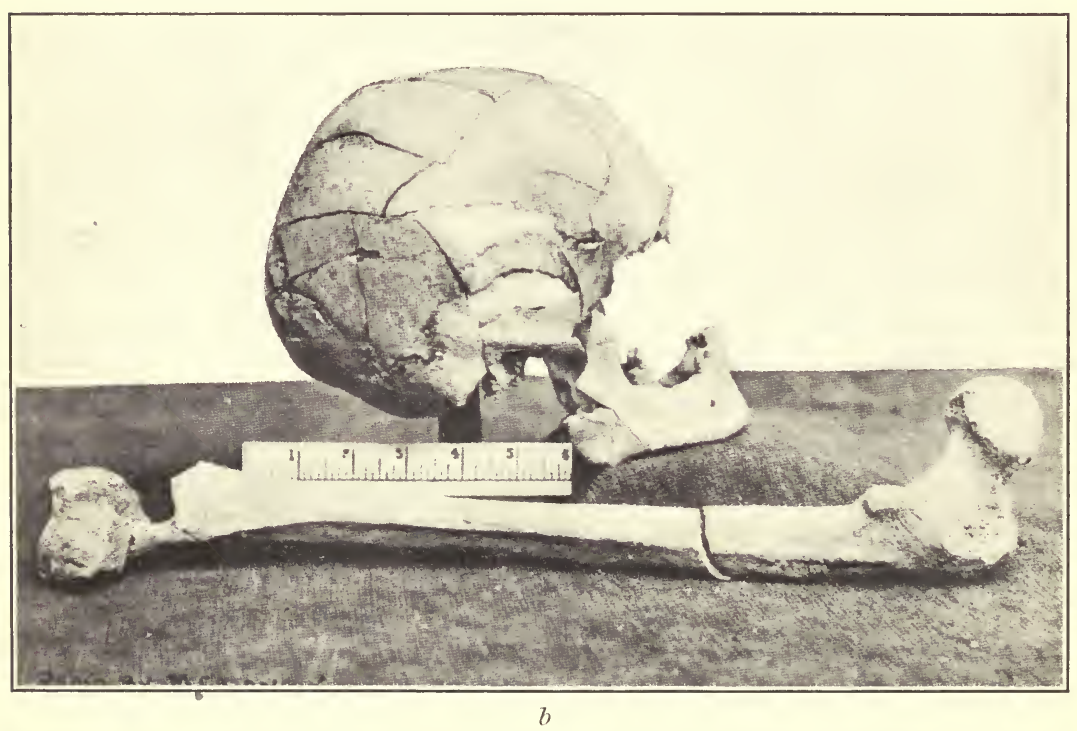

THE LANSING (KANSAS) SKULL

$a$ Front view of skull, with femur and tibia: $b$ side view of skull, with right femur 
Considered anthropologically, all the parts of the skeleton, and the skull in particular, approach closely in every character of importance the average skeleton of the present-day Indian of the Central states. Zoologically, as well as in growth, the Lansing skeleton and the skeleton of the typical present-day Indian of the upper Mississippi region are of the same degree and quality.

There is no resemblance whatever between the Lansing skull and the low skulls from Trenton. ${ }^{a}$

As to the skull, the vault is fairly well preserved, but the facial parts and the base are to a large extent destroyed. When recovered by $\mathrm{Mr}$. Long the specimen was in pieces, but it has been well repaired and is suitable for measurement. (Plate.v, $a, b$.) The skull shows good development and is in no way artificially deformed. It exhibits slight asymmetry, the left part of the frontal bone protruding somewhat more than the right; such asymmetry is quite common and is not due to any detectable abnormal condition. Viewed from side, top, or base, the skull is ovoid in shape, the smaller end forward; from front and back, particularly the latter, it appears pentagonal, with the summit of the figure upward. The forehead is somewhat low and sloping when compared with that of a well-developed skull of a white man, but appears normal in comparison with the forehead of undeformed skulls of Indians.

The temporo-parietal region shows but moderate convexity; the parietal bosses, however, are well defined, though not unduly prominent. The sagittal region is somewhat elevated, forming a moderate sagittal ridge, which extends from about the obelion to bregma; a slight ridge is also seen along the metopic line over the middle third of the frontal bone. These ridges which, separated or more often joined, are common in Indian skulls, give the cranium, when viewed from the front or from the back, its pentagonal appearance. About midway between the bregma and lambda the ridge, which from this point backward rapidly diminishes, forms a quite marked but in no way abnormal summit.

The occiput is rather bulging, as common in dolichocephaly. The base is much damaged, but so far as can be determined it agrees in its general features with that of an average skull of the modern Indian. The lower jaw also is somewhat damaged; it agrees in sexual character with the rest of the skeleton; it may be described as about medium in all its features and in no way peculiar; the chin shows fair prominence. There are nine teeth remaining in the lower jaw, all of about a verage male size and all considerably worn down; such attrition is the rule with older individuals among the Indians.

The thickness of the cranial vault and the weight of the skull are 
in no way extraordinary; the thickness of the left parietal below the temporal ridge ranges from 4 to $5 \mathrm{~mm}$.

The supraorbital ridges are quite pronounced, but not unusual for a male; they are restricted, as is the case in many Indian crania, to the median half of the supraorbital distance. The glabella is not very prominent. The temporal ridges are moderate; nearest approach to sagittal suture $4.5 \mathrm{~cm}$. Occipital ridges, except the superior, quite indistinct. The zygomæ and mastoids are broken; the remnants show nothing unusual.

The nasion depression is well marked; the interorbital distance is moderate (at level of nasion, $2.6 \mathrm{~cm}$.). Nasal bones show fair breadth ( $8 \mathrm{~mm}$. beneath nasion, right $\tau \mathrm{mm}$., left $5 \mathrm{~mm}$., broad). The walls of the orbits are rounded, not unduly heavy; orbital depth ordinary.

Parietal foramina absent, mastoidal moderate. The situation and inclination of the foramen magnum (so far as it is possible to judge) and the depth of the glenoid fossæ are as in an ordinary Indian skull.

The sutures show medium complexity and are considerably involved by synostosis (senile). This is most marked in the coronal and the anterior part of the sagittal suture, but extends in lesser degree through the rest of the sagittal and the whole lambdoid. All the sutures about the temporal bone, and the fronto-sphenoidal, fronto-malar, fronto-nasal, and internasal articulations are still free.

Ventrally the skull shows but few brain impressions, except on the temporals, as among modern Indians. The metopic crest is low. The capacity must have exceeded 1,500 c. c.

The skull is dolichocephalic (cephalic index, 73.75) and quite high (basion-bregma very nearly $14.0 \mathrm{~cm}$.). The nasal index can not be determined. The orbits were probably mesoseme.

\section{Detail measurements}

Diameter antero-posterior (glabello-occipital) ____________centimeters__ 18. 9

Diameter antero-posterior from ophryon______

Diameter lateral maximum____ 9

Diameter bregma-basion, near____ 0

Diameter bregma-opisthion

Diameter bregma-biauricular line _____ 6

Diameter frontal minimum

Diameter frontal maximum (along coronal suture) _-_____

Nasion-bregma are

Bregma-lambda are

Lambda-opisthion are ___________

Circumference maximum (above supraorbital ridges) _-___________do_-__ 52.0

Thickness of left parietal, below temporal ridge__________millimeters__ 4-5

Thickness of left parietal, above temporal ridge

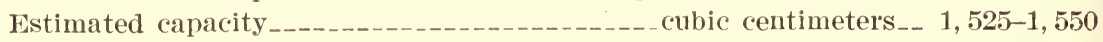

The remaining parts of the skeleton have the following characteristics:

Femora. Maximum length of right, $44.0 \mathrm{~cm}$.; left, broken. 
Torsion and inclination of neck moderate. Linea aspera rather pronounced but not abnormal. The bones are quite strong. The shaft presents a well-marked upper subtrochanteric flattening, as is common in the femora of Indians. There is on each femur a rough, long, low elevation in the location where the so-called third trochanter is sometimes found. This low ridge represents a muscular insertion (gluteus max.), and its marked development is a sign of muscular activity.

Tibice. Maximum length of left tibı, mmus spine, about $35.7 \mathrm{~cm}$. Right tibia, broken. Bones of medium masculine strength, showing neither in form nor in inclination of head anything abnormal.

Fibula in fragments, no unusual features.

Humeri. Length (maximum) of right, nearly $32.0 \mathrm{~cm}$.; left, defective (part lost). No unusual torsion. There was apparently a bilateral moderate perforation of the fossa.

Radii. Length (maximum) of left, $25.4 \mathrm{~cm}$; right, broken. The length of the radius as compared with the humerus is somewhat greater than in whites, but such proportion is not rare in Indians.

Ulna in fragments, no special features.

All the bones of the upper extremity are somewhat slender.

Pelvis much damaged, but enough remains to indicate that it was rather small and masculine. The superior semicircular lines are represented by a marked elevation.

Ieasurements

\begin{tabular}{|c|c|c|}
\hline & Right. & Left. \\
\hline Femora: & $\mathrm{cm}$. & $\mathrm{cm}$. \\
\hline Diameter antero-posterior maximum at middle ............ & 2.75 & 2.8 \\
\hline 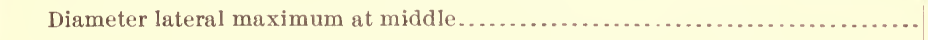 & 2.75 & 2.6 \\
\hline Diameter antero-posterior at upper flattening . . . . . . . . . . . . . . . . & 2.45 & 2.3 \\
\hline Diameter lateral maximum at upper flattening $. . . \ldots \ldots \ldots \ldots \ldots . . . . . .$. & 3.25 & 3.35 \\
\hline Shape of shaft, right, approaching $1 u^{.}$ & & \\
\hline Shape of shaft, left, 4. & & \\
\hline \multicolumn{3}{|l|}{ Tibiæ: } \\
\hline Left, diameter antero-posterior at middle . . & 3.1 & \\
\hline Left, diameter lateral at middle............ & 2.0 & \\
\hline 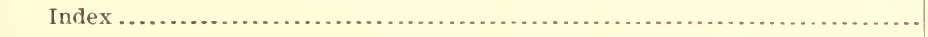 & 64.5 & \\
\hline Shape of shaft, both, 3 and somewhat 4 . & & \\
\hline \multicolumn{3}{|l|}{ Humeri: } \\
\hline Diameter antero-posterior at middle.... & $1.5 \check{z}$ & 1.5 \\
\hline Diameter lateral maximum at middle................. & 2.2 & 1.85 \\
\hline
\end{tabular}

a See Hrdlička, Typical Forms of Shaft of Long IBones, Proceedings of the Association of American Anatomists, 14th Annual Session, 55, 1900.

As these measurements show, the shaft of the tibia as well as the humerus is somewhat flattened.

The height of the individual, judging from the long bones, by Manouvrier's tables, ${ }^{b}$ was about $1.65 \mathrm{~m}$.

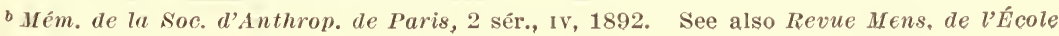
d'Anthrop. de Paris, II, 227. 


\section{Conchusion}

The inevitable conclusion from the above examination, which was conducted with a hope that the specimen might prove beyond doubt an ancient one, since such a discovery would be of the greatest importance to American and even to general anthropology, is, as expressed before, that the Lansing skeleton is practically identical with the typical male skeleton of a large majority of the present Indians of the Middle and the Eastern states. Any assumption that it is many thousands of years old, dating from a past geological period, would carry with it not only the comparatively easily acceptable assumption of so early an existence of man on this continent, but also the very far-reaching and far more difficult conclusions that this man was physically identical with the Indian of the present time, and that his physical characteristics during all the thousands of years assumed to have passed have undergone absolutely no important modification.

In order to present further evidence in support of the view here taken the writer has selected from the collection in the National Museum several moder'n male adult crania of individuals belonging to tribes that occupy or occupied sections not far distant from that in which the Lansing skeleton was found. The measurements of these skulls, contrasted with those of the Lansing cranium, are appended, with an illustration (figure 7 ). The similarities are very apparent. If the Lansing skull differs in any way from the others, it is in its somewhat better development, particularly over the frontal region. But the type of the skulls is the same. It would have been well to include some Potawatomi and Kickapoo crania, but these tribes are poorly represented in our cranial collections.

Comparative measurements of the Lansing skull and the stulls of other Plains Indians

\begin{tabular}{|c|c|c|c|c|c|}
\hline & $\begin{array}{l}\text { Lansing } \\
\text { skull. }\end{array}$ & $\begin{array}{c}\text { Ponca } \\
\text { skull ( } 796, \\
\text { National } \\
\text { Museum). }\end{array}$ & $\begin{array}{c}\text { Kaw } \\
\text { skull (152, } \\
\text { National } \\
\text { Museum). }\end{array}$ & $\begin{array}{c}\text { Pawnee } \\
\text { skull (550, } \\
\text { National } \\
\text { Museum). }\end{array}$ & $\begin{array}{l}\text { Pawnee } \\
\text { skull (531, } \\
\text { National } \\
\text { Iuseum). }\end{array}$ \\
\hline $\begin{array}{l}\text { Diameter antero-posterior maximum } \\
\text { (glabella-occipital) .......centimeters.. }\end{array}$ & 18.9 & 18.85 & 18.4 & 18.9 & 18.7 \\
\hline Diameter lateral maximum ....... do.... & 13.9 & 14.2 & 13.6 & 14.05 & 13.9 \\
\hline Basion-bregma height ..............do.... & $a 14.0$ & 14.0 & 13.75 & 13.4 & 13.7 \\
\hline 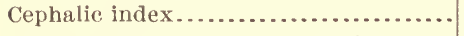 & 73.5 & 75.3 & 78.9 & 74.8 & 74.3 \\
\hline Diameterf rontal minimum.centimeters.. & 9.4 & 9.0 & 9.2 & 9.0 & 8.9 \\
\hline $\begin{array}{l}\text { Diameter frontal maximum (along coro- } \\
\text { nal suture).................. centimeters.. }\end{array}$ & 11.3 & 11.5 & 11.6 & 11.7 & 11.1 \\
\hline Nasion-opisthion arc........centimeters.. & 37.8 & 37.7 & 36.6 & 38.1 & 35.2 \\
\hline $\begin{array}{l}\text { Circumference maximum (above the } \\
\text { ridges) } . . . \ldots \ldots \ldots \ldots \ldots \ldots \text { centimeters.. }\end{array}$ & 52.0 & 52.0 & 51.2 & 52.3 & 51.8 \\
\hline $\begin{array}{l}\text { Thickness of left parietal below tem- } \\
\text { poral ridge ............... }\end{array}$ & $4-5$ & $4-6$ & $4-5$ & $4-4.5$ & $3.5-4.5$ \\
\hline Cranial capacity......cubic centimeters.. & $(b)$ & 1,530 & 1,445 & 1,530 & 1,480 \\
\hline
\end{tabular}


Near the Lansing skeleton was found a portion of the upper jaw of a child six or seven years of age. The bone shows nothing extraordinary. Three of the teeth (first dentition premolars and a permanent first molar) are still preserved; their size is moderate; the

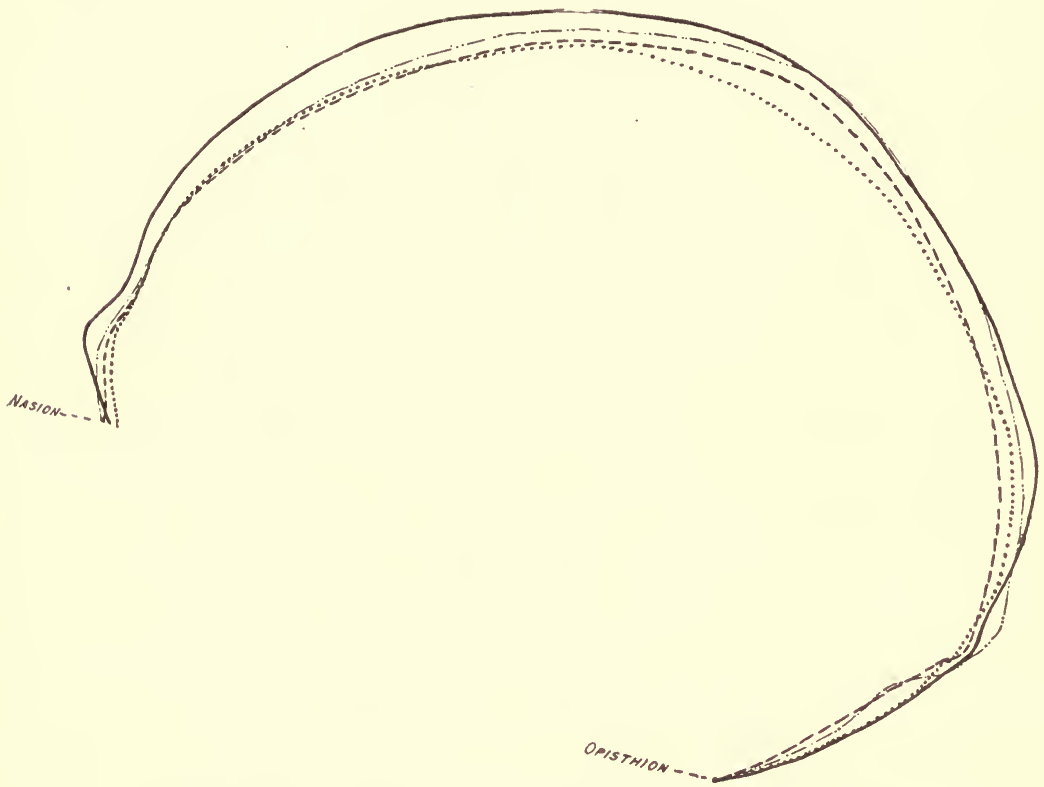

Fig. 7.-Comparison of tre nasion-opisthion arcs, geometrically constructed, of the Lansing skull and three modern Indian crania. — Lansing skull; _ _ _ Kaw skull $(152$, N. M.) ; l'awnee skull (550, N. M.) ; -..-..-..- I'onca skull (796, N. M.).

enamel is white, quite bright, and without any cracks. The first permanent molar shows three roots and four cusps.

\section{XV.-TIEE FOSSIL MAN OF WESTERN FLORIDA}

Several lots of human bones, more or less thoroughly fossilized in various ways, were discovered on different occasions during the latter part of the last century along the western coast of Florida, south of Sarasota.

\section{The Osprey Skull}

This find dates from 1871. On June 4 of that year Mr. J. G. Webb, of Osprey, Manatee county (see figure 8), wrote to Prof. Joseph Henry, Secretary of the Smithsonian Institution, as follows:

I discovered in ditcling in my hammock a perfect skull. It was unfortunately broken in digging it out, but I shall send all the pieces and you will find no difficulty in gluing it into perfect shape. It was intentionally buried (without doubt) face up, lying on its lack, about 3 to 4 feet below the surface, but had become surrounded by a soft, ferruginous rock, which is constantly forming wherever a spring comes to the surface. I live on a shell mound adjoining the hammock. 
The specimen was sent by Mr. Webb as a gift to the Smithsonian Institution, and what remains of it is now in the collections of the division of physical anthropology of the National Museum. A short account of it was published in 1889 by Prof. Joseph Leidy. ${ }^{a}$ On

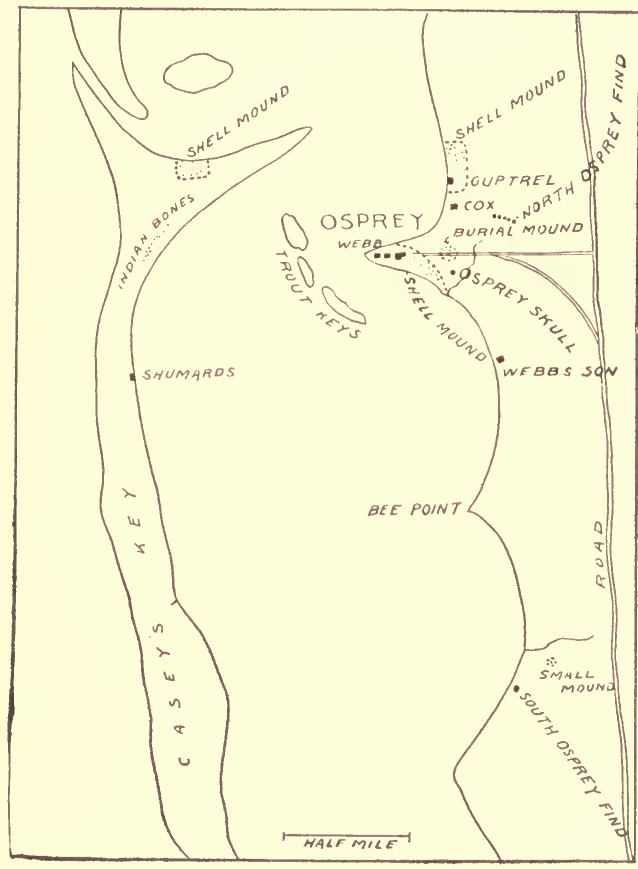

FıG. 8.-Sketch map of Osprey and vicinity. continuing the excavation in the same place some additional pieces of human bones were found, but Mr. Webb does not now know in what condition they were or what became of them.

\section{The North Osprey Bones}

About 1872, in digging another ditch in a shallow dry pond bed on the northern part of his property, about ten minutes' walk from the location of the above-mentioned skull, $\mathrm{Mr}$. Webb and his son, J. WV. Webb, discovered, "less than 3 feet deep," another lot of fossilized human bones, and these also were sent to the Smithsonian Institution. ${ }^{b}$ There was no ferruginous or other rock in the neighborhood of these bones, and their fossilization is of a different nature from that of the Osprey skull. Most of these specimens, which are in very good condition for study, are preserved in the National Museum, a few pieces are in the Peabody Museum, Cambridge (mentioned in the Seventh Annual Report of that institution, 1874, page 26), and a few other portions are in the Army Medical Museum.

a Notice of Some Fossil IIuman Bones, Transactions of the Wagner Frec Institute of science, II, 9-12, Philadelphia, 1889.

${ }^{b}$ The exact location is described by .J. W. Webb, in a recent letter, as follows: "North of the old sugar mill, on the road to Guptrel, is a ditch running east and west, which drains the 'Banana' pond; the ditch which now runs on line between the lowland on the south and the sandy land on the north used to run through the lowland. If a point is taken in a line of the second row of orange trees east of the road a little more than halfway from the northernmost tree to the ditch, it will about correspond to the site of the old ditch where the bones were taken out. In this lot there were arm and leg bones and parts of skull and part of a jaw. They were less than 3 feet deep.' 


\section{The Hanson Landipg Remains}

About 8 miles north of Osprey and on the same line of shore is a locality called, after its owner, Hanson's landing, and here also some fossil human bones, consisting of a skull and several other parts of the skeleton, were discovered. Early in 1886 this locality was visited by Prof. Angelo Heilprin and Mr. Joseph Wilcox, and several parts of a fossilized human skeleton were actually found in situ. Professor Heilprin described the find ${ }^{a}$ as follows:

I was conducted to a spot where it had been reported a human skeleton lay embedded in the rock. The rock $I$ found to be a partially indurated ferruginous sandstone, removed but a short distance from the sea and but barely elevated abore it; the condition of its exposure was doubtless the result of recent sea waste. I was much surprised to find actually embedded in this rock and more or less firmly united with it the skeletal remains of a mammalian which I had little difficulty in determining to be the genus homo. Most of the parts, including the entire head, had at various times been remored by the curiosity seekers of the neighborhood, but enough remained to indicate the position occupied by the body in the matrix. The depression which received the head was still rery plainly marked, but unfortunately the outline had been too much disturbed to permit of any satisfactory impression being taken from it. I was able to disengage from a confused mass of stone and skeleton two of the vertebræe, which Doctor Leidy has kindly determined for me to be in all probability the last dorsal and first lumbar. The distinctive cancellated structure of bone is still plainly visible, but the bone itself has been completely replaced by limonite.

The same locality was visited again the following spring by Mr. Wilcox, who obtained several specimens of fossilized human bones, among which was a fairly well-preserved calcaneum. Finally, on still another occasion, Mr. Wilcox secured at Hanson's landing "a piece of the rock containing the end of a human thigh bone, also altered into limonite," which specimen he gave to the University of Pennsylvania.

\section{The South Osprey Remains}

About 1888 Mr. J. G. Webb and his son-in-law, Mr. Griffith, in looking for "phosphate rocks" $b$ along the shore, discovered about a mile and a half south of Osprey the remains of a human skeleton embedded in and partly projecting from the exposed rock. The following interesting notes concerning this find were furnished by Mr. J. G. Webb in a letter addressed to Dr. W. H. Dall, dated October 29, 1890 :

[The human bones embedded in rock] were found on the shore washed by every tide, but not so always or very long. The mainland shores of the bay

a Transactions of the Wagner Free Institute of Science, 1, 14-15, Philadelphia, 1887.

$b$ The so-called phosphate rocks in this region consist of ancient water-worn fossil bones, particularly ribs of large cetaceans. These fossils are found, already in their water-worn condition, cemented in the shore rocks and are now being washed out wherever the rocks are exposed to the action of the waves. 
are wearing away very rapidly-in places a score of feet since I first knew the bay. Not so much in this place, but some. Tlre rock in which this specimen is embedded was not long ago covered by the soil and subsoil, which has been washed away. Now all aloug the shore in places, not continuously, are beds or masses of a conglomerate rock, ferruginous, varying in color from red to black, and which the late Professor Meek said was bog iron ore, and containing pebbles, many of them phosphate of lime. It was in this hard rock that I found and sent Professor W'ilcox pieces of Indian pottery, though he discovered some himself before that. These beds of conglomerate rest upon sand, and so did this other kind of rock I sent you, and you will see projections on the bottom of it where the mud of which it was made was cast into holes and inequalities in the sand. This same rock, containing occasionally an oyster shell, lies in places on top of the hard conglomerate, which would seem to show that the skeleton was embedded subsequent to the formation of the hard conglomerate, but by an agency similar or identical.

The bones consisted of the larger part of the thorax, lying, particularly as regards the vertebrx, fairly well in situ. Two pieces of the rock in which the bones were included were chiseled ont and sent to the Smithsonian Institution and are now preserved in the National Museum. Both Mr. Webb (J. G.) and Mr. Wilcox found small fragments of pottery in the rock in several places along the shore of the bay adjoining Mr. Webb's property on the south; one of these potsherds, apparently a piece of a simple Indian cooking pot, is also preserved in the National Museum.

\section{Examination of the Specimens}

With the exception of a brief report on the Osprey skull and the Hanson Landing calcaneum by Leidy, the western Florida fossil human bones until now have not been described. In undertaking the description of the more important of the specimens, it was recognized that the first desideratum was a competent chemical analysis. This was kindly made at the Museum chemical laboratory by Mr. IV. C. Phalen. Four different specimens were analyzed at the same time by exactly the same method, and the results were as follows:

\begin{tabular}{|c|c|c|c|c|}
\hline Constituents. & $\begin{array}{l}\text { Osprey } \\
\text { skull. }\end{array}$ & $\begin{array}{l}\text { North Os- } \\
\text { prey bones. }\end{array}$ & $\begin{array}{l}\text { Indian } \\
\text { bones from } \\
\text { a Florida } \\
\text { mound. }\end{array}$ & $\begin{array}{l}\text { Fossil mus- } \\
\text { todon. }\end{array}$ \\
\hline 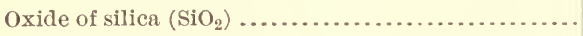 & 5.87 & 5.83 & 1.08 & 2.03 \\
\hline Phosphoric acid $\left(\mathrm{P}_{2} \mathrm{O}_{5}\right) \ldots \ldots \ldots \ldots \ldots \ldots \ldots \ldots \ldots \ldots \ldots \ldots \ldots \ldots$ & 23.07 & 31.66 & 34.02 & 35.72 \\
\hline 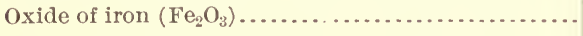 & 24.19 . & 10.16 & .80 & 1.52 \\
\hline Oxide of aluminum $\left(\mathrm{Al}_{2} \mathrm{O}_{3}\right) \ldots$ & None. & 3.44 & .12 & 5.46 \\
\hline Oxide of manganese $(\mathrm{M} n \mathrm{O}) \ldots \ldots \ldots \ldots . . . \ldots . . . . . .$. & None. & Trace. & Trace. & Trace. \\
\hline 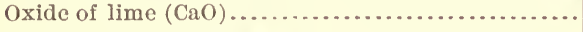 & 30.02 & 32.60 & 46.77 & 45.72 \\
\hline Oxide of magnesium $(\mathrm{MgO}) \ldots \ldots \ldots \ldots \ldots . . . . . . . . . .$. & .64 & .09 & Trace. & .34 \\
\hline 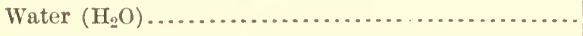 & a 12.61 & 416,20 & a 12.09 & a 6.49 \\
\hline Carbonic-acid gas $\left(\mathrm{CO}_{2}\right) \ldots \ldots \ldots \ldots \ldots \ldots \ldots \ldots \ldots \ldots \ldots$ & b1. 75 & 10.22 & $b 5.12$ & b 2.72 \\
\hline
\end{tabular}




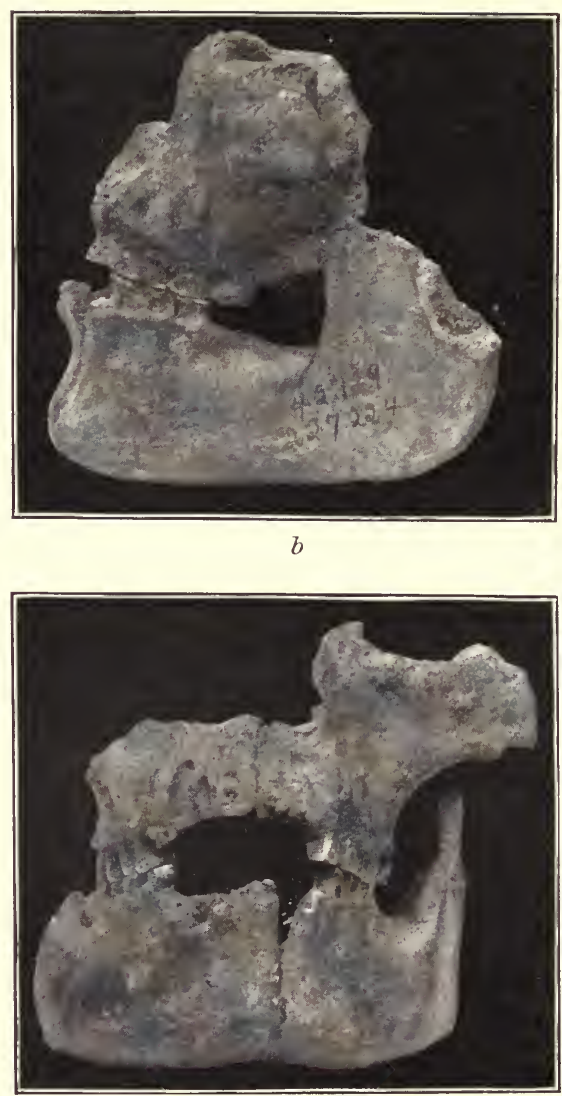

$c$

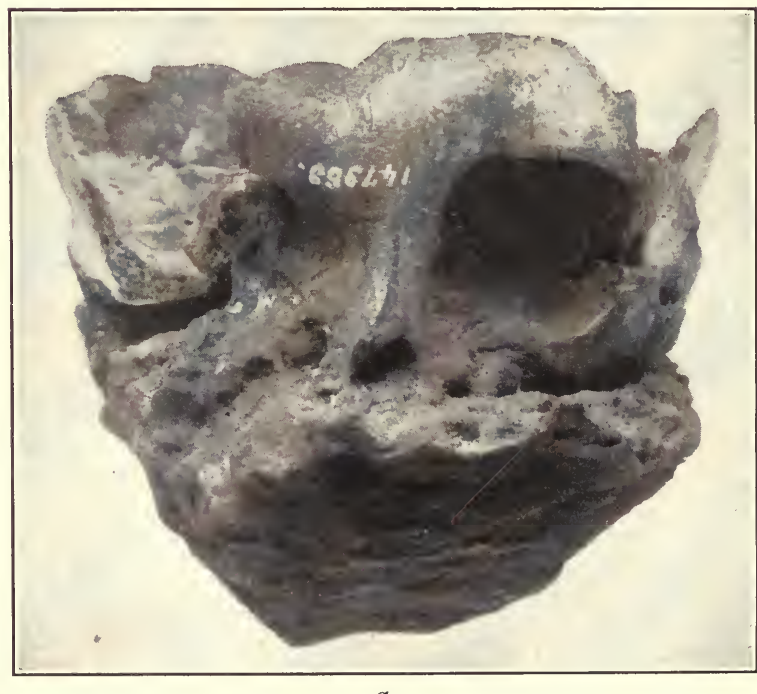

SKULLS FROM FLORIDA

$a$ Front view of Osprey skull $; b$, $c$ remains of face of North Osprey skull 
Mr. Phalen's figures indicate that, except as regards oxide of aluminum, both the Osprey skull and the North Osprey bones show greater alteration in their inorganic constituents than do the bones of the fossil mastodon.

The Osprey skull presents a marked diminution of the phosphoric acid-that is, the phosphates-as well as of oxide of lime, and a pronounced increase of silica and especially of iron. It is plain that a portion of the phosphates and calcium compounds have been replaced by silica and iron, and in that degree the bone is a fossil.

The North Osprey bones show a somewhat smaller loss of their original inorganic constituents than the Osprey specimen and a correspondingly smaller gain of iron; but the increase in silica is abont the same as in that skull, and there is present a considerable portion of oxide of aluminum, absent from the Osprey cranium. The bones are therefore to be looked on as being slightly less fossilized than the Osprey skull and as fossilized in a different manner.

The chemical determinations accordingly leave no doubt that the bones in question are fossilized in a considerable degree, a condition which has been very generally regarded as an important indication of antiquity.

\section{Physical Characters}

\section{The Osprey skull (plate vi, $a$ ) was thus reported by Leidy: ${ }^{a}$}

The specimen consists of the base of a skull, the vault broken off and lost, but retaining part of the face and a fragment of the mandible. The alveolar portions of the jaws and teeth are also absent. The fossil beneath is embedded in a mass of hard bog ore, while the bottom of the cranial cavity is occupied by fine, coherent, siliceous sand.

The fossil skull itself is converted into limonite, and the portions where exposed are well preserved and not in the slightest degree eroded or waterworn. The specimen indicates a well-proportioned ovoid skull, and closely approximates in shape an ordinary prepared French skull, such as the writer has lying at the side of the fossil. The forehead and contiguous portions of the face accord with the usual condition in a white man's skull. The superciliary ridges are but moderately produced and the nasal bones are large and prominent. The occiput has the usual appearance, while its muscular markings are not more developed than commonly. Comparative measurements of the fossil with a French skull are as follows:

Glabella to occipital protuberance Fossil
skull $170 \mathrm{~mm}$. Breadth above the auditory meati $131 \mathrm{~mm}$. Breadth of forehead at the temporal ridges $102 \mathrm{~mm}$.

To the above description may be added the following: The specimen is a small adult or nearly adult and apparently masculine cra-

a Notice of Some Fossil IIuman Bones, by Prof. Joseph Leidy, Transactions of the Wagner Free Institute of Science, II, 11-12, Philadelphia, 1889. 
nium, in no way deformed or diseased. The nasal bones are not above medium in size or prominence, and Leidy must have compared them with unusually small specimens to arrive at the conclusion that they are "large and prominent." The glabella and supraorbital ridges are of moderate masculine dimensions, and remind the observer in no way of primitive cranial forms. There is but little left of the forehead, but what is present shows a fair degree of arching. The orbits are not massive and were mesoseme or slightly megaseme in form. The mastoids are well developed, masculine. The walls of the skull are of moderate thickness only. The maximum anteroposterior diameter (from glabella to most prominent point of occiput) measured accurately amounts to $16.9 \mathrm{~cm}$., but it must have been a little greater before the specimen was damaged; the greatest breadth can not be measured, but must have been near $14 \mathrm{~cm}$.; in all probability the skull was mesocephalic. The sutures, so far as shown, are all patent, or were so before the fossilization took place. There is nothing unusual about the remaining visible parts.

As to the geological age of the skull, it is safe to say that from the somatological standpoint there is absolutely nothing about the specimen which could not be found in recent crania of Florida Indians. All anatomical indications of great antiquity are wholly lacking. The small size of the skull as well as its form is very nearly duplicated by nos. 228451 and 228452 , two comparatively modern Indian skulls in the National Museum collection, from south of Lake Okeechobee, Florida.

The North Osprey bones in the Museum collection consist of about twenty pieces of one or two adult skulls, parts of two left ossa innominata, a femur, a tibia, parts of an ulna and of two fibulæ, several vertebræ, portions of ribs, a patella, and a number of tarsal bones and phalanges.

The skull pieces are rather above medium (Indian) in thickness (the right parietal 6 to $9 \mathrm{~mm}$.), but show no compression or any abnormality. It is not possible to reconstruct enough of either cranium to show its size and form, but the size can be judged of as quite ordinary, and as to the form the uniform convexity of the occipital bone speaks against any higher grade of dolichocephaly. The upper jaw (plate vi), which is left almost entire, shows a 2.6 $\mathrm{cm}$. wide nasal aperture, a high and strong nasal spine, and quite a marked grade of alveolar prognathism-less than in the negro and about equal to that of the present-day Indian. There were 16 second dentition teeth of moderate size, the canines and the incisors being rather submedium. All the teeth that are still present show - a moderately advanced degree of wear. The palate measures, externally, about $5.4 \mathrm{~cm}$. in length and $6.2 \mathrm{~cm}$. in greatest breadth, and is quite deep and parabolic in form. The lower jaw is appar- 


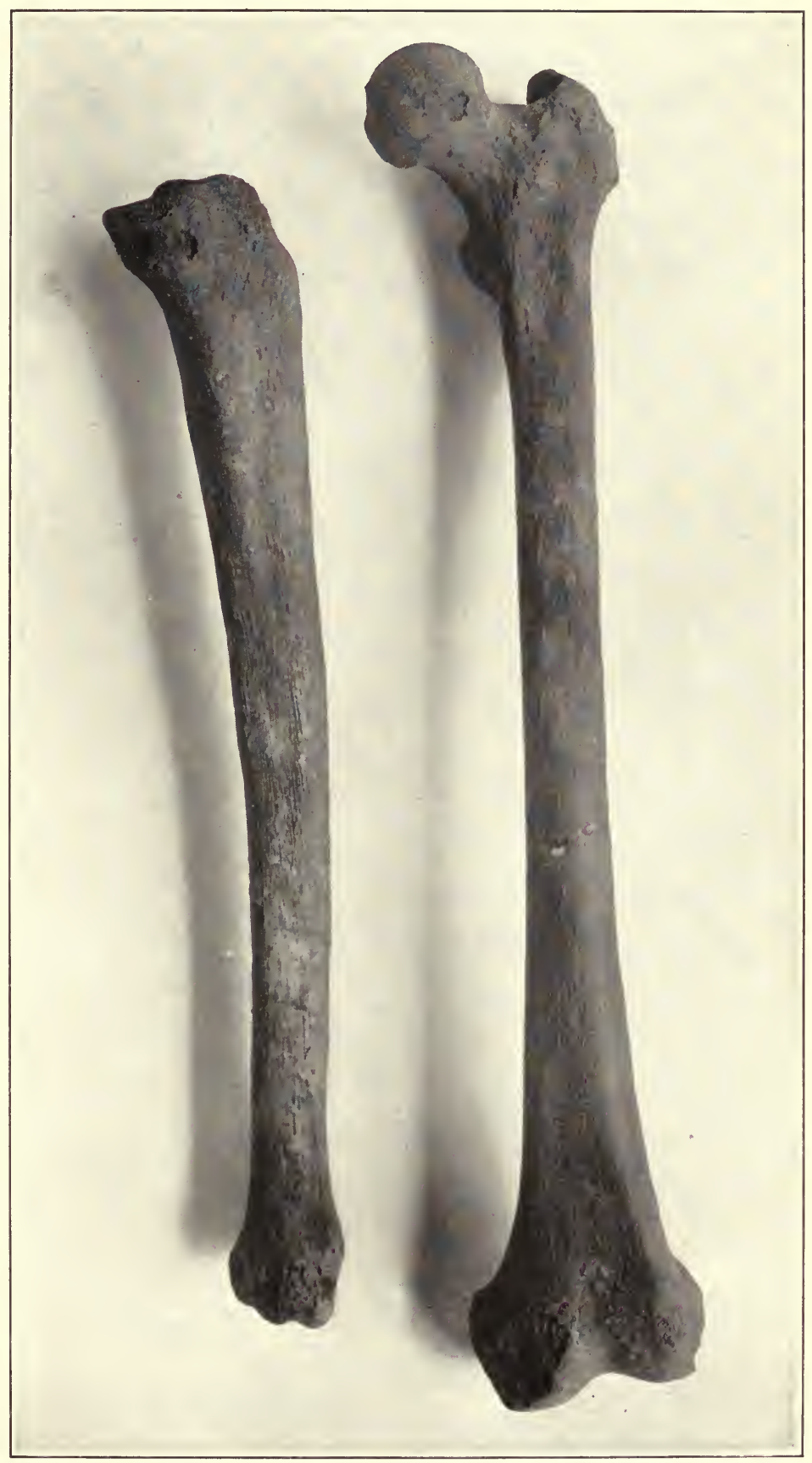

THE NORTH OSPREY (FLORIDA) FEMUR AND TIBIA 


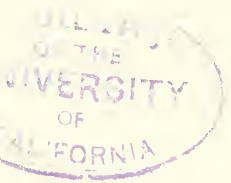




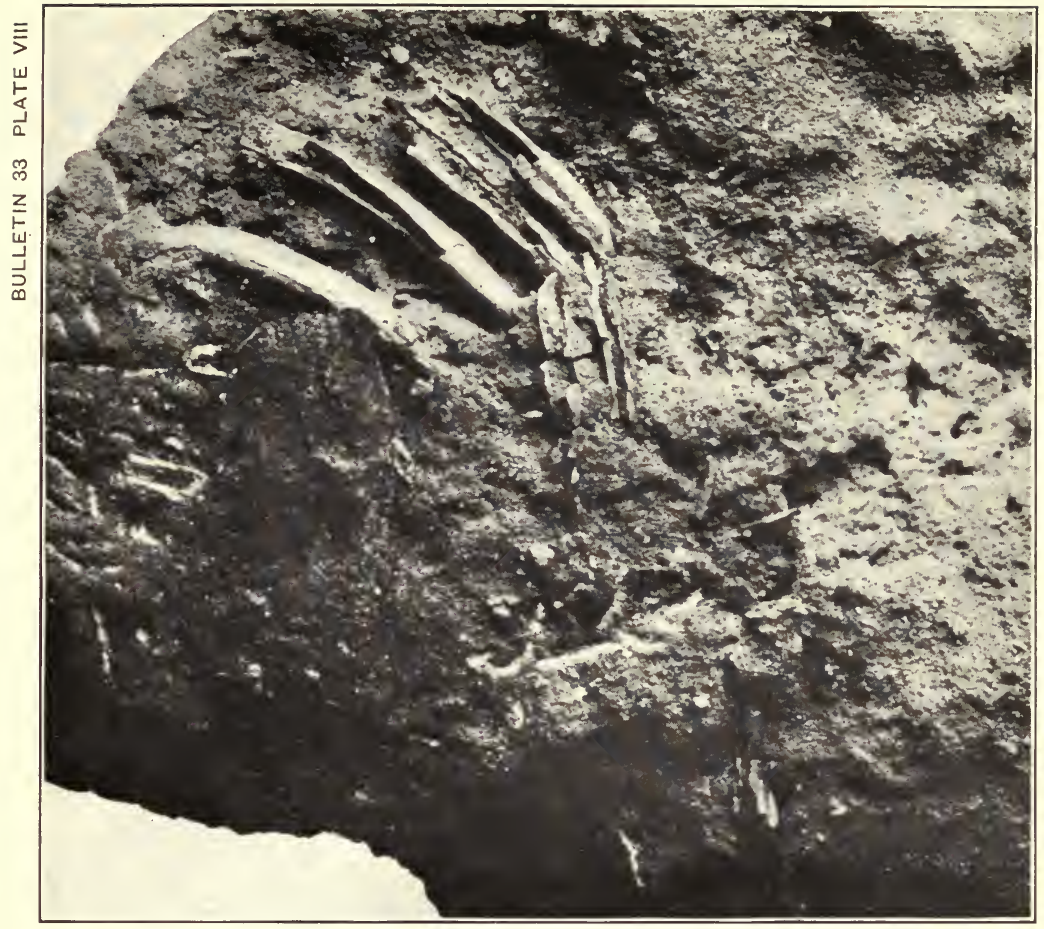

2

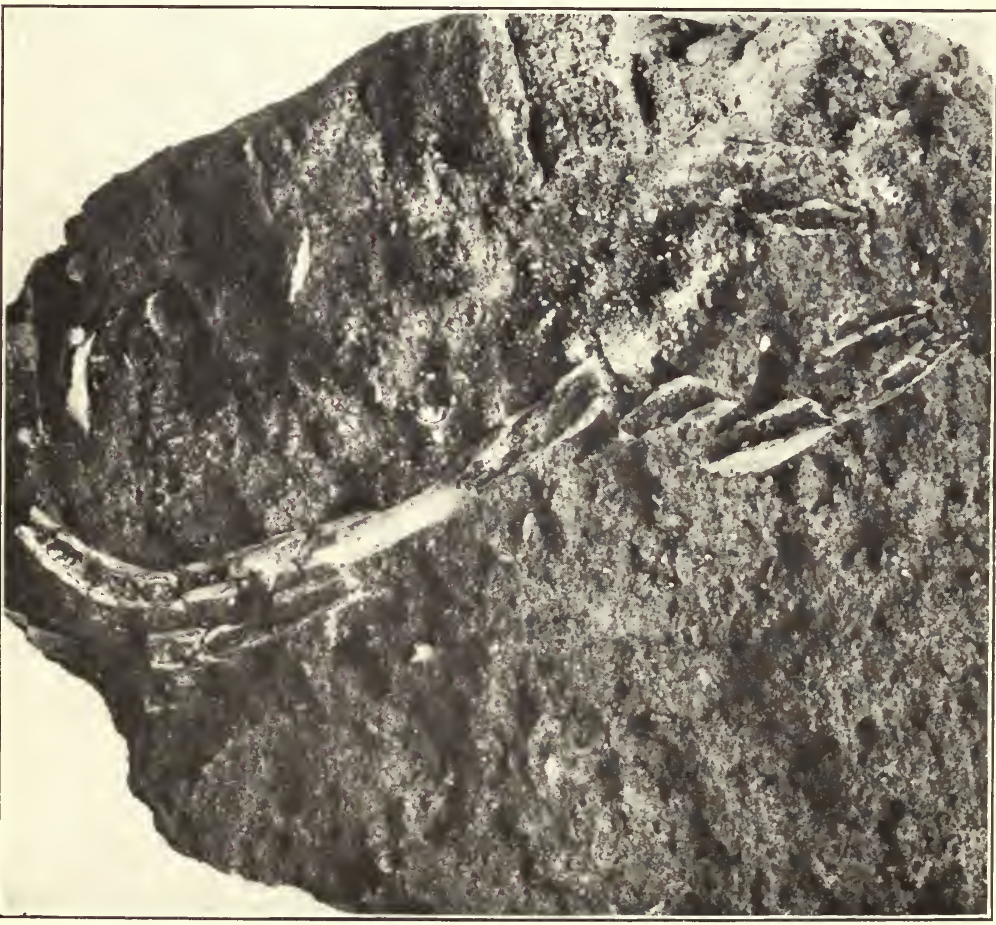


T- $\frac{\text { SiE }}{\text { Or ThE }}$ thet

UNIVER ITY

OF

CAL'FORIIIA 
ently that of a male (as are in all probability all the other skull fragments) ; it shows a fairly well-developed chin and alveolar protrusion in a moderate degree. Horizontal length of the lower ramus is about $9.8 \mathrm{~cm}$; height at symphisis is $3.5 \mathrm{~cm}$. There were 16 lower second dentition teeth; the molars of moderate size, the others rather submedium; the remaining teeth are normal in form, but are somewhat worn down. The upper and lower jaws fit well together and undoubtedly belong to the same cranium.

The two ossa innominata indicate medium masculine size and massiveness and are in no way peculiar in form. One measured about $19.5 \mathrm{~cm}$. in greatest height and $14.2 \mathrm{~cm}$. in greatest breadth (between the anterior-superior and the posterior-superior spines). The femur (plate viI) measures $40.5 \mathrm{~cm}$. in the bicondylar and 40.7 $\mathrm{cm}$. in maximum length; the neck shows an angle of $130^{\circ}$; the shaft approaches type 1 , or the prismatic, in form ${ }^{a}$ and is of moderate strength; the index of the subtrochanteric flattening is 75.8 ; and there is present a quite pronounced third trochanter. The tibia (plate vII), measured without the spine but with the malleolus, is $34 \mathrm{~cm}$. long and moderately platycnæmic (index at middle 64.9, at nutritive foramen 63.8). The inclination of the head is such as would be considered about medium in an Indian; traces of some slight superficial inflammatory process are apparent on the lower third of the bone: The remaining bones and fragments are all characterized by moderate dimensions, and none show any disease or abnormality.

When compared with ordinary recent Indian skeletons, it is found that not a single piece of the North Osprey bones exhibits any characteristic that is beyond the range of normal variation of modern specimens. As with the Osprey skull, there is again possible only one conclusion, namely, that there is absolutely nothing in these bones which would suggest great or even considerable antiquity, geologically speaking.

As to the Hanson Landing finds, all seem to have belonged to one skeleton, buried in the ground, before its consolidation took place. About all that can be said of the bones from the somatological standpoint is contained in the report of Professor Leidy, ${ }^{b}$ who states, with special reference to the better-preserved specimens of Mr. Wilcox, "They do not differ in any respect from corresponding recent human bones."

The South Osprey fossils (plate vin, $a, b$ ) in the hands of the writer, are so defective and so embedded in the rock that but little can be said regarding them anatomically. There are visible parts

\footnotetext{
a See Typical Forms of Shaft of Long Bones, Proceedings of the Association of American Anatomists, 14 th session, 55 et seq., 1900.

- Transactions of the Wagner Free Institute of Science, 11, 10, Philadelphia, 1889.
} 
of eight dorsal vertebra, a number of ribs, and a remnant of the sternum. All of these bones are plainly parts of a single adult, apparently male skeleton, and their relative positions, with the vertebræ still in situ, indicate burial, intentional or accidental, of the whole body. They show no unusual features.

\section{Résumé}

Summarizing briefly, it may be said that the fossil human bones from the west coast of Florida show, somatologically, marked likeness to recent Indian bones, and not a single feature indicative of a zoologically lower or otherwise substantially different type of humanity. The anthropological evidence of these bones as to any considerable geological antiquity must be regarded, therefore, as wholly negative.

The above decisive results of somatological examination when contrasted with the fossilized condition of the Osprey bones suggested the desirability of an exploratory visit to the locality, and such a visit was made by the writer, under the auspices of the Bureau of American Ethnology, in February, 1906. As it was apparent that the problems involved were largely geological, the Director of the U. S. Geological Survey was requested to detail a geologist familiar with the Florida formations to accompany the writer in the exploration. The request was kindly granted and Dr. T. Wayland Vaughan was assigned to this duty. His interesting report is embodied in subsequent pages.

Osprey was found to be a very small settlement on the little Sarasota bay, about 12 miles south of the town of Sarasota and about 70 miles south of Tampa. Mr. Webb's property lies on and at the base of a promontory which projects westward nearly half a mile into the bay. For about one-third of a mile along the southern shore of this promontory runs a well-preserved artificial shell mound. This mound commences near the point and reaches an elevation of from 15 to 16 feet, with a maximum breadth of about 125 feet.' Mr. Webb's main house stands in the middle of the widest and highest part of the mound, which is truncated or platform-like. From this point the mound diminishes in width toward the mainland and eventually tapers off to a point. Before the shell heap was erected the promontory was very low, and it seems that the pile may have been raised gradually by the aborigines for the purpose of giving a high and dry location for their dwellings. The structure consists entirely of closely packed shells of different sizes, all of existing species. Many of the inner shells of the mound show but slight traces of decay and not a few still preserve in large part their color. In the course of earlier excavations in this mound, undertaken by Mr. Norman Spang, it was found that old fire- 
places are irregularly scattered throughout the mass of shells at different levels. Shell implements and some fragments of culinary pottery were encountered, but no burials.

Situated near the base of the promontory and not covered by the shell mound is the so-called hammock land, a layer of black soil composed largely of decayed organic matter mixed with sand. There are several depressions in this piece of land, which to-day is covered by an orange orchard. One such depression is situated between the shell mound, near its southeastern end, and a low burial mound over which passes a wagon road leading to Mr. Webb's residence. It was in this hollow, less than 30 feet from the base of the burial mound, that Mr. Webb discovered in 1871 his first human fossil, the specimen now known as the Osprey skull. Mr. Webb, who is still alive and in good health, conducted the writer to the locality, and there, with the assistance of a laborer, a trench was dug 15 feet long, 6 feet wide, and a little more than 3 feet deep. No bones were found, but the character and condition of the deposits was seen to advantage (figure 9). Immediately below the surface were from 15 to $20 \mathrm{~cm}$. (6 to 8 inches) of black soil, somewhat mixed with white sand, under which was a layer of white sand. Two feet below the surface this layer showed patches of yellowish to rusty discoloration, due without doubt to depr osition of iron. Some shells

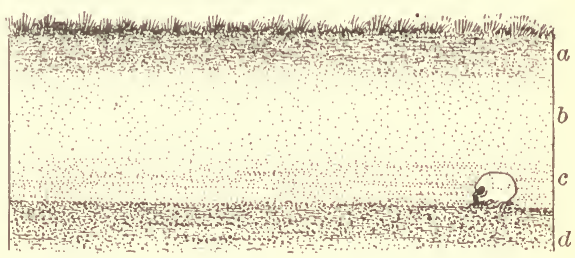

Flg. 9.-Seetion of deposits showing position of the Osprey skull. $a$, Blaek soil mixed with sand, 15 to $20 \mathrm{~cm}$. (6 to 8 in.); $b$, white sand, showing in lower parts yellow patches due to ferruginous deposits, 50 to $60 \mathrm{~cm}$. (20 to 24 in.); $c$, About where Osprey skull lay; $d$, Greenish clayey, sandy, and gravelly layer, $74 \mathrm{~cm}$. (29 in.) below surface. Extent unknown.

were found in this sand, but no concretions. Seventy-four cm. (29 inches) below the surface was encountered a more compact, greenish layer, consisting of sand, clay, and fine gravel; this extended to the full depths of the excavation. The limonite skull was recovered from the middle of the sandy ${ }^{*}$ layer, and presumably, from the description, near its base.

T'he exact location of the North Osprey find was not remembered by $\mathrm{Mr}$. Webb (the information given was obtained subsequently from his son) and in consequence the spot could not be located, but it also was in the dry bed of a small pond.

It remained to explore the locality where the South Osprey skeleton was found. Mr. Webb led the party to the spot. Since the date of the find the shore has suffered some loss by erosion, but the general conditions remain unchanged (figure 10). The shore is low, the elevation a veraging perhaps 2 feet above high tide. Beginning at the surface the soil consists (figure 11) of a layer of varying depth much 
mixed with white sand, and of sand, which is more or less replaced over large areas by flat, irregular masses of fine or coarse fossil-bearing conglomerate of widely differing consistency, ranging in color from gray to dark brown or blackish. These masses, which in spots reach 20 inches and even more in thickness, rest upon the irregular surface of a more clayey deposit, allied to the greenish basal layer of the Osprey skull locality and less permeable by water than the sand and soil above it. In this deposit were seen small waterworn pebbles, but no larger rocks or consolidations. As to the conglomerate, that found at the surface, which forms in places a detachable layer looking not unlike a lava flow, is finer grained, more grayish in color, and

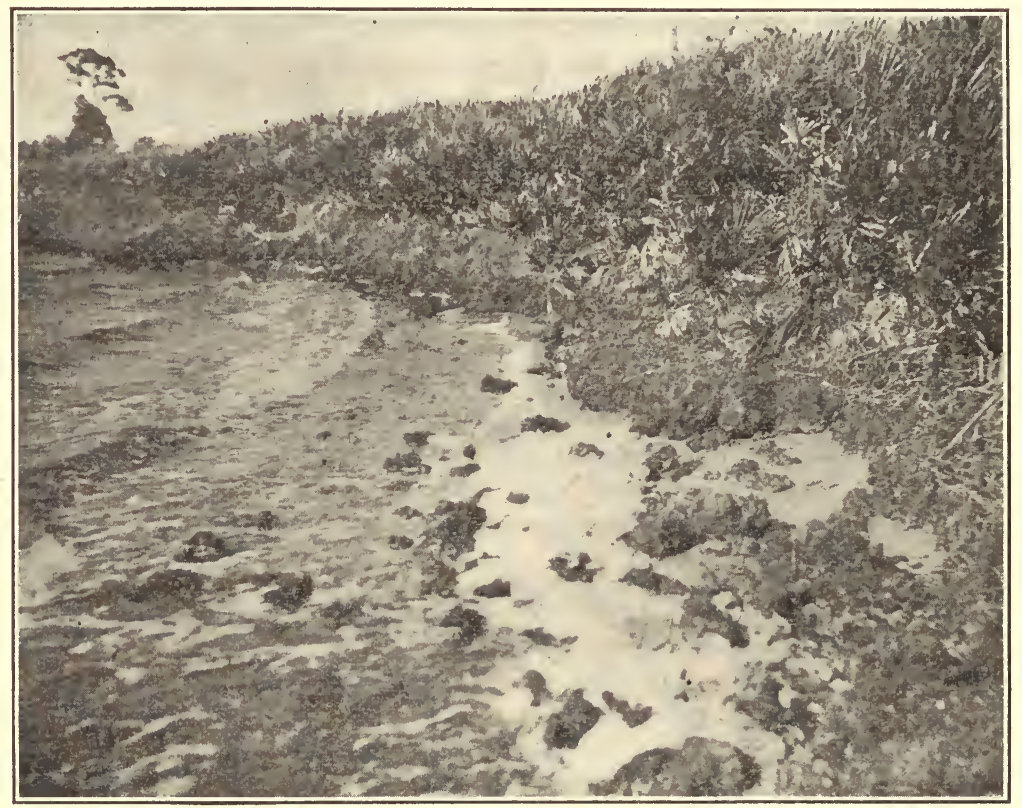

Fig. 10.- Shore line at South Osprey.

contains but few fossils. In places it is as hard as flint, while in others, sometimes in close proximity, it lacks firmness and crumbles to pieces readily, hardening somewhat, however, on exposure in dry places. Below this layer, which is very variable in thickness, and sometimes in places where it is absent, is found the coarser conglomerate, of a darker color, in places visibly ferruginous, also differing in consistency from spot to spot and containing fossil sharks' teeth and many waterworn fossils of cetaceans. These fossils, jasper-like in appearance and hardness and plainly not contemporaneous with the rock that holds them, are being slowly washed out by the waves to lie along the beach. The human skeleton was found in a grayish-black portion of the upper, finer conglomerate, 
A closer examination of the land along the shore northward, as well as southward, revealed many interesting conditions. Beginning with Mr. Webb's house, it was found that a short distance eastward from the spot where the Osprey skull was discovered and near the end of the shell mound a small stream of brownish water flows into the bay; at the mouth of the stream is a bed of irregular, ferruginous limonite concretions, mostly connected, but easily detachable. The concretions appear to be at about the level of the sand which is marked by ferruginous discolorations at the locality of the Osprey skull. They rest on a clayey and sandy deposit containing no solid rock, probably an ancient bed of the bay. The surface of the concretions nearest the mound was seen to include some shells of recent species, which may have formed part of the great shell heap. In

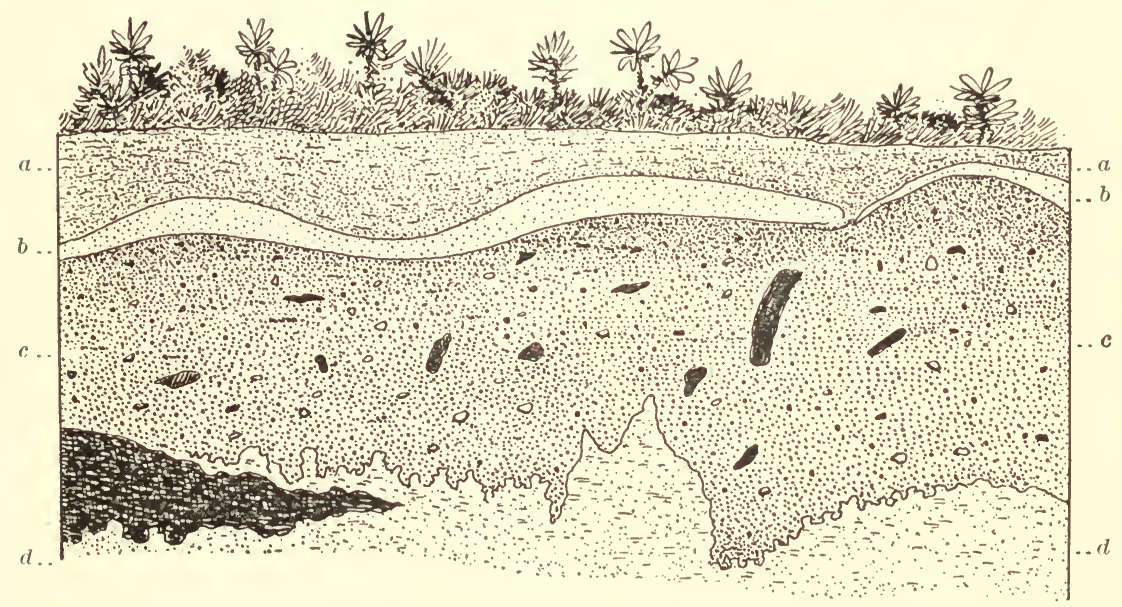

FIG. 11.- Section of the layers at the locality of the South Osprey find. $a$. Soil mixed with sand. $b$, Light fine-grained rock in which the human bones were found. $c$, Darker coarser-grained conglomerate containing ancient fossils. $d$, Greenish sandy and clayey layer.

these concretions, which resemble those in which the Osprey skull is held, were found also small pieces of ordinary Indian pottery. For a considerable distance east and south of this locality no rock is exposed, but about half a mile to the south ferruginous concretions and also some washed-out "phosphate rocks," consisting of cetacean fossils, appear on the beach and in the shore; thence they increase southward until near the place of the South Osprey find, where they form a substantial part of the shore. They are covered with the grayish finer conglomerate above described. They extend for an unknown distance south of this locality, and wherever they exist the beach is lined with pieces of rock, undermined by the waves and broken down by their own weight, as well as with remnants of old fossils washed out from this rock. A careful and repeated search failed to bring to 
light any human bones, but there were found in different places, embedded in the grayish rock of varying degrees of hardness, many recent shells, including, especially, numerous oyster-shells, a few pieces of partially mineralized animal bones (deer astralagus and calcaneum) that showed no attrition, as do the old fossils, a conch shell of a living species with ferruginous concretionary matter adhering to it much like that in the case of the Osprey skull, and, finally, roots of a burnt pine, still lying on the beach, about which the concretion was in process of formation. (Plate $\mathrm{I} x$.) Everything scen strengthened the impression that the solid deposits visible are largely if not wholly of recent formation. While these rocks where exposed are being slowly disintegrated by the action of the waves, in all probability they are actually forming in other localities, as about the above-mentioned pine roots. All the waters in the district, even those of artesian origin, are more or less mineralized; they sink readily through the surface soil into the underlying sand, but can not penetrate so easily into the clayey layer beneath. The result, possibly furthered by some chemical affinity of the sand, is a gradual deposition of mineral, principally ferruginous, matter, which in the course of time becomes sufficient in some places to cement into hard rock the sand and whatever the latter contains. The mineralogical conditions seem to favor also in an extraordinary way the infiltration of the bones and even replacement of their normal constituents, the latter process constituting fossilization. This is, at least, the sum of the unbiased impressions carried away by the writer as a result of the examination of the Osprey and South Osprey formations from which fossil human bones have been obtained. These impressions, the result of independent personal observations, are fortunately supplemented by the more expert observations embodied in the report of Doctor Vaughan, transmitted to the Chief of the Bureau of American Ethnology by the Director of the United States Geological Survey. The essential portion of Doctor Vaughan's report follows:

\section{REPORT OF DR. T. WAYLAND VAUGHAN}

Osprey is situated on a narrow tongue of land rising some 15 to 20 feet above sea level, about one-third of a mile long and from 100 to 150 feet wide. The ridge of the tongue is formed by an Indian shell mound. There is an Indian burial mound at its base, on its northeast side, and about one-fourth of a mile east of Osprey. Portions of a skeleton enveloped and partly replaced by limonite were found at this locality. Doctor Irdlicka had a pit about $3 \frac{1}{2}$ feet deep dug at this place, and exposed the following section:

4. Black soil, about___-___- 1 foot.

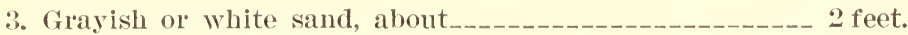

2. Irregular bed of yellowish sand, continuous with the above A few inches.

1. Greenish, argillaceous, and sandy layer-_____-_____-_ Thickness unknown.

The yellowish sand is the layer in which the skeleton was found. 


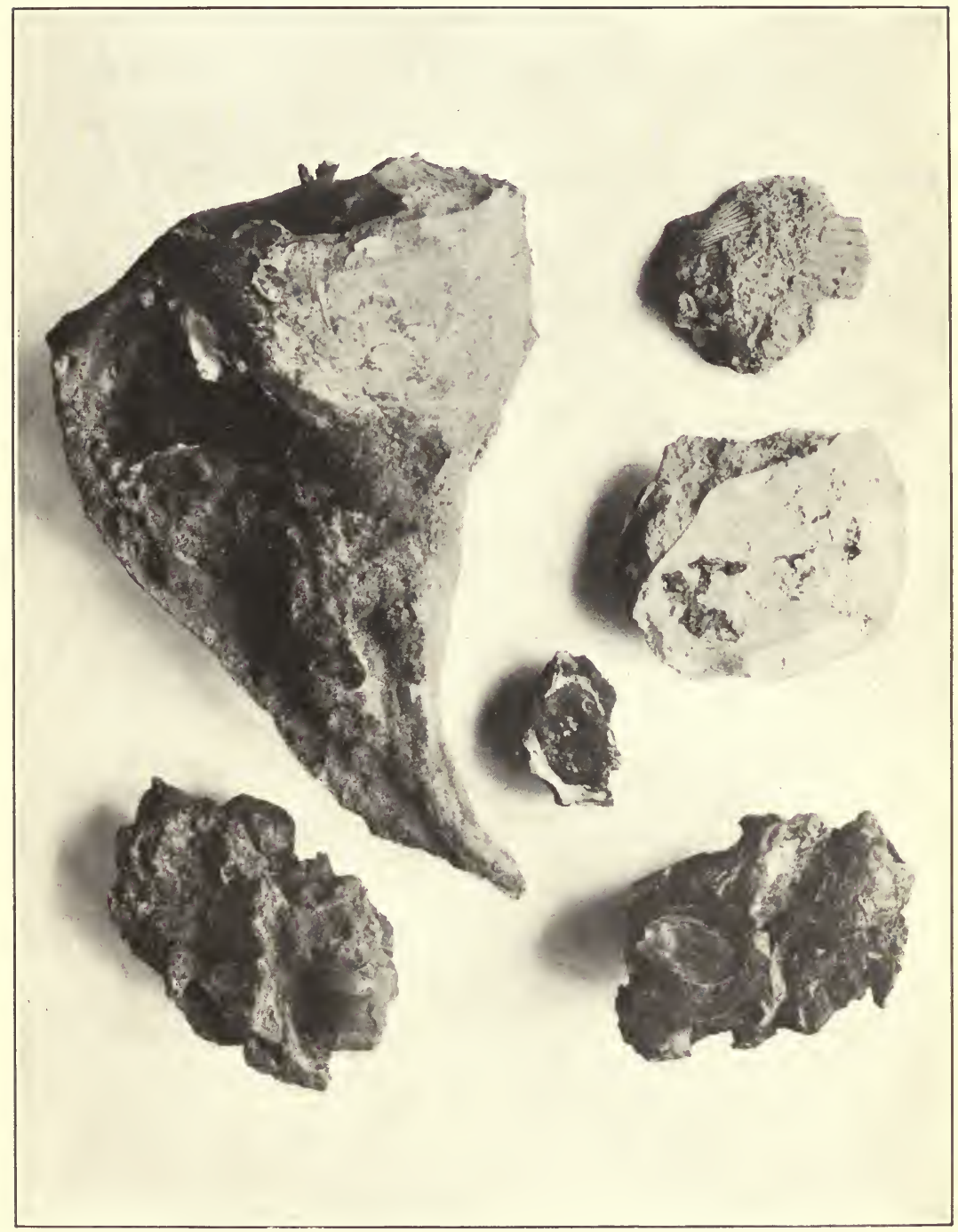

OSSEOUS REMAINS IN PROCESS OF SILICIFICATION, FOUND AT SOUTH OSPREY, FLORIDA 

A study of the lower end of the shell mound on its side next to the bay gave the following section :

4. Black soil Several inches.

3. Shells, numerous species, all of which are recent. about 4 feet.

2. 'The base of the mound contains shells, many of which are cemented together and filled with ferruginous sandstone; others are filled with greenish sand. All stages from the green sand to the ferruginous sandstone are renresented. 'The layer is not uniformly developed, cccurring only in places-

1. Green sand to the water level in the bay

(6inches.

Thickness undetermined.

A collection of shells was made from numbers 2 and 3 of the rection and were determined by Dr. Wm. II. Dall.

All the species found in no. 2 were also found in no. 3, and all of them are recent.

The geologic age of .2 and 3 is post-Pleistocene. Both from the contained fossils and stratigraphic relations they are younger than the I'leistorene of North reek. The material in which the fossil human remains were found in the old burial mound seems to correspond to the ferruginous layer at the base of the shell mound, and can scarcely be older-that is, the human remains are post-Pleistocene in age.

The fossilized condition of the human skeleton was considered ci particular importance. A study of the processes at present going on at the base of the shell mound clearly shows that no importance can be attached to the ferrusinous replacement of the bones. All stages in the transformation of the unconsolidated greenish sand filling the shells to a filling with sand cemented by limonite and the cementation of the whole by limonitic naterial can be seen. Numerous seepages or springs occur along the upper surface of the green sand bed. It is evident that this water contains considerable quantities of oxygen, and that it is transforming the green colored ferrous silicate into red or brown ferric oxide and silica. Ideal conditions are here realized for this transformation of one form of iron into another.

The conclusions regarding the skeleton found at Osprey are: lirst, no importance can be attached to its state of fossilization; second, the stratigraphic relations of the skeleton are such as to indicate a post-Pleistocene, or, expressed in other words, a geologically recent age.

The human bones found along the shore between 1 and 2 miles south of Osprey were calcareous but inpregnated with minerals. The ferruginous material which has been described as from the lower end of the shell mound at Osprey is found southward, occurring discontinuously for several miles. The upper part of the bank along the beacls is a sandy, often hummocky, soil. The iron near the water's edge cements together pebbles, shells, or whatever happens to be there. The material whence the human bones were obtained is a lighter colored, more sandy incrustation orer the ferruginous layer. There i: nothing in the geological conditions under which they were found to indicate other than a geologically recent age.

Between twenty-four and twenty-five years ago a skull was found in ferruginous material a short distance above the pier, at IIanson's landing. The skull was, at least partially, replaced by ferruginous matter. The locality was studied geologically. The ferruginous material there is similar to that at Osprey. It underlies surface soil and sand, consists of sand bound together

3453 -No. $33-07-5$ 
by the brown oxide of iron, and occurs noncontinuously just above the water's edge. There is no evidlence to suggest its not being a recent formation. All the conditions under which this skull was found seem to be identical with those under which the one at Osprey occurred. Therefore I am of the opinion that the IIanson skull occurs in a geologically recent formation.

\section{Conclusions as to the Age of the Human Remains}

1. No importance can be attached to the fossilized condition of the human remains found at any one of the three localities studied.

2. At Osprey, where paleontologic and stratigraphic evidence is available, the evidence is in favor of the human remains being geologically recent.

3. l'ositive paleontologic and stratigraphic evidence is absent at the locality between 1 and 2 miles south of Osprey and at IIanson's landing. In each locality, however, there is no evidence to favor the remains being geologically as old even as I'leistocene.

4. All of the positive evidence and the conditions under which these fossilized human bones were found in Florida favor the opinion that man geologically is a recent immigrant into that area.

\section{XVI.-MOUNI) CRANIA (FLORIDA)}

On further exploration of the Osprey region it was found that it had been well peopled by the Indian tribes up to comparatively recent times. A large artificial shell mound (see figure 8) occurs near the shore just north of Mr. Webb's property, not very far from the North Osprey find of fossil human bones. On the mainland near the South Osprey find was a small earth-and-sand mound containing ashes. On Caseys key, which lies opposite the Osprey promontory and about three-quarters of a mile distant, is another large artificial platformlike shell heap, and a little south of this were discovered on digging many pieces of human bones and even entire bones, apparently quite recent, representing probably a secondary multiple Indian burial. Finally, 6 or 7 miles south of Osprey, near Laurel, occurs a large sand mound which contained many Indian burials; similar mounds north of Osprey were learned of, especially about Sarasota and on a key opposite Sarasota. A skull which the writer recovered from the Laurel mound is in form much like the Osprey skull; and the bones from the Casey Key burial are in general much similar to the fossils of North Osprey.

\section{XVII.-THE NEBRASKA "LOESS MAN"}

After having concluded the above review of the older discoveries of human remains in North America to which considerable antiquity has been attributed, the writer was fortunately afforded the opportunity of making detailed studies of the most recent example of finds of that class-the so-called Nebraska "loess man." The following pages embody the resuits of these investigations. 


\section{History OF Finds}

In June, 1894, during a search for the buried remains of the famous Indian chief Black Hawk, Messrs. F. T. Parker, William Morris, and Charles S. Huntington, all of Omaha, Nebraska, dug into a low eminence on the crest of a wooded ridge known as Long's hill, situated near and running parallel with the Missouri, about 3 miles north of Florence and 10 miles north of Omaha. According to Mr. Huntington, the only survivor of the three, they made a moderate-sized excavation in the elevation. When the work had progressed to a depth at which Mr. Huntington's head was, as he expresses it, "about on a level with the surface of the ground" (his height is 5 feet 7 inches), he uncovered on one side, in the wall of "yellow dirt," a about 20 inches ${ }^{b}$ above the floor of the pit or trench, a skull which fell out with the earth surrounding it, and on coming in contact with the ground separated into a number of pieces. ${ }^{c} \mathrm{Mr}$. Huntington says that he was impressed at once with the unusual forehead of the specimen, a feature which induced him to carry the fragments home with him. No other skulls or large bones were uncovered, and as the mound yielded no archeological objects, the work of excavation was soon abandoned. The fragments of the skull were placed in the garret, and there lay unnoticed until the latter part of 1906, when, reading of the Gilder discoveries, Mr. Huntington recalled his own find; thereupon he gathered the pieces and sent them, through Mr. Gilder, to the University of Nebraska. This specimen, which is truly remarkable, has been skillfully reconstructed in the geological laboratory of the university, and is now known as skull no. 8 of the Gilder Mound series.

A second episode in the exploration of the mound is best told in the words of one of the explorers. The following account, prepared for the writer by Mr. R. F. Gilder, a journalist and amateur archeologist, residing in Omaha, was received February 15, 1907 :

During the early summer of 1906 , in looking for flint implements, I came accidentally across the mound in the summit of Long's hill, dug into twelve year's before by Messrs. I'arker, Morris, and IIuntington. The excaration was about $t$ feet square and 2 feet deep, and was filled with leaves from the adjacent trees and refuse mold from the ground about the opening.

Warly in September I revisited Long's hill and found that in the interval some one had been digging in the old excavation. A few pieces of human bones lay on the comparatively fresh earth, and I found later that Mr. Bankey, a neighboring farmer, had picked up on the mound portions of the upper and lower jaws from the right side of a skull.

a Mr. Huntington makes no distinctions in the deposits beneath the 10 or 12 inches of dark surface earth, referring to them in general as "yellow dirt."

${ }^{b}$ Mr. Huntington indicated about this height from the floor, on the side of his safe.

c According to a later recollection of Mr. Huntington, the skull was taken from the earth in one piece; it was filled with clay and later separated into fragments. 
'Three days thereafter I started my first ditch through the old excavation, beginning on the east side of the hole and rumning eastward. The bottom of the hole was filled with loose earth, which had been recently mored. I did not find anything that day and only made fair progress through the mound, as I worked from top to bottom, a depth of about 5 feet.

The Sunday following, accompanied by Omer Butler, an artist on the WorldHerald, I continued my work at the hill. . . . The very first shovelful of earth brought out a large femur and then immediately a mass of bones were brought to light, many of which were broken.

I then cleared off the surface and worked down from above. The upper part of the mound consisted of earth which I knew had been moved. . . . At $2 \frac{1}{2}$ feet . . small pieces of charcoal, bits of mussel shell as large as iny finger-nail, and quartzite spalls were found in the earth. I judged the burial to be similar to other (fire) burials in that and other sections which I had previously encountered. Beneath the blackened mass I found fragments of calcined clay, bits of which I have retained, while beneath this again, at a depth of $4 \frac{1}{2}$ feet from the surface, the ground was so hard and compact that it was removed with the greatest difficulty in my rather cramped quarters in the trench. Four inches beneath this compact earth-which at the time I believed to have been hardened by fire-and nearly 5 feet from the surface, I brought out skull no. 5. There was no other bone near it. I was obliged to return to the city, but before the skull was removed Mr. Butler made a sketch of it as it lay in the ground and of the trench and its surroundings. I held my tape measure from the surface to the skull so that it would be accurate, and the tape was sketched in the picture.

I have unearthed many skulls in this vicinity of what I- term ancient and modern Indian types, and I at once noted the rast difference between them and the one I held in my hand.

After securing the first skull I worked in the hill at every arailable moment, but I was accompanied by personal friends whom I requested to memorize everything pertaining to the bones, skulls, and enviromment.

With my stepson, George C. Clark, I began on the south side of a 20 -foot circle from what I took to be the mound's center and drifted in toward the point whence I had taken the skull, expecting to strike the skeletal parts. Our trench was wider than my first. We were compelled to build smudge fires to keep the mosquitoes away, but we worked several hours and found the larger bones of a skeleton at a level 12 inches (tape measure) above the level of no. 5 skull. No other skull was found; the femurs and shin bones were in good condition. Skulls nos. 3 and 4 were also taken at this point, but several inches lower than the femur bones. The earth was as hard as plaster, and digging was exceedingly difficult. Whatever bones were found near the skulls were combined with them as if belonging to the crania.

The following day Mr. Clinton A. Case accompanied me. We widened the ditch I had first dug and carried it 8 feet to the west. We then cut off the intersecting corner of the first ditch and that which I had run with my stepson. At 3 feet deep we secured skulls nos. 1 and 2 . . and some of the upper parts of the skeleton bones. They lay with their heads toward the center, skeletons radiating from the center. We also took a skeleton without skull lying at same level.

The following day I worked alone. I sunk a ditch from the surface, 5 feet long and 3 feet wide, 2 feet south of the ditch running east and west, and secured the lower leg and foot hone of the skeletons recovered with Mr. Case. In the south corner of this ditch I sunk a shaft $4 \frac{1}{2}$ f'eet and brought out the mandible of a skull. No other bones were within 15 inches of it. I tunneled 
under the north and south ditch dug with my stepson and found a jumble of what I believe are the skeletal parts of a gonth.

The next operations were made with Mr. Bankey. We took from a 3 -foot level on the northeast corner of the intersection of both ditches, or at the north end of the north and south ditch, a badly mashed skull in some score or more of pieces. I believe this is no. $\mathrm{x}$ in the collection. The skull is very thin, and when taken out it was hard to tell which way it lay. There were also two femur bones reposing vertically, which led to the belief that the body had been buried squatting.

I had determined when at work with my stepson and again verified in my own mind when working with Mr. Case that an intrusive burial had taken place.

I first showed the crania of nos. 3,4 , and 5 to people in the oflice of the WorldHerald, then to Dr. E. C. Henry, demonstrator of anatomy at Creighton Medical College in Omalha, and Ioctor Henry wrote a description of them, which we published. I took the three skulls to Jincoln and showed them to 1)octor Ward and I'rofessor Barbour. . . . When the featured article in the WorldHerald of October 21 reached my brother's and sisters in New York, they notified Prof. Henry Fairchild Osborn, who came at once to Omaha, examined the material and gave me a statement for publication. Skulls nos. 1 and 2 had been added since Doctor Ward and Professor Babour had seen the collection, and Professor Osborn immediately noted a valiation and cailed on me for an explanation, which was given him as I give it to you.

A week after my story was figured in the World-Herald of October 21, Joseph's father called me by telephone and told me that his son had a skull similar to the ones figured. I visited his house and saw the similarity to my own crania. His mother told me to take it, that her son was at the university, and that she knew he would be glad to have it go with the others.

The lad came to see me a month afterwards. He said he had been looking for Indian turnips in the neighborhood of Long's hill and had come onto the old excaration made by the three men twelve years ago. He said he had, with the aid of his knife and sticks, penetrated into the old loose earth and run onto skull no. 6 when he had gotten down to a level of his shoulders. IIe is nearly f feet tall. It took him a half day to get it out with a large pocketknife. and he also found a portion of another. He thought it was an Indian skull and took it home. With the skull was a piece of a jaw (lower), and this fitted exactly with the one found by Mr. Bankey.

I have said little about this skull. Joseph thinks he can get a fortune for it.

With or near the bones discovered by Mr. Gilder were several stone implements, among them two flint blades of ordinary form. There was no trace of pottery. The better-preserved bones were collected and kept about Mr. Gilder's house until the question of possible geological antiquity of the deeper burials arose, when they were transferred to the University of Nebraska, at Lincoln.

On November 16 Prof. E. H. Barbour, geologist and paleontologist of the University of Nebraska, by arrangement with Mr. Gilder, took charge of the further excavations. As the work progressed he became convinced that the bones of the lower levels-that is, those more than $4 \frac{1}{2}$ feet, approximately, from the surface, were contemporaneous with the original (lacustrine) loess deposits; and thenceforth the excava- 
tions, in what came to be known as the " (xilder mound, were prosecuted with particular care. Shafts were sunk in several localities, and one of these was carried down 12 feet. The results of this work, which continued with the assistance of Doctor Condra and several others as long as the weather permitted, were not very striking; the finds, however, consisted of about 200 fragments of bones, which were attributed to the ancient and undisturbed loess deposits. They were found very much seattered, there being only about "five or six bits to the cubie yard." These showed no regularity of distribution, and grew scarcer with increasing depth. The piece of what is probably human bone found at the greatent depth was $11 \frac{1}{2}$ feet below the surface. Some of the fragments lay apparently outside of the mound proper. There were no animal bones, implements, or pottery.

The first notice of the discovery in a scientific journal was published by Professors Ward and Barbour in Science of November 16, 1906 , and since then there have appeared a number of other papers

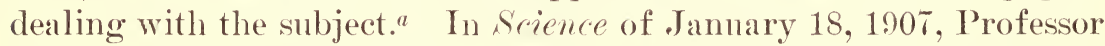
Barbour expressed definitely his belief in the antiquity of the deeperlying bones and proposed to designate the "primitive type" which he was convinced they represented, as the "Nebraska loess man."

Extracts from several of the paper's referred to, embodying the conclusions of the writers regarding the "loess man," are given in the following pages. As the matter thus presented is necessarily incomplete, however, and may possibly do injustice to the authors, the student of the subject is advised to consult the original publications.

Barbour and Wapd, Science, November 16, 1906. "The skulls of the Nebraska man seem to be inferior to those of the mound builder, but for the present at least will be viewed as early representatives of that tribe. In corroboration

a Biblicgraphy: Gilder, R. F. . First notice, World-Herald, Omaha, October 21, 1906.

BaRborr. F. II., and II. B. WARD. Preliminary Report on the Primitive Man of Nebraska (October 26, 1906), Nebraska Geological survey, II, pt. 5, 219-327, 4 figs.

BARBOyr, E. II., and II. B. WARD. I iscovery of an Early Type of Man in Nebraska (October 24), scienee, November 16, 1906.

Gilder, R. F. A I'rimitive lluman Type in America; the Finding of the "Nebraska Man," Putnam's Magazine, 407-409, 2 figs., January, 1907.

Ward, 11. B. I'eculiarities of the "Nebraska Man," Putnam's Magazine, 410-413, 3 figs., January, 1907.

Barbour, E. H. Prehistoric Man in Nebraska, I'utnam's Iragazine, 413-415, 502-503,

3 figs., January, 1907.

Osborn, II. F. I)iscovery of a Supposed I'rimitive Race in Nebraska, Century, 371-375, 7 figs., .January, 1907.

Barbovr, E. II. Evidence of Man in the Loess of Nebraska, Scienee, 110-112, January $18,1907$.

Gilder, R. F. The Nebraska Loess Man, Reeords of the Past, vi, pt. 2, 36-39, 5 figs., February, 1907.

Barbour, E. II. Ancient Inhabitants of Nebraska, Records of the Past, vi, pt. 2, 40-46, 5 figs., February, 1907.

Barborr, E. 11. Evidence of Loess Man in Nebraska, Nebraska Geological Survey. II, $329-345$, with figures, 1907 .

Blackman, E. E. Prehistoric Man in Nebraska, Records of the Past, vi, pt. 3, 76-79, March, 1907. 
are the flint implements or chips found assoriated with the skulls and bones, and the mode of burial."

Osborn, Century Magazine, January, 190\%. I'age 373. "The parts of the older four crania found beneath the rlay layer are of the same type, it being probable that difference in age may arcount for the slight difforences in the development of the supraorbital ridges. In each the facial profile is almost the same. . . This profile is seen to be of a murol more momitive character, surrounding a bone with a more depressed frontal area than that of the skulls found above the clay. Cnfortumately the back part of each of these four crania is wanting, and until this can be secured through subseguent discoveries it is impossible to give an exact estimate of the ('lanial calpacity or hrain weight of this primitive man. Fstimating the back of the skull as of the same height as that of the normal Intian skull,. . . We still have a very low cramial ("aparcity and a type of skull resembling that of the Australian negro, which is vilutully the lowest existing type known at present. While the sumaorbital ridges are not more pronounced than that of the Australian negro, $a$ the forehear is even more receding and flattened. In other words, the portions of the cranim preserved indicate, so far as they go, a man of small cerebral (*apacity, having a brain inferior to that either of the Indian or the typical mound builder."

Page 375. "To return to the recent discovery in Nebraska, the comparisons which we are able to make now prove that this cranim is of a more recent type by far than that of the Neanderthal man. It may prove to be of more recent type, eren, than that typified by the early Neolithic man of Europe. Even if not of great antiguity it is celtainly of rely prinitive type and tends to inerease rather than diminish the probability of the early alvent of man in America."

Gruder, Putuam's Magazine, January, 1907. In commencing the excavations in the mound I came, "at 4 feet beneath the surromaling level, upon what appeared to be a compart clay berl, differing from the loess covering in which I lad been working. There were visible evidences of ancient fire. What I took to be a clay bed burned into a semblance of brick proved to be the original top) of the loess hill. Fire had been built upon it, and on the ashes an upper layer of bones was laid. It was so hard as to resist the spade. I managed, however, to make a considerable hole through the surface, and few inches down I found the upper portion of a human cranium.

"In drifting in another ditch, from the south side, I encountered the same stratum of baked earth. Fifteen feet from the beginning of the ditch I crosssectioned the mound from west to east and then cleared a circle 8 feet in diameter. . . This gave me a much better opportunity to work from above the bones. Evidence of fire above the bones was very marked. The earth beneath the ash bed was very dry and extremely hard, and I was puzzled not a little as to how the burial had been made. Nor was I able to tell precisely how the skeletons had been laid, but aplearances indicated that the lieads lis toward the center and that the feet radiated therefrom. Two seemed to ha ve been placed in a squatting position-the femurs and spinal vertebra being in a rertical position close together.

"The manner of burial differed radirally from that observed in other mounds I had opened in this vicinity and elsewhere. It seemed that a lower stratum of skeletons had been placed in the mound. and that carth had then been piled on top and burned to the eomsistency of a plaster wall. In another part of the

a "It will be understood that some of the existing types of savages and aborigines have, through survival or degeneration, a smaller cranial capacity than the ancestors of the European types. For example, the Botocudo Indians of Brazil are described as having a very low type of cranium." 
mound, some if feet distant, lay the mper layer of skeletons; but with three exceptions these skeletons had heen disarticulated and more or less scattered about. Over the bones had been laid a covering of loess, scraped up and carried to the mound for the purpose. Through this covering were scattered small pieces of shells of a kind very different from the bivalves of the streams in this vicinity at the present day."

Gilder. Records of the Past, February, 1907. Skull no. 5 "lily in what I took to be a baked clay matrix. Before I reached the skull I had worked through earth similar to other coverings of remains in the neighborhood and through several inches of what appeared to he earth and ashes, heneath which was the stratum which looked as. if it had been hurned. I had not at that time learned that an intrusive lomial had taken place, and naturally coicheded that the earth had been baked over the skull in order to prevent the leaching of the bones by rains."

Ward in Barbotr and WARD, Nebrasha Geological surey, II, part 5, 1906. Page 321. "The limb bones are massive and large, indieating a stature of 6 feet, and uncommonly rough, indicating a people who were very muscular, partieularly in the lower extremities. The strikingly large protuberances support this view. The crania are low browed, with heary, protruding superciliary ridges, and receding foreheads, which lack frontal eminences. In life these people had flat heads, protruding muzzles, large chins, and heary brows, shading eyes deep set and (dose together. The low-browed crania are not the result of head-binding, nor are they those of idiots, nor are they malformed. Insteal they are normal and represent the cranial development of the time. Though showing many points of similarity as well as differences, on the whole they seem inferior to the mound builder, and we may for the present at least consider the Nebraska man as a very early or degenerate mound builder. In corroboration are the crude flint implements or chips, whichever they are, assoeiated with the bones, and the mode of burial in mounds."

Page 325. "The writers have frequently seen examples equally ancient, but these are the first anthentically located."

Page :327. "The bones of the lower layer seem synchronous with the loess formation and antedate the hill itself, while those of the upper layer are younger than the loess and subsequent to the hill."

WARD, I'utmam's IIagazime, January, 1907. "The skeletons collected by Mr. Iobert F. Gilder all present such striking characteristics that even at first glance one is compelled to reeognize their peculiar type. The individual bones are well preserved, but heary, brittle, and without the spongy character of sueh as have been exposed to the leaching of water in the soil.

"All the long bones of the skeleton are massive, of more than average length, and distinguished by the very unusual prominence of the rough areas for musele attachment and also of the protuberances which subserve the same function. In these particulars the leg bones are the most striking. Their development indieates clearly the platyenemic condition usually regarded as characteristic of primitive people. The femur has a strong curve forward, which is not lacking in modern skeletons but has been noted by many as peeuliarly eharacteristie of ancient femora.

"Judging from the loeation of the glenoid eavity and the length of the lower jaw, the latter probably did not project very conspieuously. This lower jaw is one of the most remarkable narts of the skeleton. It is relatively short, very massive, and double the thickness of a modern mandible."

The skulls show that "the bone is on the whole massive beyond the usual limits in modern skulls."

"The sutures are usually distinct, sometimes simple, sometimes complicated, 
marked by numerous Wormian ossides, and in one (alse with a latger triangulal interparietal between the occipital and parietal bones.

"In the calvaria, the two mo:t conspicuous elements are the enormonsly developed superciliary ridges and the low arch of the crown.

" The parietal diameter or maximum breadth of the skull reached 140 to 1.50 mm. The cephalic index could not be calculated with full accuracy on account of the imperfections of the specimens, but in one case was estimated as 79 and in a second was somewhat less. In two of the skulls from the higher level of the mound, the cephalic index was 71 and 78 , while their maximum breadth wats 1:3:3 and $1+1 \mathrm{~mm}$., which serves to indicate the prominent differences in form letween the two groups of calvaria. In the skulls of the upper layer, moreover, the bone is very much thinner and has an entirely different appearance and texture.

"All in all the skeletons of the lower layer show many points in common with primitive types of the human race. In some particulars these primitive characters agree with those of the mound-builders, and yet points of difference are also observable. Compared with the tribes of Indians which inhabited this region immediately before the coming of the Caucasian, these remains show radical differences."

Barbour, Science, January 18, 1907. "Long"s hill . . . is a hill of erosion, and no discoverable land slip has complicated its simple geologr. On its summit is Gilder's mound, in the superficial layer of which were found moundbuilder remains and in the deeper laver eight skulls and many bones of a still more primitive type."

The upper layer, in which the two "mound-builders" "skulls were discovered, "has a thickness of $2 \frac{1}{2}$ feet. Below it was an undisturbed layer of unmistakable loess and in it numberless fragments of human bones and an occasional animal bone, loess shells, and stray angular pebbles.

"In brief, the conclusion is that in the case of the upper bone layer there was a burial: in the lower, deposition. Those in the loess doubtless antedate the hill itself, while those in the upper laver are subsequent to it. That archaic burial could have taken place in loess without detection is altogether improbable. Of necessity there would result a mixture of black with light soil and a breaking up of the lithologic structure. Where these bones occur, the loess structure and color is perfectly preserved, and it contains characteristic vertical lime-tubes, concretions, and shells, precisely as is customary. Out of the evidence at hand the writer concludes that bones of this layer were strictly srnchronous with the loess formation in which they were found, in substantiation of which comes the fragmental nature of all of the bones, their waterworn condition, their range of distribution, and disassociation of parts.

"One would scarcely think of such conditions being possible in the case of liuman burial ; besides, it is improbable that a primitive people would dig graves to a depth of 12 feet."

As to the age of the supposed loess man, Professor Barbour says: "The chief point is the evidence that human remains have been found in the loess, and whether this is the very oldest or newest loess seems a secondary consideration. The loess here is not leached of lime salts, but is actively effervescent at all lẻvels, arguing for recency of deposition. All recognize the chronological diversity in the loess formation, and whether Long's hill is in the main loess body, as we believe it to be, or in a much more recent one does not materially affect the relation of the bones to some stage of glaciation, the precise glacial or interglacial age being as yet undetermined.

"The loess in question rests on Kansan drift, and though as young as the later Wisconsin sheet or younger, it is nevertheless old." 
Barbour, Nebraslia deological survey, n, part 6, 1907. For the most part the same words as in science, January 18.

Adritionis. Page 3:36. "IRespecting the antiquity of the remains, the chief evidence paleontologially must be derived from the skulls. which seem to be of the Neanderthal true. Evidences from other skeletal parts are subject to error. owing to the wide range of variation in humam bones. The association of loess fossils is significant, and when even a remnant of any extinct species is found it will be final. No sign of stratification, which wonld be raluable evidence, an be reprorted."

Page 3tt. "The skulls are of the Neanderthal type, with thick protruding hrows, low forehead devoid of frontal eminences, large parietal eminences, narrow temples, thick skull walls. and small brain capacity." "They are highe" in the human scale than Neanderthal man, but lower than the mound builder. They resemble the man of Syy."

Page $3+7$. "Skull 8 scarcely varies in size and shape from Pithecanthropus ereetus."

As to the age of the man in the Nebraska loess, Professor Barbour repeats, with but slight modifications, his conclusions on the subject published in science of January 18. The discovery is believed to carry "man in America hack to Glacial times." But he adds that "In several places adjacent to Gilder's monnd exposures of human bones in supposed loess are already known, and investigation promises to extend the present known limits of the supposed human bone bed."

Blackman, Records of the Past, March, 1907. No personal observations on Gilder mound or specimens from the same. Quotes Professor Barbour as follows: "From a geologist's standpoint there is scarcely a possibility that these bone fragments were ever buried by human hands. Instead, the bones were doubtless deposited with the loess, the age of which may be safely reckoned at ten thousand to twenty thousand years or more."

Further on (page $7 \tau$ ) Professor Blackman records the following interesting observation: "I suggested to Doctor Parbour the possibility that gophers may have worked the bones from the higher to the lower level. I have found buffalo bones 10 feet deep in gopher holes. It was very difficult to observe the moved loess which filled the hole, as all the hill was the same kind of deposit. But the Doctor assured me that this could not possibly be the case."

Professor Blackman finishes by giving brief notes on several other finds which may have bearing on the question of man's antiquity in Nebraska and the neighboring states.

Toward the end of January, 1907, the writer was directed by the Chief of the Bureau of American Ethnology to visit the University of Nebraska and examine the Gilder Mound bones. The specimens were placed at the writer's disposal in the most liberal manner by Professors Barbour and Ward, and every needed assistance was accorded. When the examination was completed these gentlemen, as well as Mr. Gilder, accompanied him to the mound, which, fortunately, was almost wholly free of snow and could be fairly well observed. In the following pages is given a brief account of the mound and its examination.

\section{Description of the Mound}

North of the small town of Florence, and to the west of the Missomri, the comitry presents some rather bold elevations, composed of 
accumulations of fine loess. modified in contour by the action of wind and rain. The southern portion of one of the most prominent of these elevations, known as Long's hill, consists (in the part nearer to Florence) of a ridge about 600 yards long, running parallel with the Missomi. 'This ridge is covered with timber of recent growth, the original forest having been cut by contractors for the Union Pacific railroad. Geologically the ridge is composed of carboniferous strata forming the base, on which rest from 10 to 15 feet of glacial drift containing Sioux quartzite and granitic bowlders; above this is about ton feet of finc light-lutf loess (Barbour). I wagon road, which has been wasthed out until it forms quite a deep ravine, runs along the whole length of the ridge, rising gradually to its crest. Near the southern end of this crest is seen a small elevation, which might easily pass for a natural feature of the hill; its center originally could not have been more than 2 or 3 feet above the line of the crest, and, while its circular form is appreciable, its onter boundaries are so indistinct that measurements of its diameter can not be more than approximations. This is the Gilder mound. A few yards to the north is visible another low dune-like swell, possibly also an artificial mound; some years ago another low elevation, about 250 yards north of this, was dug into and viclded human bones, and about the same distance still farther in the same direction, three imperfect human skulls were foumd by Mr. Cxilder in the west bank of the road, within less than 2 feet of the surface.

The structure of the Gilder mound, which was examined so far as the partially frozen condition of the ground permitted, is as follows: The whole knoll is covered to a depth of 10 inches with dark surface soil, which contains roots and other vegetable matter. Beneath this is the loess, apparently entirely free from coarse material. The color of this deposit is deeper in its upper portion, fading out gradually to the characteristic yellowish hue of the dry loess beneath. The darker color above is due in part to moisture, in part to a thin admixture of ashes and occasional minute bits of charcoal. The signs of fire are most noticeable toward the center of the mound, where they extend to a depth of nearly 3 feet. In effort was made to ascertain whether there is a bed of baked earth beneath the superficial layer, as reported by Mr. Gilder, but without success, on account of the frozen condition of the ground. It was plain, however, that at no point had the baking progressed so far as to render the earth impervious to water. No definite line of separation between the superior and the inferior levels in the mound was observed, and there is no perceptible difference in the density or structure of the loess at different levels; in fact, the exposed surfaces, being everywhere smoothed by the shovel or trowel, showed no trace of structure whatever. Two large rodent burrows, one running very deep, were 
exposed during the little ligering that was done. There were foum also sereral chanmols. left by the decaly of roots, which passed deep down into the loess. One small phalanx and two slivers of bone were discovered in situ in the exposure previously made by Barbour, one of the slivers occurring at a depth of 5, the phalanx at nearly 6 , and the other sliver at a depth of $7 \frac{1}{4}$ feet from the surface. What were pointed to as excavations outside of the mound were difficuli to distinguish as such, there being no lines of demarkation to indicate the limits of the mound.

\section{Examination of THE Bones}

\section{SKULI, NO. 1}

A past-middle age. masculine, moderate sized, slightly asymmetric, but not pathological cranium, found by R. F. Gilder, about 3 feet deep in the Gilder mound. Large portions of the right side and of the base are wanting; part of the left side has been repaired, but warping prevented a good restoration.

Color pale yellowish, agreeing with that of other specimens from the mound; there are a few spots of slight black discoloration, such as are met with on many of the other specimens from this locality. There is no trace of fossilization, in fart the bones appear quite recent.

The skull is nearly dolichocephalic. The angles of all the planes are rounded. The antero-posterior surface-are is elliptical and shows no distinct summit. The supraorbital ridges are of approximately medium masculine proportions, and extend orer but little more than the median half of each supraorbital space. The forehead is not high, but presents a fairly well-marked vaulting; the left side is slightly more anterior than the right. There is but little sagittal elevation. The temporal regions present no special features; the temporal ridges are not prominent, and their nearest approach to the median line is $5.5 \mathrm{~cm}$. on the right and $6.1 \mathrm{~cm}$. on the left side. The occiput, moderately convex, shows a pronouncer, but not excessive, superior crest, and marked depressions for the attachment of the smaller recti muscles; the right side is slightly more prominent than the left. The right mastoid (left mastoid wanting) is of moderate masculine size. The glenoid fossie, which are well preserved, are of ordinary form and good depth. The serration of the sutures approaches, especially in the lambdoid, about the medium form, as observed in whites. In the right half of the lambdoid are two small and two larger sutural bones. Obliteration has adranced externally in the coronal below the temporal ridges, and in the posterior half of the sagittal, with traces in the lambdoid; rentrally the three sutures are wholly occluded, with the exception of small end portions of the lambdoid. The thickness of the left parietal ranges from 4 to $6 \mathrm{~mm}$.

A portion of the face, separated, shows an apparently mesorhynic nose, moderate alveolar prognathism, somewhat prominent malars, and well-marked submalar fossie. The lower jaw (somewhat damaged) is of moderate masculine size and massireness, with chin slightly squarish and well protruding; diameter bigonial 10.5, vertical height at symphisis $3.3 \mathrm{~cm}$; the angles show rather strong effects of muscular attachment. The teeth in both jaws are of medium size and, so far as can be seen, of ordinary form; they are all much worn off. The enamel is everywhere of good luster and uncracked. On the 
right side in the lower jaw may be noted the absence of one incisor, due apparently to nondevelopment: on the left there are two incisors, both small. The third molars, now absent, must have been small: their cavities show a single root of rather submedium proportions.

Measurements of $x l: ? l l$ II:, I

cm.

18. 9

Diameter antero-posterior maximum 14. 4

Breadth maximum, approximately.

Cephalic index, about

76

Basion-bregma height, approximately.

1:. 9

Diameter bizygomatic maximum, approximately 14. 3

Circumference maximum, above supraorbital ridges 52.2

Arc nasion-bregma, 13.2; bregma-lambda, 12.0; lambda-opisthion, 12.5;

total antero-posterior arc 37.7

SKULL NO. ¿

A very defective adult specimen, found in Gilder mound, by Mr. Gilder, at a depth of about 3 feet; sex uncertain, though probably female; color dirty yellowish, ventrally and to a slight extent dorsally with spots of blackish discoloration; no fossilization, no aspect of great antiquity ; cranium of good size, normal; shape oblong, contours rounded, outline of posterior plane approaching pentagonal; supraorbital ridges above medium feminine, or submedium masculine, limited to median half of each supraorbital space. Forehead low but vault-bend distinct (above the bend the bone slopes backward); diameter maximum (along coronal suture), approximately 11.1; cll., nasion-bregma are $12.7 \mathrm{~cm}$. No sagittal ridge. Thickness of left parietal :3 to $5 \mathrm{~mm}$. Sutures (coronal, sagittal) patent, serration fair. No brain impressions rentrally.

SKILI, NO. :

A good-sized adult female cranium (defective) showing a slight asymmetry, otherwise normal. Discovered by Mr. Gilder in the mound now named after him; exact depth of find uncertain, but probably not more than 4 feet. Color pale dirty yellowish; no fossilization-has the appearance of a fairly recent specimen. Was apparently dolichocephalic; greatest length 18.9 or $19 \mathrm{~cm}$.

The contours of the skull are but little angular. The supraorbital ridges are of about medium feminine size. The forehead is of moderate height and fairly good vaulting; the right side is somewhat more prominent than the left. Diameter frontal minimum 8.6, frontal maximum $11.1 \mathrm{~cm}$., nasion-bregma are 12.1. There is scarcely any sagittal elevation. The temporal ridges are but slightly marked and are distant from the median line. The glenoid fossip are deep. A slight dehiscence, such as occurs quite frequently in the Indian, is seen in the floor of the left auditory meatus. All the remaining sutures are patent, serration submedium. Thickness of left parietal 4 to $5 \mathrm{~mm}$.

SKULL NO. 4

Only the frontal and parts of the parietals remain. Found "deep" (though less than (; feet from the surface) in the mound by Mr. Gilder. It is apparently a good-sized adult normal male skull. Color dirty yellowish, with some 
dark d-scolorations, as on other specimens from this locality ; there is no percept ble fossilization, the bones appearing quite recent. The skull is rather broad hough not brachycephalic. The supratorbital ridges are of submedium masculine size. The forehead is low and rather sloping, but the vault-bend is quite marked; diameter frontal minimum 9.7, frontal maximum 12.1 cm., nasion-bregma are near $13 \mathrm{~cm}$. Temporal ridges not pronounced; nearest apprcach to median line on the right 5 , on the left $4.8 \mathrm{~cm}$. There is a slight sagittal eleration. The remaining sutures are all patent; serration of coronal submedium, of sagittal about medium; a moderate-sized accessory bone exists on each side in the coronal, in the locality of the fotal antero-median fontanel. Ventrally the frontal hone ererywhere shows good impressions of brain-convolutions. Thickness of left parietal (as far as preserved), 4 to $6 \mathrm{~mm}$.

This specimen bears on its surface marks of antting-an interesting feature which occurs on many other bones from this mound. 'The incisions extend along the whole border of what remains of the right parietal and over 4 of that of the left parietal, running nearly parallel with the coronal suture. Numerous vertical cuts or markings on the left resemble rery closely imitations of the articular surface of the frontal bone. Another evidence of cutting is seen on the anterior part of the specimen, where a portion of the right supraorbital ridge was thus removed. The incisions were all made with some sharp instrument, and the clear-cut edges and ridges produced are not perceptibly worn off.

\section{SKUTL NO. 5)}

Frontal part only. The forehead, which is quite low, shows two well-defined depressions which mark it as ahnormal, and on this account the specimen can not well be utilized for comparisons.

\section{SKULL, NO, 6}

This specimen (plates $\mathrm{x}, b, \mathrm{xI}, b$; figures $12,13,15$ ), which was dug out from the Gilder mound, at an estimated depth of 5 feet, by a farmer's boy named Joseph, is the cranium pictured in Irofessor Osborn's account and in the Barbour-Ward papers. It is a moderate-sized defective adult male normal cranium. Color pale yellowish, with black discoloration on the dorsal surface of the vault. No perceptible fossilization; all the parts look quite recent and still retain considerable animal matter.

The skull was apparently mesocephalic, with a cephalic index of about 79 . The anterior plane shows a moderate sagittal elevation, the lateral and superior planes are ovoid with the smaller extremity anteriorly, and the posterior plane is pentagonal-forms all quite common among Indians. The supraorbital ridges are pronounced, about as in the Rock Bluff and the Albany Mound crania described in another part of this paper (see page 28 et ser.), and their distal extension aids in the formation of a complete, though not rery heary, supraorbital arch. The forehead is quite low and sloping, yet some ranlting and frontal bend are distinctly noticeable. The temporo-parietal region is some; what fuller than in the other skulls from the mound, showing otherwise nothing unusual; the temporal ridges are moderately marked and their nearest approach to the median line is $5 \mathrm{~cm}$. on the right and $4 \mathrm{~cm}$. on the left side. The occiput is not protruding; it shows a prominent superior ridge and a separation of the supraoceipital part (epactal bone). The right mastoid is of about average masculine size. The ventral surface shows nothing peculiar. Thickness of left parietal 4 to $6.5 \mathrm{~mm}$. 
Above the foramen magnum, on the right side, the bone has been cut away to some extent with a sharp implement; on the left the occipital squama in this locality is so damaged that the original presence or absence of incised marks can not be determined.

A portion of the upper face and a lower jaw are said to have been found with this skull, but on account of the defects they can not be fitted. They agree with the skull in color and both look quite fresh. They show the presence of alveolar prognathism of a medium grade, such as occurs in general in the Indian. The nasal aperture was apparently mesorhynic; its maximum breadth is $2.55 \mathrm{~cm}$. The nasal spine is now but of fair length; the borders of the nasal apertures are sharp. 'The submalar fossie were of good depth. The height of the upper alveolar process in the median line is very moderate, amounting to only $1.7 \mathrm{~cm}$., without perceptible atrophy. The palate was well formed; maximum external breadth 6.4 $(\cdot \mathrm{m}$. A bluish-black discoloration

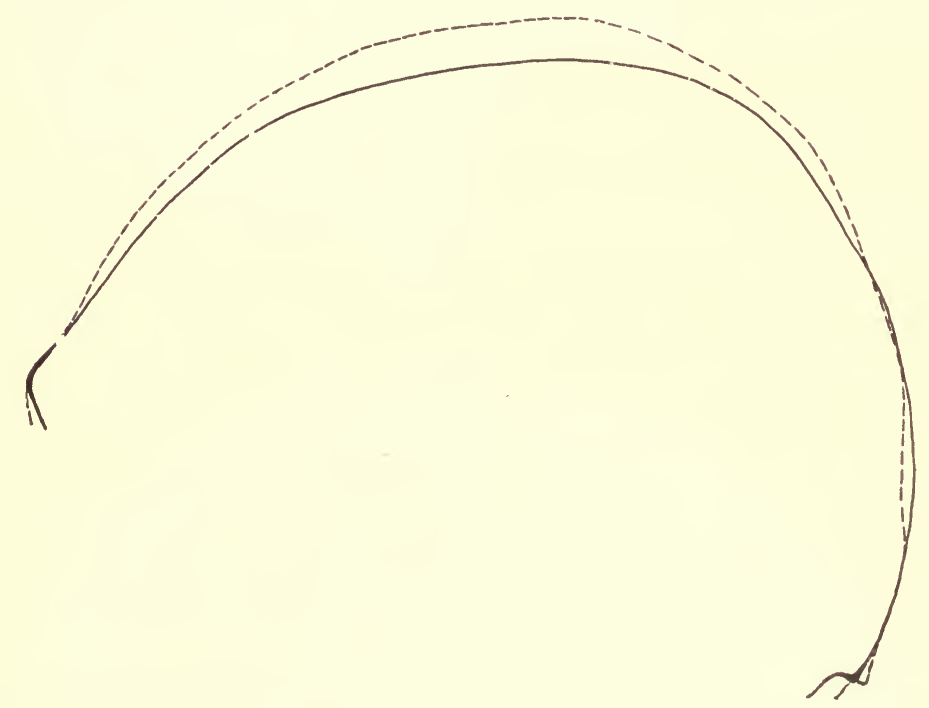

Fig. 12.-Antero-posterior ares of skulls no. 8 and no. 6. No. 8- - , no. (0

is seen on the left side of the maxilla. The lower jaw $a$ has been reconstructed from several pieces, and unintentionally the separation of the rami has been increased. It is a normal specimen of moderate strength, and is a part of the same face to which belongs the above-described upper' jaw; it shows a square chin and quite prominent and pronounced effects of muscular attachment on the external surface of the angles. The rertical rami with their processes and notch present nothing unusual. The teeth of both jaws are of moderate size; all are much worn off; only two molars exist on the left side in the upper jaw (right side broken), and on the right sicle in the lower one. The dentine and enamel of all the remaining teeth are in perfect condition, the latter preserving its normal luster. 'There is absolutely no feature of inferior development about these specimens.

\footnotetext{
a The lower jaw depicted in Professor Ward's paper, in Putnam's Magazine for January, 1907 (page 413), and marked "lower jaw of Nelraska skull no. 6," is a specimen different from the one here described; it would seem that there must have been an error in assigning the Ward specimen to this skull.
} 
Vault :

cm.

Diameter antero-posterior maximum 18.6

Diameter lateral maximum, about_____ 7

Height medium.

Diameter frontal minimum

Diameter frontal maximu:n

Nasion-bregma arc

Bregina-lambda arc

Lower jaw :

Vertical height in middle.

Length of right horizontal ramus

10.8

Length of left horizontal ramus

10. 5

Ileight of right vertical ramus

6. 8

Least breadth of right vertical ramus

\section{SKull No. 8 (plates $\mathrm{x}, a, \mathrm{xI}, \alpha$; figures $12,14,16$ )}

Discovered in 1894, at a depth of less than 5 feet, in Gilder mound, by Charles S. Huntington. A moderate-sized imperfect adult masculine cranium, reconstructed in the proper way and without distortion, from about a dozen fragments. The specimen shows a most interesting conformation but is in no way disensed or deformed. Color pale-yellowish to grayish, with some dark discoloration similar to that shown in patches by almost all the crania and many other bones from the same source. The dorsal surface of the vault shows a tendency to scaling, but there is no chalkiness of the bone, which has a firm structure and no perceptible trace of fossilization.

The skull is mesocephalic, with length-breadth index of approximately 78 . It is ovoid in shape, with the smaller end anteriorly, when viewed from the side or the top, while the outline of its posterior plane approaches the pentagonal. Its most striking and anthropologically interesting characteristics are a very deficient vaulting of the forehead and a large forestructure to the same, consisting of a pronounced supraorbital crest and ridges. In this respect it can best be described as neanderthaloid. It does not equal the well-known Neanderthal skull in its crest, ridges, and flat forehead, but approximates it quite closely. The supraorbital ridges and crest are so pronounced that along their whole length a well-marked depression exists between them and the forehead. There is no trace of frontal bosses and but little vaulting. The glabella lies in a depression $2.5 \mathrm{~mm}$. deep between the excessive ridges. There are a slight metopic ridge and a little more pronounced sagittal elevation, terminating at the middle of the sagittal suture in a well-marked summit. The temporoparietal regions, moderately convex, show nothing unusual. The temporal ridges, nowhere pronounced, are marked over the anterior half of the parietals by a depression; their nearest approach to the median line on the right is 4.5 $\mathrm{cm}$. (left?). The occiput shows medium convexity and a pronounced superior crest. "The right mastoid is of rather submedium male proportions. The sutures show submedium serration; obiiteration is visible externally in the posterior four-fifths of the sagittal, and in small spots along the lambdoid. The base is wholly lacking. Ventrally there is no special feature. Thickness of left parietal, 5 to $7 \mathrm{~mm}$. 

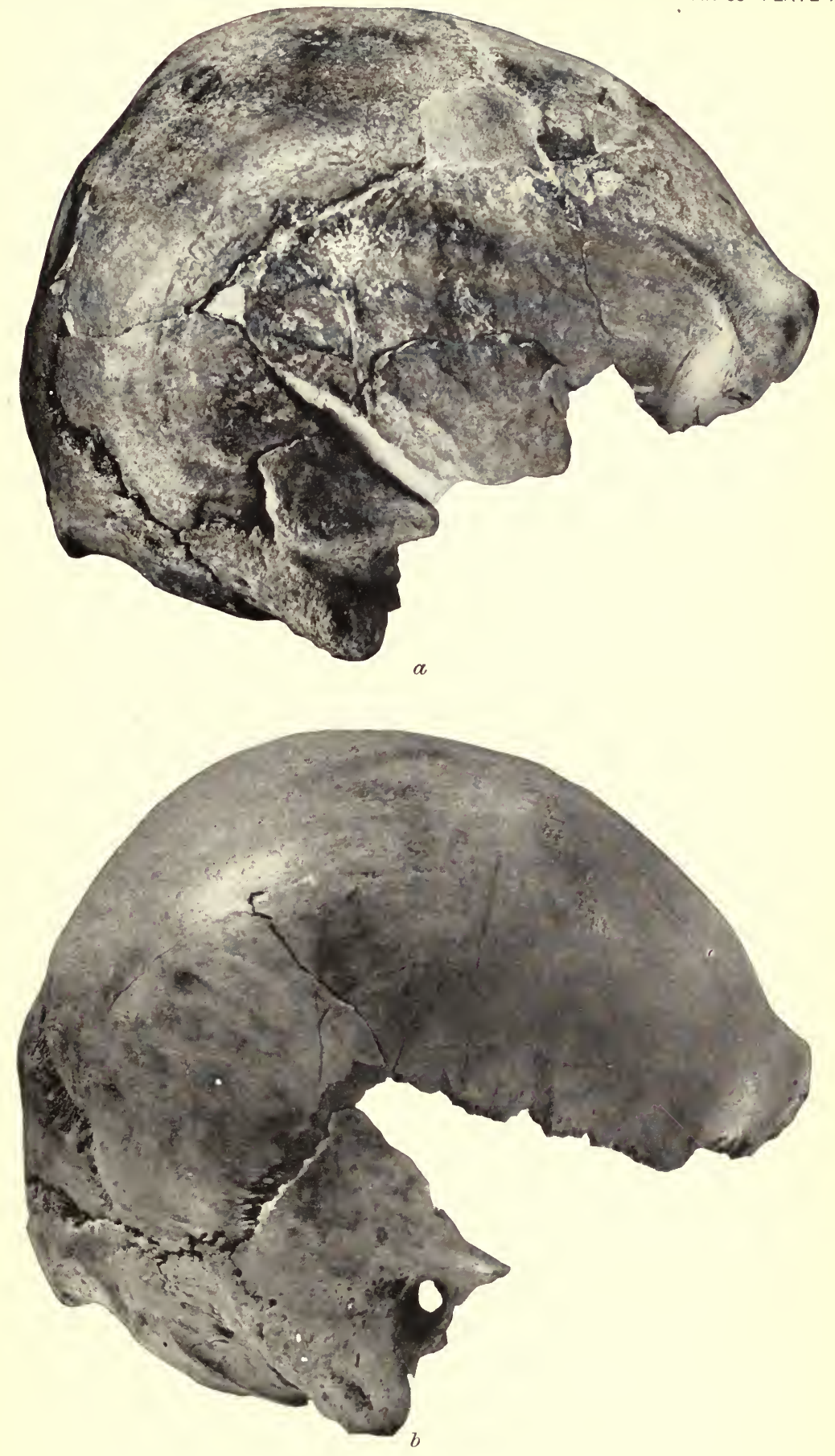

SKULLS FROM GILDER MOUND

$a$ Side view of skull no. $8 ; b$ side view of skull no. 6 


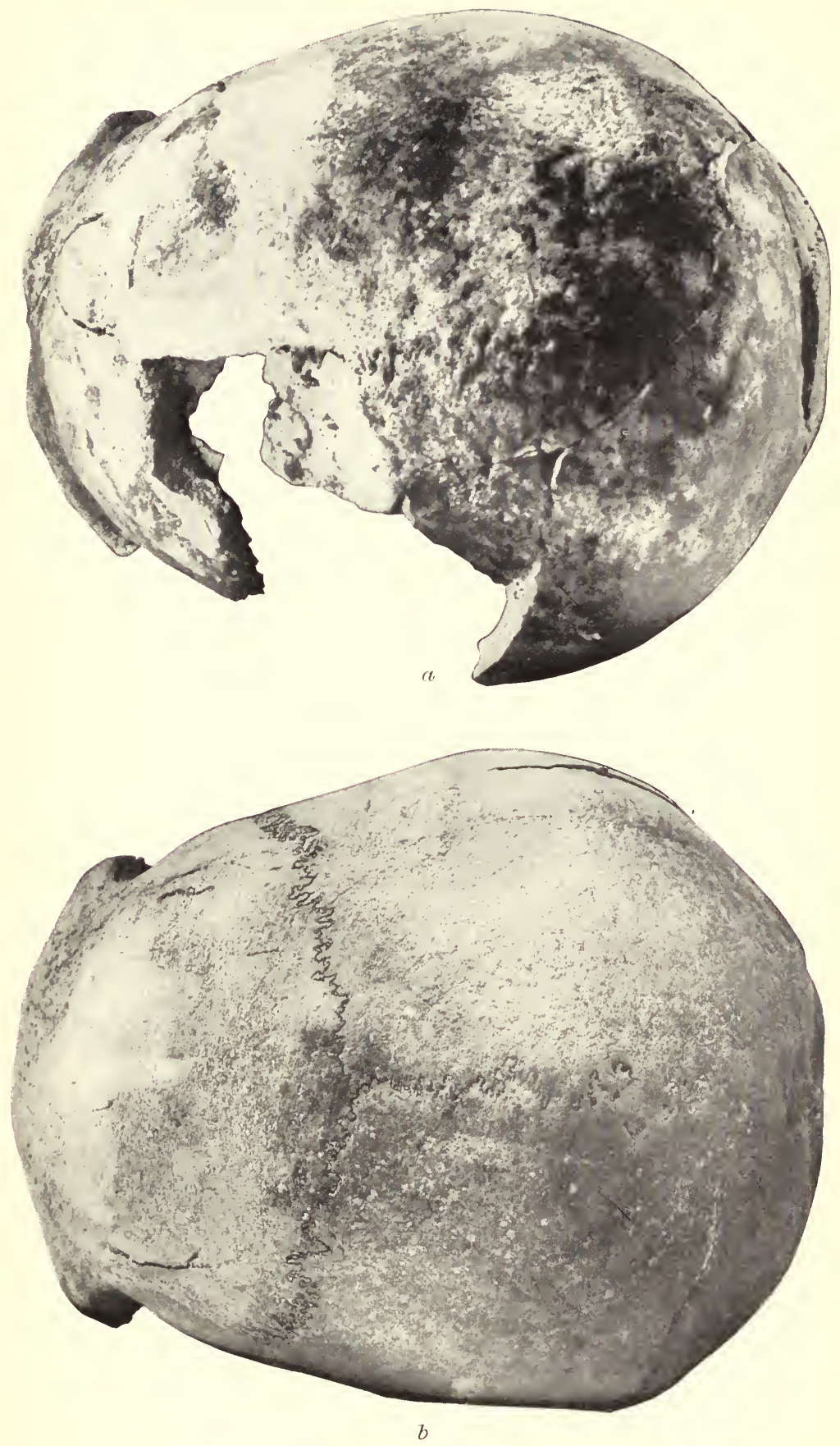

SKULLS FROM GILDER MOUND

$a$ Top view of skull no. $x ; b$ top view of skull no 6 
$\left(\begin{array}{c}\text { YATLARTE } \\ \text { OF THE } \\ \text { UNIVERSITY } \\ \text { OF } \\ \text { CALIFORNIA }\end{array}\right)$ 
Diameter antero-posterior maximum

Diameter lateral maximum

Height, medium.

Naslon-opisthion diameter

Diameter frontal minimum

Diameter frontal maximum

Circumference maximum, above supraorbital ridges, about 50.2

Arc nasion-bregma, 12.7; bregma-lambda, 12.7; lambda-opisthion, 11.8;

total nasion-opisthion 37.2

SKULL NO. $\mathrm{x}$

This is the skull of an approximately 6-year-old child, found by Mr. Gilder buried rather superficially in the Gilder mound. It is apparently quite recent, well developed, thin, and decidedly brachycephalic. A small portion of the occipital bone above the foramen magnum has been cut away in nearly a straight line, with some slarp instrument. The color of this specimen is brownish yellow, not radically different from that of other bones in the mound.

\section{FRONTAL BONE}

This specimen was recorered in two widely separated pieces from the Gilder mound by Professor Barbour. It lay 4 feet below the surface. It is a portion of an adult, and apparently normal, male skull, of medium thickness. It shows moderate masculine ridges and glabella, and a quite well raulted forebead. Diameter frontal minimum, $9.6 \mathrm{~cm}$. Color agrees with that of other specimens from the mound. No fossilization.

\section{LOWER JAW}

Found in Gilder mound by Professor Barbour, at the depth of 4 feet. It is the jaw of a young subject (posterior molars not yet erupted) and shows in every way an ordinary Indian form. The chin is square, fairly prominent. The dental arch indicates moderate prognathism. The teeth were all lost after death except three of the molars, which are of moderate size and normal form; the anterior molars show each five cusps; the one median molar presents four, as usual in modern skulls. The enamel looks fresh. The bone shows no trace of fossilization.

The point of the left coronoid process had been cut off with some sharp instrument.

\section{PORTION OF LOWER JAW}

Found "deep" in the Gilder mound by Professor Barbour. The fragment consists of about two-thirds of the left horizontal ramus, without the ehin or angle. The jaw was apparently masculine and rather strong, but, so far as

a Pictured in Professor Barbour's paper in the Records of the Past, in, pt. 2, 43, February, 1907.

3453-No. 33-07-6* 
can be seen, in no way extraordinary. The teeth are of moderate size, much worn; the molars show diminishing size from front to rear, as in recent skulls. The enamel is lusterless and cracked; the dentine is also cracked. The bone is not fossilized, but has the appearance of greater age than any of the other specimens.

\section{PORTION OF LOWER JAW ${ }^{a}$}

Found in the Gilder mound by Professor Barbour at a depth of 5 feet. The only part remaining is the left vertical ramus. This is $5.7 \mathrm{~cm}$. high, $3.55 \mathrm{~cm}$. broad at its narrowest part, and but moderately thick; it shows a notch of good depth and a feminine angle. There is no perceptible fossilization.

About 200 yards north of the eminence from which skulls nos. 1-8 were recovered, another similar elevation on the ridge was dug into in 1894 by the Parker, Morris, and Huntington party; some human skulls and other bones were found here, but nothing was preserved. Still farther north, in the west bank of the wagon road that runs along the ridge, toward the end of 1906 Mr. Gilder found, not more than 2 feet below the surface, three defective female skulls. Two of these are apparently dolichocephalic, while one-the best preservedis mesocephalic (cephalic index 79.3). These crania are all darker in color than the specimens from the Gilder mound-a fact which may be due to their more superficial position; the surfaces of all three show many minute pits and furrows, root-erosions. In skull no. $x$, the occipital squama above the foramen magnum has been cut away on each.side of the median line, leaving two quite symmetrical curved defective portions. This suggests the cutting in the Joseph skull (no. 6, Gilder mound) in the same location.

\section{HUMERI}

Five entire bones (of which two form a pair) and 12 pieces of distinct humeri, recovered from the mound by Mr. Gilder at various depths not ascertained. All show good, but not extraordinary, sizes and dimensions, and in flatness of the shaft, its shape, and in the frequency of perforation of the septum between the coronoid and the olecranon fosse, approximate closely the humeri of Indians. A rare feature in two of the specimens, although one not unknown in Indians, is the presence of ridges 3 and $4 \mathrm{~mm}$. high, respectively, at the highest point, in the locality of the supracondyloid process. None of the bones show any trace of fossilization. On three of them are seen border scratches, cut-marks, or marks resulting from the gnawing of rodents-the scratches, smaller cuts, and teeth marks can not well be distiuguished one from another.

${ }^{a}$ Pictured in Professor Barbour's paper in the Records of the Past, II, pt. 2, 45, February, 1907 . 


\begin{tabular}{|c|c|c|c|c|}
\hline Specimens. & Length. & $\begin{array}{c}\text { Diameter } \\
\text { lateral at } \\
\text { middle } \\
(=\mathrm{A})\end{array}$ & $\begin{array}{c}\text { Diameter } \\
\text { antero- } \\
\text { posterior at } \\
\text { middle } \\
(=\mathrm{B}) .\end{array}$ & $\begin{array}{c}\begin{array}{c}\text { Index at } \\
\text { middle }\end{array} \\
\frac{(B \times 100)}{A} .\end{array}$ \\
\hline$a, a$ right $\ldots .$. & $\begin{array}{l}\mathrm{cm} . \\
34.8\end{array}$ & $\begin{array}{l}\mathrm{cm} . \\
\quad 2.50\end{array}$ & $\begin{array}{l}\mathrm{cm} . \\
1.60\end{array}$ & 64.0 \\
\hline$b$, left $\ldots \ldots \ldots \ldots \ldots$ & 34.3 & 2.25 & 1.65 & 73.3 \\
\hline$c$, right............. & 34.5 & 2. 50 & 1.80 & 72.0 \\
\hline 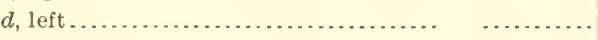 & 35.0 & 2.15 & 1.55 & 72.1 \\
\hline 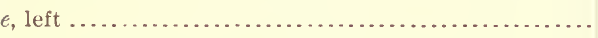 & 33.2 & 2.35 & 1.35 & 57.4 \\
\hline 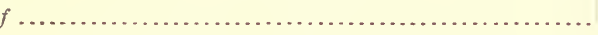 & $(?)$ & 2.25 & 1.45 & 64.4 \\
\hline 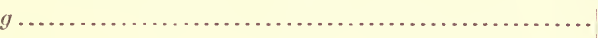 & $(?)$ & 2.55 & 1.75 & 68.6 \\
\hline h & $(?)$ & 2.05 & 1.50 & 73.2 \\
\hline 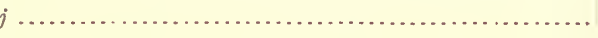 & (?) & 2.30 & 1. 70 & 73.9 \\
\hline o & (?) & 2.25 & 1.50 & 66.7 \\
\hline$p \ldots \ldots \ldots \ldots \ldots \ldots \ldots . . .6$ & (?) & 2.25 & 1. 70 & 75.6 \\
\hline 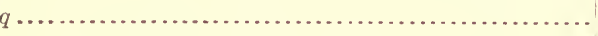 & $(?)$ & 2.35 & 1.65 & 70.2 \\
\hline
\end{tabular}

a Provisional designations; $a$ and $b$ belong to the same skeleton.

Shapes of shaft. Specimens $a, b$, and $q=$ near prismatic (type 1 ). $b$ Specimens $c$ and $e=$ near lateral prism (type 2). Specimens $d, g, j, o, p=$ near planoconvex, or plano-convex (type pc.). In $a, b, c$, and $e$ there is also a tendency toward the replacement of the anterior border by a tourth surface (type 4).

Perforations between coronoid and olecranon fossw (in specimens where the lower end of the bone is preserved) :

Ifumerus $a=$ none.

Humerus $b=$ none.

Humerus $c=$ none.

Humerus $d=$ large.

Humerus $e=$ large.

Humerus $h=$ small.
Iumerus $i=$ two small and one pinpoint.

Humerus $k=$ large.

Humerus $l=$ none.

Humerus $m=$ none.

Total, five (50 per cent) with and five without perforation.

\section{FRAGMENT OF A IIUMERUS}

Found "deep" in the mound by Professor Barbour. Shape of shaft at middle, nearly plano-convex; diameter of antero-posterior at middle, $1.8 \mathrm{~cm}$; diameter lateral, $2.5 \mathrm{~cm}$; index, 72 . Lower end lacking. No fossilization.

\section{FRAGMENT OF A RIGHT ULNA}

Found "deep" in the mound by Professor Barbour. An adult female bone, with prismatic shaft (type no. 1), in no way peculiar. No fossilization. Cuts on the interosseous border and anterior surface.

${ }^{b}$ See Typical Forms of Shaft of Long Bones, Proceedings of the Association of American Anatomists, 14th session, 55-60, Dec., 1900. 


\section{RADII}

Three whole good-sized atlult normal radii (among which two are from one subject), recovered from the mound at unrecorded deptlis, by Mr. Gilder; these show no unusual features. Lengths: $a^{1}$, right, $27.8 ; a^{2}$, left, $27.4 ; b$, left, $23.3 \mathrm{~cm}$.

\section{FEMORA}

Eight entire adult bones (in which there are three pairs), with nine pieces and three femora of small children, obtained from the mound by Mr. Gilder. at various depths, not ascertained. Two of the whole bones (a pair $c^{1}, c^{2}$ ) show an abnormal curvature forward; the rest are normal and indicate good stature and strength of the people. The general shape and the subtrochanteric flattening (platymery) of most of the bones indicate a close approximation to Indian femora. There is no fossilization.

\section{Inetails-Measurements}

\begin{tabular}{|c|c|c|c|c|}
\hline \multirow[b]{2}{*}{ Specimens. } & \multirow[b]{2}{*}{$\begin{array}{l}\text { Length (bi- } \\
\text { condylar). }\end{array}$} & \multicolumn{2}{|c|}{ Subtrochanteric flattening. } & \multirow[b]{2}{*}{$\frac{\begin{array}{c}\text { Index } \\
(\mathrm{B} \times 100)\end{array}}{\mathbf{A}}$} \\
\hline & & $\begin{array}{c}\text { Greatest } \\
\text { breadth }(A) .\end{array}$ & \begin{tabular}{|c|} 
Smallest \\
antero-poste- \\
rior dimen- \\
sion $(\mathrm{B})$.
\end{tabular} & \\
\hline$a^{1}$, right...... & ${ }_{48.5}$ & $\begin{array}{l}\mathrm{cm} . \\
\quad 3.55\end{array}$ & $\begin{array}{r}\mathrm{cm} . \\
\quad 2.55\end{array}$ & 71.8 \\
\hline$a^{2}$, left $\ldots \ldots \ldots \ldots$ & 48.4 & 3.65 & 2.50 & 68.5 \\
\hline$b^{1}$, right............... & 48.0 & 3.70 & 2.65 & 71.6 \\
\hline$b^{2}$, left............ & 48.3 & 3.50 & 2.70 & 77.1 \\
\hline$c^{1}$, right $\ldots \ldots \ldots \ldots \ldots \ldots \ldots \ldots \ldots \ldots \ldots \ldots \ldots \ldots \ldots \ldots$ & 47.8 & 3.20 & 2.60 & 81.2 \\
\hline$c^{2}$, left $\ldots \ldots \ldots \ldots \ldots \ldots \ldots \ldots \ldots \ldots \ldots \ldots \ldots \ldots$ & 48.4 & 3.20 & 2.80 & 87.5 \\
\hline$d$, left, about......... & 47.3 & 3.20 & 2.55 & 79.7 \\
\hline$e$, right.............. & $(?)$ & 3.05 & 2.50 & 82.0 \\
\hline$g$, right $\ldots . . . . . .$. & (?) & 3.20 & 2.25 & 70.3 \\
\hline 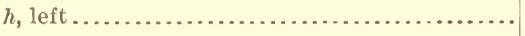 & $(?)$ & 3.10 & 2.20 & 71.0 \\
\hline 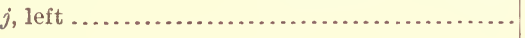 & $(?)$ & 3.20 & 2.40 & 75.0 \\
\hline$k$, left ................. & $(?)$ & 3.40 & 2.45 & 72.1 \\
\hline$l$, left $a \ldots \ldots \ldots \ldots \ldots$. & 46.1 & 3.70 & 2.30 & 62.2 \\
\hline$m$, left.................. & $(?)$ & 3.55 & 2.40 & 67.6 \\
\hline
\end{tabular}

a In two pieces; one found by Gilder, November 1, 1906; the other, at a deeper level, November 7, 1906.

\section{SHAPES OF SHAFT}

In seren instances $\left(a^{1}, a^{2}, b^{2}, c^{2}, g, j, l\right)$ the shape is indeterminate; in six $\left(b^{1}, c^{1}, a, e, f, m\right)$ it is the prismatic (type no. 1) or approximate thereto; and in two $(h, i)$ the shaft is nearly cylindrical. In $c^{1}$ and $c^{2}$ is shown, as a compensation for the curvature, excessive linea aspera.

\section{TIBIE}

Two entire adult bones (a pair) and ten pieces, obtained by Mr. Gilder from various levels (unnoted) in the mound. The bones are of good length and strong; they show ordinary forms and only moderate inclination backward of the head. They approximate in general the tibiæ of Indians without showing 
the excessive flattening met with in some parts of the country. Three of the bones (two of which belong to one skeleton) are diseased (probably syphilitic), and on three pieces with the head lacking are seen in the superior border (twice in the posterior part thereof) what are apparently cuts; some of these marks, however, resemble marks made by rodents' teeth. None of the specimens show any trace of fossilization and a few look quite fresh.

\section{Details-Measurements}

\begin{tabular}{|c|c|c|c|c|}
\hline \multirow[b]{2}{*}{ Specimen. } & \multirow{2}{*}{$\begin{array}{l}\text { Length } \\
\text { (minus } \\
\text { spine). }\end{array}$} & \multicolumn{2}{|c|}{ Diameter. } & \multirow{2}{*}{$\begin{array}{c}\begin{array}{c}\text { Index at } \\
\text { middle } \\
(\mathrm{B} \times 100) \\
\mathbf{A}\end{array}\end{array}$} \\
\hline & & $\begin{array}{l}\text { Antero-pos- } \\
\text { terior at } \\
\text { middre (A). }\end{array}$ & $\begin{array}{c}\text { Lateral at } \\
\text { middle }(\mathbf{B}) \text {. }\end{array}$ & \\
\hline & $\mathrm{cm}$. & $\mathrm{cm}$. & $\mathrm{cm}$. & \\
\hline$a^{1}$, right............. & 40.7 & 3.50 & 2.30 & 65.7 \\
\hline$a^{2}$, left.............. & 41.0 & 3.35 & 2.20 & 65.7 \\
\hline 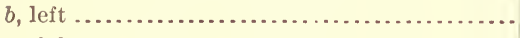 & $(?)$ & 3.50 & 2.50 & 71.4 \\
\hline 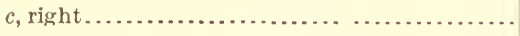 & $(?)$ & 3.55 & 2.90 & 81.7 \\
\hline 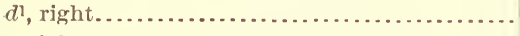 & $(?)$ & 3.50 & 2.50 & 71.4 \\
\hline 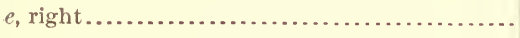 & $(?)$ & 3.20 & 2.60 & 81.2 \\
\hline$f$, right $\ldots \ldots \ldots \ldots \ldots \ldots \ldots \ldots \ldots \ldots \ldots \ldots \ldots \ldots \ldots \ldots \ldots \ldots$ & $(?)$ & 3.50 & 2.45 & 70.0 \\
\hline$g$, right............... & $(?)$ & 3.10 & 2.25 & 72.6 \\
\hline$i$, left.................. & $(?)$ & 3.00 & 2.10 & 70.0 \\
\hline 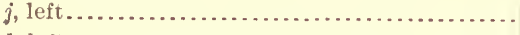 & $(?)$ & 3.30 & 2.30 & 69.7 \\
\hline$k$, left............................................... & $(?)$ & 3.40 & 2.25 & 66.2 \\
\hline
\end{tabular}

Shapes of the shaft. Six of the specimens $\left(a^{1}, a^{2}, b, e, f, i\right)$ are of, or closely approximate to, the prismatic (type no. 1$)$; three $\left(d^{1}, j, k\right)$ show it tendency to rhomboidal form (type no. 4); in $e$ the internal surface is hollowed out (type no. 3), and $g$ shows a lack of differentiation of the external border.

\section{FIBULA}

One adult specimen, about $39.5 \mathrm{~cm}$. long, of normal form and good strength, found in the mound by Mr. Gilder at a depth unnoted. No fossilization.

A fragment of a fibula, dug out of the mound at an unknown depth, and given by $\mathrm{Mr}$. Gilder to the writer, bears plain marks of cutting with both some sharp instrument and small rodents' teeth.

\section{SCAPULA}

Found by Professor Barbour in the Gilder mound at a depth of $4 \frac{1}{2}$ to 5 feet. A defective left shoulder blade of moderate size and not unusual form. The thin body of the bone looks fresh, and no part shows any fossilization. The superior border has been cleanly cut off along nearly its whole length close to the spine.

\section{RIBS}

Three pieces of ribs, found "deep" in the mound, of moderate proportions and ordinary form. No fossilization. On one of the specimens are seen marks which may have been made with a knife or by the teeth of rodents. 


\section{VERTEBRA}

Several dorsal and lumbar vertebra belonging, apparently, to one body, found "deep" in the mound by Professor Barbour. The bones are of moderate dimensions. The bodies of sereral of the rertebra show asymmetry, while the twelfth dorsal presents, in addition, somewhat peculiar lateral processes, a deviation of the spinous process to the left, and a plain trace of a formerly existing separation of the left lamella from the base of this process, conditions all pointing to disturbance in ossification of this spine. None of the bones show any fossilization.

\section{SACRUMI}

Found "deep" in the mound by I'rofessor Barbour. The bone is composed of five segments and shows normal size and form, with moderate curvature. Height, $11.5 \mathrm{~cm}$; maximum breadth, about $11.4 \mathrm{~cm}$. No fossilization.

\section{PELVES}

Two adult male pelves, found in the mound by Mr. Gilder; depth not recorded. The specimens in every respect are normally dereloped, and anproximate in form the pelvis of the Indian. One, accompanied by several of the lumbar vertebræ, shows some senile marginal exostoses, such as are common in aged whites and occur also in old Indians.

I'elvis $a$, somewhat defective; is strougly built. Diameter external maximum (bi-iliac), $31.4 \mathrm{~cm}$; height maximum, about $202.7 \mathrm{~cm}$. ; greatest breadth of right ilium, $17.1 \mathrm{~cm}$; of left ilium, $17 \mathrm{~cm}$; greatest transverse diameter of the superior strait, 16.8 ('m. The sacrum consists of fire segments, but the last iumbar shows on the left side a tendency to assimilation; currature medium: height, $11.1 \mathrm{~cm}$; greatest breadth, $12.9 \mathrm{~cm}$.

Pelvis $b$, defective; shows bones of moderate strength. Greatest height of right os innominatum, $22.9 \mathrm{~cm}$; greatest breadth, $16.7 \mathrm{~cm}$. Sicrum damaged; curvature moderate; was composed, apparently, of six segments. Neural canal shows posteriorly throughout its height a defect, due to imperfection of the neural arches of the vertebra composing the bone.

\section{OS CALCIS}

Found "deep" in the mound. Form quite ordinary. No fossilization. Greatest length, $7.8 \mathrm{~cm}$. ; height at middle. $4.25 \mathrm{~cm}$. ; smallest breadth at middle, $3.15 \mathrm{~cm}$.

\section{PHALANGES}

Several phalanges and pieces thereof from "deep" in the mound. The bones are of moderate size and show no special features. Some of the slivers look very fresh.

\section{LONG BONES OF A CHILD LESS THAN A YEAR OLD}

Found "deep" in the mound by Professor Barbour. The bones are slender, but normal; the right femur measures, minus epiphyses, $10.7 \mathrm{~cm}$. The bones look quite fresh, and certainly retain a good proportion of animal matter. The ends of the apophyses, except where broken off, show the delicate cancellous tissue in a perfect state of preservation. 


\section{Discussion}

The examination of the human remains from the Gilder mound being concluded and their somatological characters described in detail, it is now necessary to consider the question of their probable relations to the geological formation with which they were associated and the bearing of these relations on the question of antiquity.

It is not questioned that the various explorations have been intelligently conducted and that sincere effort has been made to ascertain and promulgate the entire truth regarding the finds, but if the present knowledge concerning these specimens is impartially considered, it is apparent that the theory of a more than recent geological origin of any of them meets with serious objections, while, on the other hand, no insurmountable obstacle appears in connection with the assumption that all are comparatively recent. If the existence of geologically ancient man in any part of this country is to be generally accepted, the evidence should be free from serious doubts and uncertainties. That this condition is not fulfilled in the present case will become manifest when due weight is given to the following considerations:

(a) Within a depth of 5 feet or less, the Gilder mound contained the remains of apparently about a dozen bodies. There were male and female skeletons, ranging in age from the infant to the senile subject. Two or three of the skulls, with some accompanying bones, lay within $2 \frac{1}{2}$ feet or less of the surface. Below this, according to the explicit statements of Mr. Gilder, was a layer of clay of undetermined area, hardened by fire. ${ }^{a}$ This is an occasional feature in burial mounds of this general region, ${ }^{b}$ the purpose of the baking being possibly to protect the bodies from animals which otherwise might prey on them. Beneath this cover of hardened earth lay in some proniscuity, but in numerous instances in partial natural association, the skeletal remains of eight or nine bodies. ${ }^{c}$ At still lower levels, down to the depth of $11 \frac{1}{2}$ feet, were found here and there pieces of human bones. Instances of anatomical association extended to the

\footnotetext{
${ }^{a}$ A small piece of clay secured by Mr. Gilder and recently sent for examination to the writer by l'rofessor Barbour, shows unmistakable signs of partial burning. l'ortions of the piece are of the color and nearly of the consistency of a light-burned brick. A sample of this nature, while not conclusive proof of an extended fire-hardened layer, is nevertheless confirmatory of Mr. Gilder's earlier statements as to the existence of such a layer.

${ }^{b}$ See Cyrus Thomas, Report on the Mound Exploration of the Bureau of Ethnology, Tuelfth Annual Report of the Bureau of American Ethnology, Washington, 1894; and Frederick Starr, Summary of the Archeology of Iowa (with Bibliography of Iowan Antiquities), Proceedings of the Davenport Academy of Scicnces, vi, 1895.

${ }^{c}$ According to information received from Professor Barbour March 5, a block of loess which was taken to the laboratory in its entirety, showed parts of another skeleton. The bones began at 4 feet 9 inches from the surface and extended down to 6 feet, several of them plainly showing anatomical association.
} 
depth of 6 or $6 \frac{1}{2}$ feet. Below this everything was disconnected and fragmentary.

Now, ordinarily, the interpretation of these facts would be quite simple, as the conditions observed are in general characteristic of the ordinary low mound of the region. Some of the bodies seem to have been buried immediately after death; others, after having been exposed to the elements on scaffolds, or otherwise treated. Later burials by the same or other peoples appear to have been made about the margins of the mound and also above the hardened clay. In the writer's view it is impossible that the nine or more bodies beneath the fire-hardened clay should have drifted into that position at any time or that they should have come there in any manner other than as direct burials; and it is highly probable that, were it not for the large supraorbital ridges and low foreheads of some of the crania, the question of geological antiquity would never have been raised with respect to any of these remains.

There is nothing in the conditions connected with the bones which came from the levels between $2 \frac{1}{2}$ and 6 feet to suggest particular antiquity. The depth at which they were found is in no way exceptional; in fact, this depth is quite the rule in low mounds. The absence of surface soil of darker color is not remarkable, since, except where charcoal is present, the color resulting from decay of vegetal matter soon disappears through chemical changes and leaching. The presence in the neighborhood of the bones of small pebbles and fossil shells would be natural, if these objects existed originally in the loess of the locality, for no one burying a body would sift the earth with which to cover it. The baking of the earth over the bodies was not accidental, for the signs of fire diminished toward the periphery of the mound, and, besides, as already stated, it was not a rare practice of the aborigines of the Missouri valley to bake the surface of burial mounds. It is likewise evident that this baking can not be attributed to the people who buried the two or three bodies above it; they would hardly have chosen a spot over a deposit of human bones belonging to a previous geological age and then, after baking the earth immediately covering the deposit, have buried their own dead on this floor, carrying to the place $2 \frac{1}{2}$ feet of earth for the purpose of covering the bodies. It is more reasonable to suppose that these people resorted to a regular burial mound of their own or of another comparatively recent tribe.

Besides the skeletal parts, which maintained more or less their natural relation, there were found at deeper levels in the mound, and possibly a little outside of it, human bones in small pieces. These fragments were scattered and comparatively few in numbernot more than "one bit of bone" to 5 or 6 cubic feet of earth. The fragmentary character of these bones and their wide dispersal 
through the formation have been regarded as evidence that they were deposited contemporaneously with that formation (loess) and, hence, that they are of great age, antedating the shaping of the hill itself. Right here, however, we are confronted with a perplexing dilemma. If these fragments found more than 6 feet below the surface are admitted to proceed from the remains deposited above the 6 -foot level and just below the baked earth-the remains of people of the low foreheads, we must then abandon the assumption that they are as ancient as the deposits of loess immediately about them, and also the idea that these deposits have remained undisturbed since their formation. On the other hand, should the fragments be regarded as distinct in origin from the skeletons found between the $2 \frac{1}{2}$-foot and 6 -foot levels, as they must be if the formations have remained undisturbed, the problem takes on a new phase, and we must account for several distinct deposits of human remains within or beneath the mound. In that case the inferior type of some of the skulls from the layer just below the baked earth can have no bearing on the antiquity of the fragments deeper down. Furthermore, the higher fragments found beneath the 6-foot level could scarcely then be regarded as of the same origin as the lower ones, for the reason that the distance between these two groups of pieces is far greater than that between the higher-lying fragments and the superimposed skeletons.

The fact that the bones between the $2 \frac{1}{2}$-foot and 6 -foot levels were mixed and broken and parts were missing may be difficult to explain. but similar conditions are common in mound burials as well as in other burials, and are especiaHy to be expected where the excavation has not been conducted from the beginning with the utmost care. Inequalities in decay, natural movements of the earth, the burrowing and direct dragging by rodents, the penetration of roots, and occasional unrecorded disturbances of the soil produce remarkable results of this nature. Whole limbs, or the entire head, and sometimes a large part of the body, may thus disappear, or the remains may be broken, teeth lost, and the bones scattered. There must have been a similar occurrence even with the uppermost or intrusive burials, for of one of the bodies, that of a child, which is regarded as the most recent. there is only the incomplete skull, while but little more was found of the other two bodies inhumed above the fire-hardened earth. The fact that there is no break or horizon of separation in the deposits between the bones of the principal deposit and those below, and that larger fragments were discovered only in the proximity of these main burials, speaks much for the common origin of all the specimens under consideration. That some slivers could have been so displaced is to lie actually beyond the limits of the mound does not seem improbable. 
(b) Observing the condition of the bones, it is noted that the color, surface markings, consistency, discolorations, and other characteristics are much the same at all levels; the differences are no greater than those observed in the different parts of a single skull or in specimens in immediate proximity to one another. Such could hardly be the case if some of the bones were thousands of years more ancient than others. The chemical action of the soil, coupled with that of organic elements within it, on human bones in some instances may be very slight, yet it is incredible that no marked differences should be perceptible in the effects of these agencies on bones of the Glacial or the immediately post-Glacial period and those of recent centuries.

This brings us directly to the very important concurrent fact of the total absence from any of the bones of perceptible fossilization. Such a condition would be hard to explain in bones dating from the period of the original loess deposit and under the circumstances in which the specimens in question were found. It is true that minor grades of mineralization, which may be difficult of detection, occur in rare instances in certain pleistocene sands or in perpetually dry cave deposits, but the fine Nebraska loess presents different conditions. The fire-hardening at one of the higher levels in the mound was not sufficient to keep out moisture and air, whose presence facilitates physical and chemical changes in inclosed bones. At the time of our visit to the locality in January the earth was found to be frozen at a level lower than the baked layer. To overcome this difficulty of absence of perceptible mineral replacement, and even of infiltration of the specimens, those who would prove that the deeper-lying bones from the Gilder mound are geologically ancient should produce satisfactory specimens of bones, unquestionably ancient yet nonfossilized, from deposits of the same nature and existing under the same conditions.

Only one piece, the fragment of a lower jaw, shows changes such as could have been produced by exposure to the elements, even for a moderate length of time. On none of the other bones do we find the easily recognizable results of bleaching or cracking caused by exposure to the sun, or of superficial abrasion that could be attribited to water action. The etching or pitting of the surface observed in some of the bones is due to the action of minute roots or to corrosion by chemical agencies in the soil or in percolating waters. These features are common to bones embedded for even short periods in various soils.

(c) Numerous bones from the different levels show marks due to the gnawing of rodents and also cuts made by some sharp implement wielded by human hands. The tooth marks indicate that at some 
time rodents did have access to these pieces, and as none of the specimens thus marked show weathering, they must have been reached by animals burrowing in the mound. ${ }^{a}$ The smaller fragments of bones would thus certainly be dragged and displaced, and it is very likely that some of them would eventually come to rest at much lower levels than before. The results of the caving in of the burrows, especially of the spacious chambers characteristic of the dwellings of certain rodents, must also be considered in this connection. The aepth the bits of bone could thus reach would be limited only by the depth of the burrowing, and that this may have reached in the fine loess $11 \frac{1}{2}$ feet, or eren more, will not be denied. It is apparent that this agency is sufficient to account for the presence of some, if not of all, of the smaller bones at the lower levels.

$(d)$ The presence of knife marks on a number of the bones has an important bearing on the question of relationship of the bones of different layers to one another. These marks are seen, as has been noted, on bones from the more superficial as well as on some from the deeper layers. They are of similar character, occurring mostly on the edges or margins of the bones and in nearly all cases are restricted to the long bones and to the skull. Their similar location on the skull-namely, in the rear of the foramen magnum-indicates an identity of custom such as might develop, for instance, in the not unusual practice of cleaning the bones before secondary burial. This peculiar cutting is seen on skull no. 6, which is described as representing the ancient loess man, as well as on the child's skull, which is regarded as the most recent, belonging to the topmost layers above the baked earth, and also on one of the female skulls taken out near the surface in the bank of the road. The advocates of great antiquity will need to explain these coincidences. It is difficult to imagine peoples, ages apart and in a locality subject, doubtless, to changes of population, engaging in exactly the same very peculiar and unusual practice of whittling away a particular portion of the occipital. ${ }^{b}$

${ }^{a}$ On March 14 the writer received from Professor Barbour several teeth, found with a crushed skull in one of the blocks of " undisturbed" loess containing pieces of human bones, at the depth of $5_{2}^{1}$ feet. All these teeth were identified, with the aid of Dr. M. W. Lyon, of the division of mammals, U. S. National Museum, as those of Geomys bursarius, or the common modern pocket gopher. See in this connection Professor Blackman's statement on p. 74 .

${ }^{b}$ Superficial cutting is present also, as described in another part of this paper, on the left side of the vault of the Rock Bluff skull, from Illinois. Besides this instance, the writer found practically identical cuttings in the occipital, back of the foramen magnum, in the National Museum skull no. 243017, from a mound at the mouth of the Illinois river (shows also cuts about the orbits) ; and in nos. 225252, 228876, 22887 $7,228878,228880$, 228881, 228882, 243223, and 243238, parts of Professor Montgomery's collection, from mounds in North Dakota. None of these specimens have any claim to geological antiquity. Some of the mounds explored by l'rofessor Montgomery and from which the above skulls are derived showed also the peculiarity of baked earth above the remains of the skeletons. 
No animal bones of any kind have been found in the excavation, unless they are represented by one specimen which does not resemble a normal human bone, but may be the proximal half of a human clavicle, ${ }^{a}$ pathologically altered. What were mentioned in one of the recent publications relating to these finds as " presumably the bones of a young wolf, with epiphyses wanting," are the long bones of a very young child.

(e) The principal support for the notion of the great antiquity of the deeper-lying remains from the Gilder mound is the low type of several of the skulls, especially those numbered 6 and 8 . The particular features indicative of low type are a remarkably low forchead and pronounced supraorbital ridges. The size of the crania, as indicated by their external measurements, their form in general, as well as in particular parts, and the thickness of their walls, show considerable uniformity among themselves and present no exceptional features when compared with those of Indians. Notwithstanding the low foreheads, the skulls do not impress one as those of idiots or imbeciles, although the possibility that one or more of them are remains of such defectives can not be excluded. Imbecility occurs among probably all peoples. The writer is inclined to regard these low-browed crania as examples of individual peculiarities. Their special features, which are really exaggerations of definite sexual characters, may indicate degeneration or they may possibly be reversions. The fact that several of the same type are found in one locality will be readily understood by those acquainted with the principles of heredity; besides, it will be remembered that only one of the skulls shows the inferior features in a very pronounced form. Exceptional cases of this nature are known to occur among all peoples with which we are acquainted; they are met with even among civilized whites. Skulls with low foreheads and pronounced ridges certainly do occur among the Indians, and it is very suggestive that the majority of the crania of this type thus far observed have been discovered in mounds of the general region in which are located the present finds. This region extends, so far as we may now judge, over portions of Illinois, Iowa, and Wisconsin, reaching the Dakotas, and the burials from which they are derived have no claim to geological antiquity. The better-known instances of these finds are as follows:

In The American Naturalist (xxiI, 185-188, 1889), Clement L. Webster reports in brief on the exploration of ancient mounds at Floyd, Iowa. ${ }^{b}$ The mounds were three in number and were sit-

${ }^{a}$ Another exception is the pocket-gopher teeth mentioned in the footnote on $\mathrm{p} .91$.

${ }^{b}$ Abstracts of this, as well as of the following Webster paper, may be found in F. Starr's Summary of the Archeology of Iowa, Proceedings of the Davenport Academy of Sciences, vi, 64, 78, 1895 . 
uated on the west side of Cedar river. In the largest of these mounds (circular in form and about 30 feet in diameter, but only 2 feet high) were found, at a depth of a little more than 5 feet from the surface, the well-preserved remains of five bodies. This mound showed several peculiarities, among which were a layer of arth mixed with ashes, some distance above the bodies, and a baking of the remaining earth above these ashes. One of the skeletons was that of an "arerage-sized woman in middle life," one of an infant, one of a large aged man, and two of young adults, sex undetermined. The bones of the woman (?) "indicated a person of low grade, the evidences of unusual muscular development being strongly marked. ${ }^{a}$ The skull of this personage was a wonder to behold, equaling, if not rivaling in some respects, in inferiority of grade, the famous 'Neanderthal skull.' The forehead (if forehead it could be called) is very low, lower and more animal-like than in the "Neanderthal' specimen. This skull is quite small for an adult individual."

Later in the same year and in the same journal (pages 650-655) Mr. Webster reports on excarations in the mounds near Old Chickasaw, Iowa, on the west side of Little Cedar river. All these mounds were "circular, with oval tops, and with a diameter rarying from 22 to 51 feet, and a height of from $1 \frac{3}{4}$ to 5 feet." In the center of the first mound examined three human skeletons were found. Above them were $1 \frac{1}{2}$ feet of mixture of earth and ashes, made very hard, with a few small pieces of charcoal scattered through it. The remaining $3 \frac{1}{2}$ feet of material composing the mound was a yellow, clayey soil, unlike anything found on the surface in the vicinity. "The crania of all three individuals showed an extremely low grade of mental development; the foreheads being, in one case, even lower than in the specimen found in the Floyd mound." "The upper" anterior portion (back of the eyes) of one of the crania under consideration was quite narrow, but expanded rather rapidly posterolaterally." The frontal bone "sloped abruptly backward, forming a slightly concave area back of and above the eyes." The largest of the three skulls measured $6 \frac{1}{4}$ by 5 inches $(15.8$ by $12.7 \mathrm{~cm}$.). " "No relics of any description were found with the bodies exhumed," including those from neighboring mounds. ${ }^{c}$

Another group of low-browed, inferior-type crania was dealt with in a previous chapter of this paper. They are the specimens from along Illinois river, including the Rock Bluff skull (plate II, $a$ ), the

a It is quite evident that an error has been made in the sex identification, and that the skeleton was that of a man.

${ }^{b}$ Nothing is stated as to how these measurements were taken.

$c$ The illustrations accompanying the two accounts of Mr. Webster can scarcely be regarded otherwise than as overdrawn, but the description points clearly to low-type crania. The specimens are still in the possession of $\mathrm{Mr}$. Webster, at Charles City, Iowa, but a personal request that they be sent to the writer for examination, or that they be photographed for his use, brought no answer. 
Albany (Illinois) Mound skull, no. 3, in the Davenport Academy of Sciences, which the writer was able to examine on his return from Nebraska, and the other Albany Mound skull, no. 242982, of the U. S.

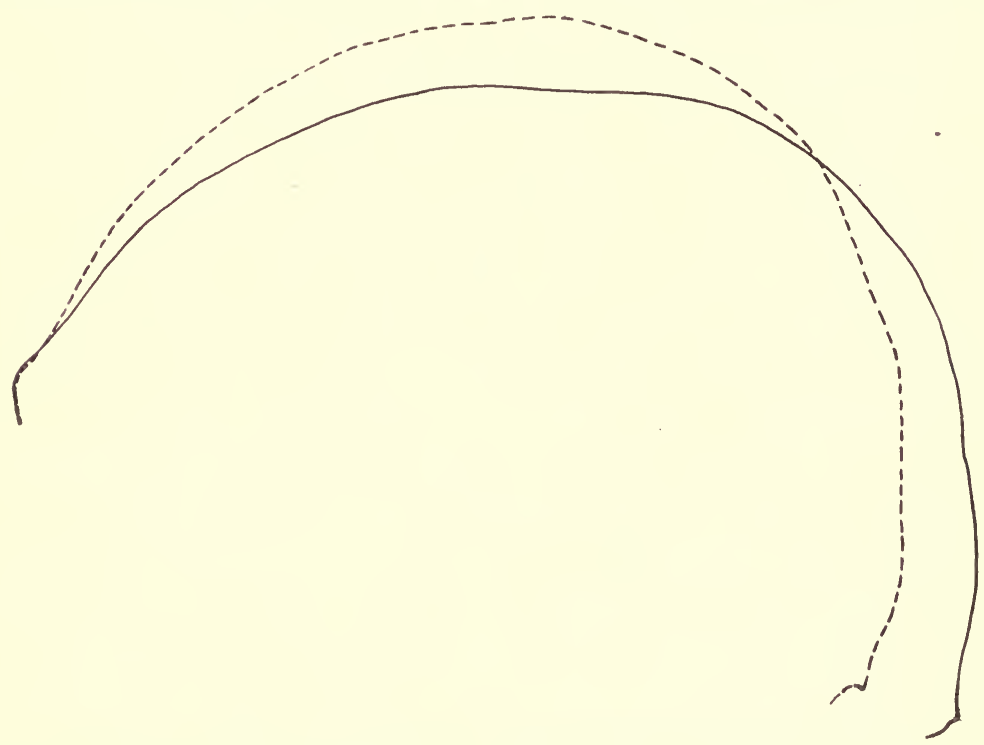

Fig. 13.-Antero-posterior ares of skulls no. 4402, Davenport Academy of Sciences, and no. 6, Gilder mound. No. 4402 , _ ; no. 6, ....-

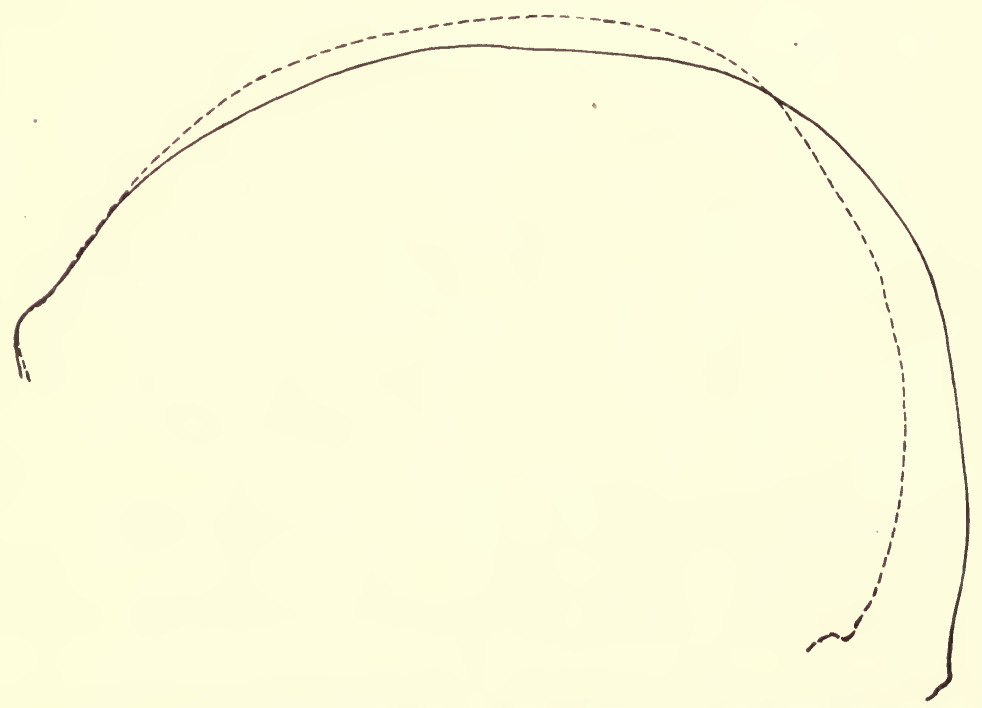

Fig. 14.-Antero-posterior ares of skulls no. 4402, Davenport Academy of Sciences, and no. 8 , Gilder mound. No. 4402 ,

National Museum. To the foregoing may be added another remarkable low-order specimen, namely, no. 4402, in the Davenport Academy of Sciences, from mound 1, near Albany, Illinois. The accompanying 

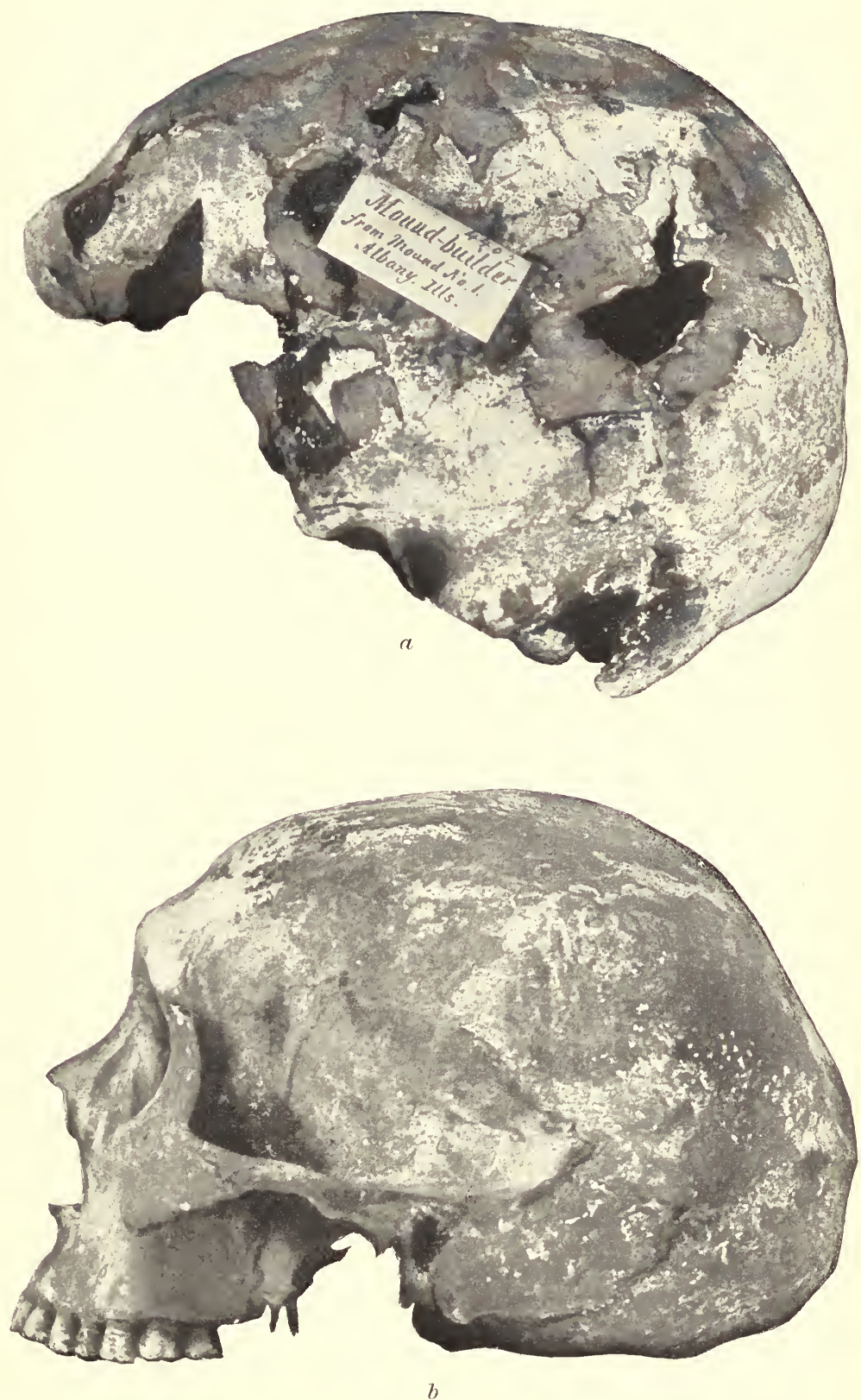

SKULLS WITH LOW FOREHEADS

a Side view of Illinois mound-builder skull (no. 4402, Davenport Academy of Sciences); $b$ side view of modern Sioux skull (Davenport Academy of Sciences) 


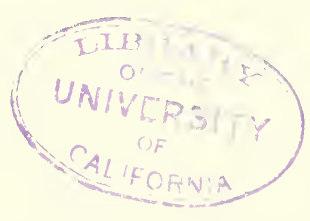



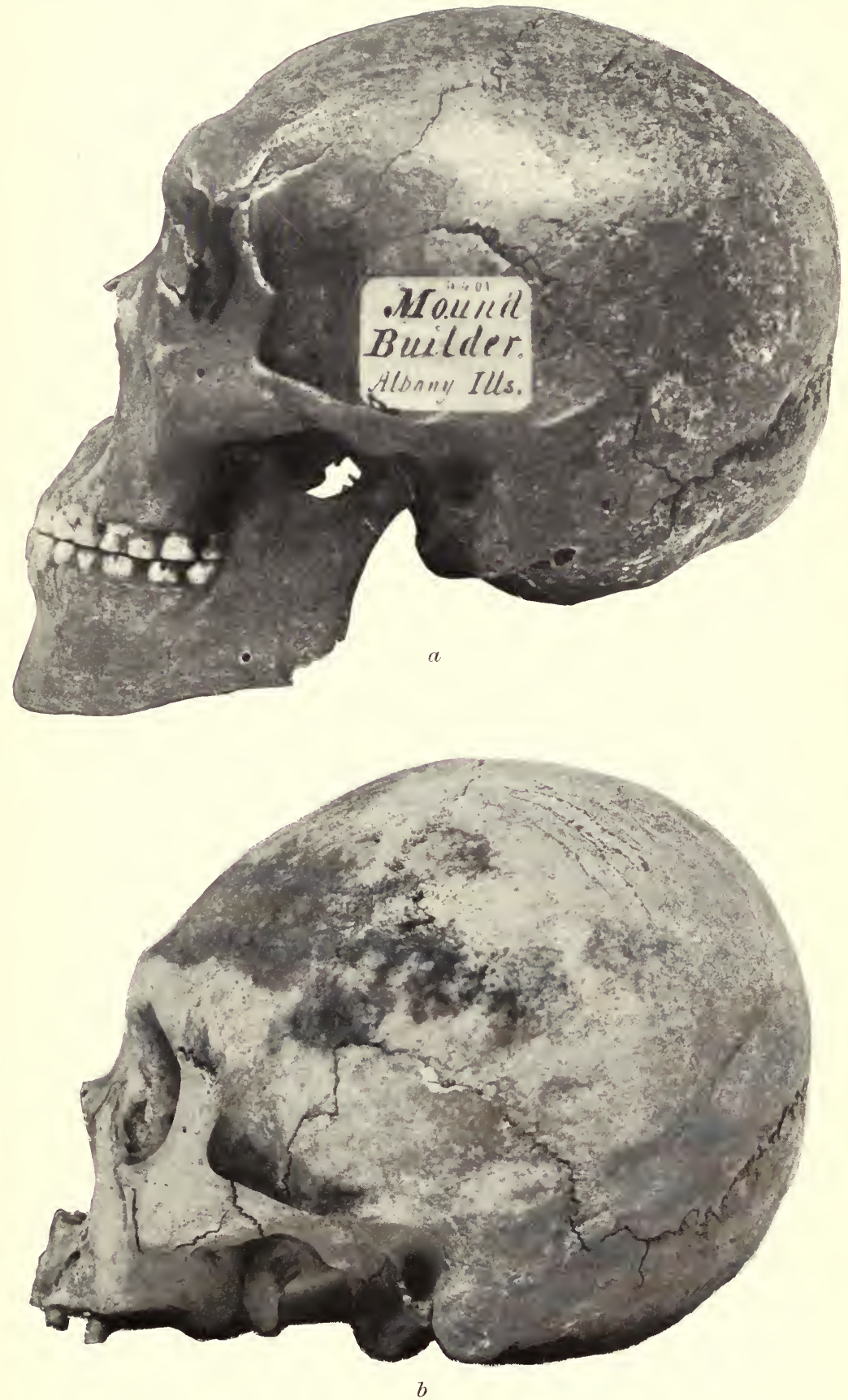

MOUND-BUILDER SKULLS (DAVENPORT ACADEMY OF SCIENCES)

$a$ Side view of skull from Illinois (no. 4401, Davenport Academy); $b$ side view of southern skull 


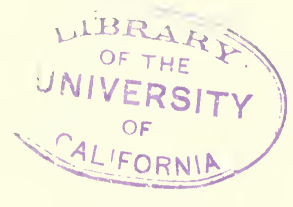


illustrations (plates xII, a, xII, a; figures 13-16) will show better than additional words could the type of these crania and their relation to the specimens from the mound in Nebraska.

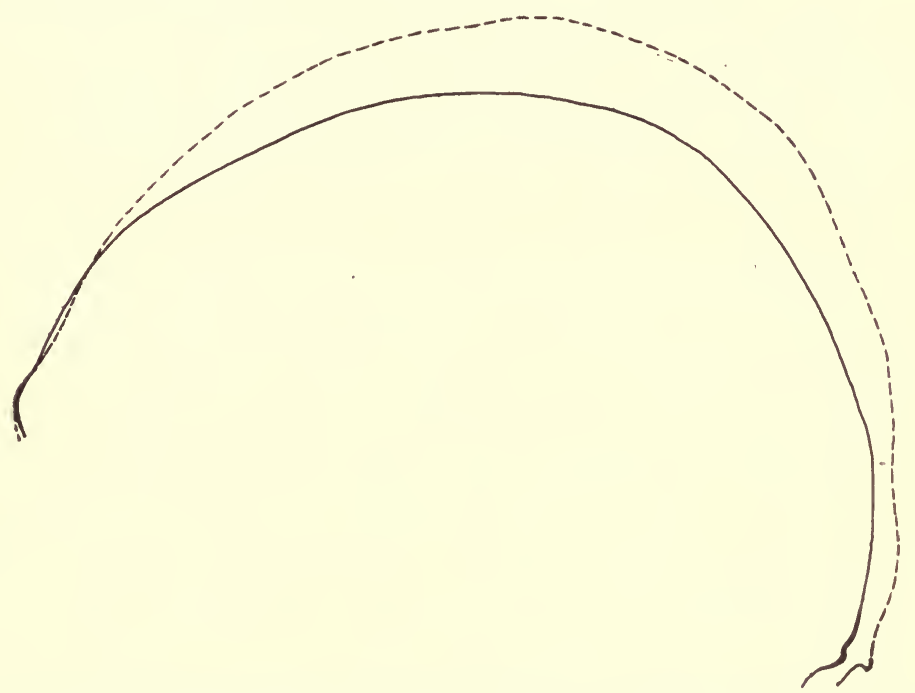

FIG. 15.-Antero-posterior arcs of skulls no. 242982, U. S. National Museum, and no. 6, Gilder mound. No. 242982, ; no. 6,

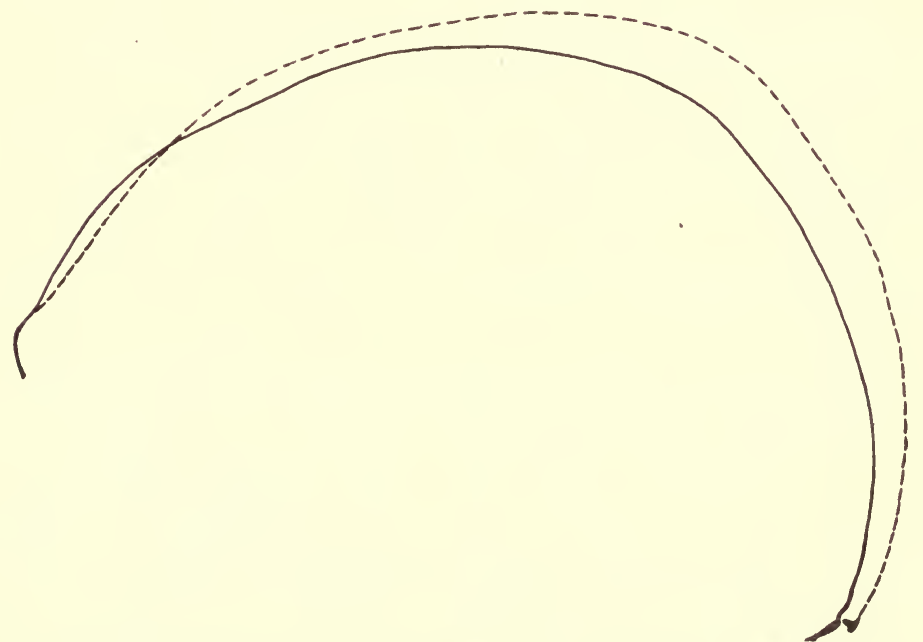

FIG. 16.-Antero-posterior arcs of skulls no. 242982, U. S. National Museum, and no. 8, Gilder mound. No. 242952, ; no. 8 ,

Still other specimens of low-type Indian crania may be adduced in this connection. Low forehead, or the absence of the frontal vaulting, occurs in rare instances-mainly in consequence of an apparently natural increase in volume of such sexual characteristics as the supraorbital ridges-in males among even the other class of mound 
skulls, namely, the brachycephals of Arkansas and farther south, and also among the skulls of recent Indians. Two such specimens, both from the Davenport Academy collection, are, the first, a normal, undeformed, Arkansas mound skull (plate xiı, $b$ ) and the other a skull of a modern Sioux (plate xiI, $b$ ), who died as a captive near Davenport. A recent examination of the great cranial collection in the U. S. National Museum showed the presence of the following additional skulls with remarkably low foreheads:

Catalogue numbers

From Indian burials in California 225176,241111 ,

$241912,241916,241927,241939,241998,242009,242014,242148,242200$ From mounds in North Dakota $228876,2.28878$ From a mound in Florida 16333

From a mound in Illinois 136778 From a mound in Illinois 242989 From a mound near Alton, Illinois 243007 From a mound in Orange county, Indiana 243855 From a mound near Sculleyville, Iowa 225296 From a mound at Eagle Point, Iowa 243845 From a mound at Albany, Iowal 243947

A Kaw, Kausas

$24: 544$

From a burial at Choptank, Maryland $24393: 3$

From a burial in Missouri

218993

A I'iegan, Montana

243673

From a burial at Durango, New Mexico

243275

From a burial at Pistol river, Oregon.

243602

From a burial at I'istol river, Oregon

243603

A Paiute, Nevadia

243817

A Pawnee, Kansas

243531

A Ponca, Kansas.

225097

A Sioux, Dakota

225238

A Sioux, Dakota

243710

A Ute, Utah

226084

From a burial at Balgley, Wisconsin

207874

From a burial in Wisconsin

243290

In most of these cases the lowness of the forehead and often also the volume of the ridges equal those of skull no. 6 from Long's hill, and in several instances they exceed this specimen in these particular. characters; no. 136778 shows even a lower forehead than the Gilder Mound skull, known as no. 8 (plates $\mathrm{x}, a, \mathrm{xr}, a$; figures $12,14,16$ ).

It is thus seen that the Gilder mound skulls are by no means unique in their low-order form, and that no definite conclusion as to their antiquity can be based on this inferiority or peculiarity of type alone. The occasional and apparently nonpathological occurrence of such forms in the males, particularly among the mesocephalic to dolichocephalic ethnic element ${ }^{a}$ of the upper Missouri and Missis-

a Suggesting in many ways the Californians; compare the writer's Contribution to the Physical Anthropology of California, University of California Publications, American Archeology and Ethnology, xv, no. 2, Berkeley, 1906. 
sippi, burying its dead in low circular mounds, the upper layers of which in numerous cases were hardened by fire, offers one of the most interesting problems to American anthropologists, largely because everything points to the fact that these low cranial shapes are comparatively recent phenomena and not occurrences of geological antiquity. Additional systematic exploration on a large scale of the mounds in the Central states is very much to be desired in this connection.

(f) The size of the Nebraska skulls and the thickness of bone (see detailed examination) are in no way exceptional when compared with similar dimensions in skulls of Indians. The thickness of the parietal bone exceeded in no case at its maximum $7 \mathrm{~mm}$. and was mostly a little below this. Professor Barbour in his paper in the Records of the Past mentions that the wall of one of the broken skulls measured $9 \mathrm{~mm}$. in thickness, but this measurement must have been taken on a bone other than the parietal. None of the fragments of the latter bone that passed under the writer's observation approximated such a dimension; but even if a very thick skull had coexisted with the others, the fact would justify no conclusion concerning the antiquity of the specimen. Thick Indian crania of a very moderate antiquity are very common in Florida and certain parts of Mexico, and occur also in other parts of the country.

(g) The long bones recovered from the mound show absolutely no type differences or racial distinction at the different levels, and in many of their characteristics approximate so closely to the corresponding bones in the Indian that their identification as Indian is permissible. Of particular value for this identification are the thickness and shape at the middle of the humeri, ${ }^{a}$ and here is found the slight relative thickness of the bone as well as the predominance of the plano-convex shape, both characteristic of the Indian. The platymery of the femora points in the same direction. The tibiæ are stronger and less platycnemic than on an average in the Indian, but were by no means unequaled among the Plains Indians who lived largely by the chase. The stature of the group of people represented in the Gilder mound, estimated from the long bones, was nearly 6 feet in the males, which is not uncommon also among the Sioux and other of the Plains hunters. Examination of the parts of the skeleton besides the skull furnishes substantial evidence that the bones have in general much more affinity with those of the Indian than with those of any other people. Speculation as to what particular tribe of Indians this group belonged would probably be fruitless, and is really not of great importance. The Omaha, it is

a A monograph showing in detail the pronounced differences in these bones between the white, negro, and Indian races is under preparation by the writer.

$3453-$ No. $33-07-7$ 
well known, were a comparatively recent arrival in that country. They may have been preceded in the region along the Missouri north of Omaha by the Mandan, the Pawnee, or the Arikara, or possibly by some offshoot of the Sioux. East of this region were the Oto and the Iowa, while little-known tribes of the Algonquian confederacy were settled in what is now the state of Illinois. ${ }^{a}$

(h) Besides all preceding considerations, it should be remembered that the ridge of Long's hill contained also at least one other mound which yielded human bones, and still another aboriginal burial. Such high places were the favorite locations for burials with the Indians on both sides of the Missouri, and it appears probable that the Gilder mound belongs simply to this category of Indian mortuary structures.

\section{XVIII.GENERAL, CONCIUUION}

The various finds of human remains in North America for which geological antiquity has been claimed have been thus briefly passed under review. It is seen that, irrespective of other considerations. in every instance where enough of the bones is preserved for comparison the somatological evidence bears witness against the geological antiquity of the remains and for their close affinity to or identity with those of the modern Indian. Under these circumstances but one conclusion is justified, which is that thus far on this continent no human bones of undisputed geological antiquity are known. This must not be regarded as equivalent to a declaration that there was no early man in this country; it means only that if early man did exist in North Imerica, convincing proof of the fact from the standpoint of physical anthropology still remains to be produced.

Referring particularly to the Nebraska "loess man," the mind searches in vain for solid ground on which to base an estimate of more than moderate antiquity for the Gilder Mound specimens. The evidence as a whole only strengthens the above conclusion that the existence on this continent of a man of distinctly primitive type and of exceptional geological antiquity has not as yet been proved.

There may be discouragement in these repeated failures to obtain satisfactory evidence of man's antiquity in America, but there is in this also a stimulus to renewed, patient, careful, scientifically conducted and checked exploration; and, as Professor Barbour says in one of his papers on the Nebraska find, "the end to be attained is worth the energy to be expended." A satisfactory demonstration of the presence of a geologically ancient man on this continent would form an important link in the history of the American race, and of mankind in general. The Missouri and Mississippi drainage areas offer exceptional opportunities for the discovery of this link of humanity if such really exists. 

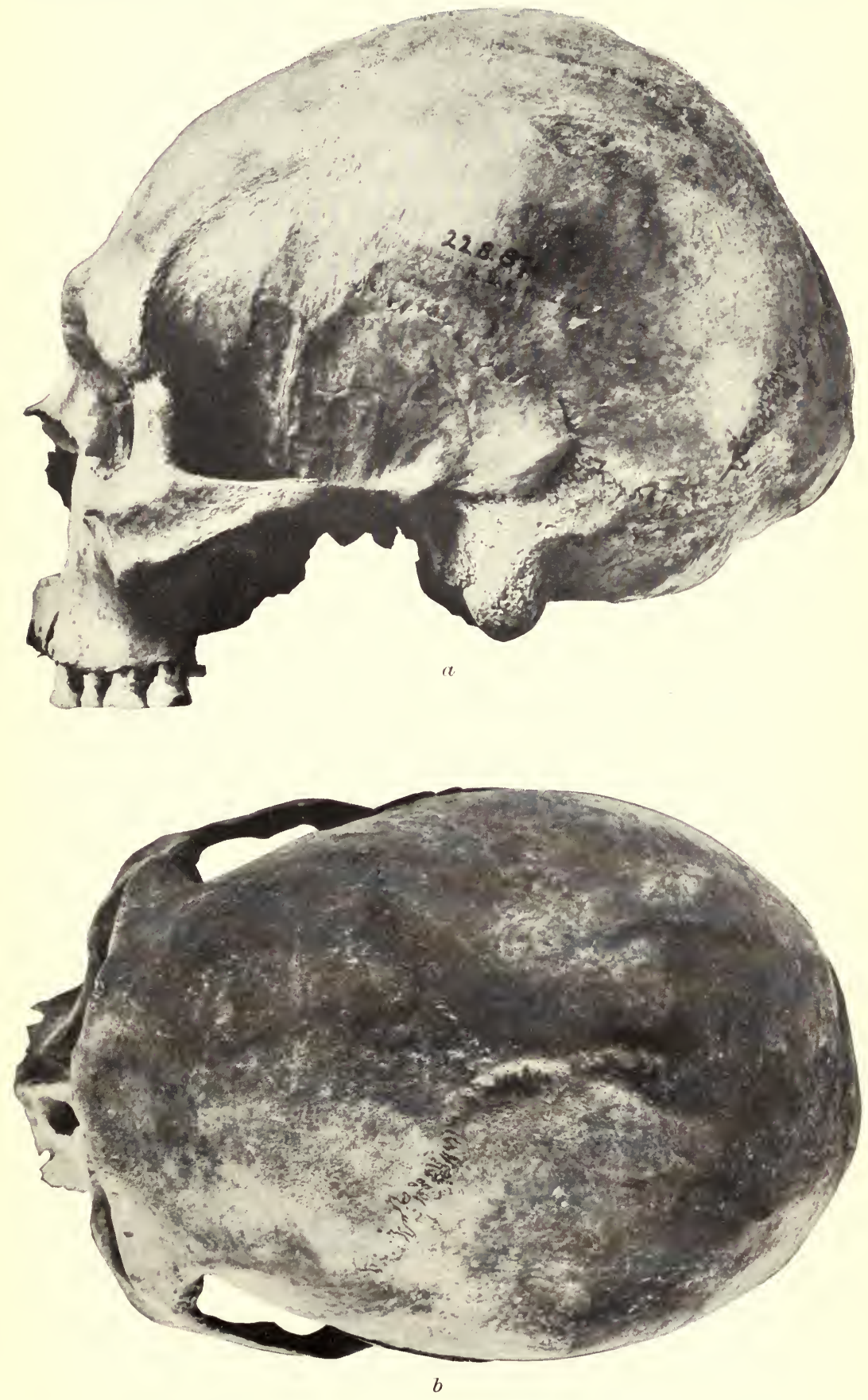

SKULL FROM MOUND IN NORTH DAKOTA (U. S. NATIONAL MUSEUM NO. 228876)

$a$ Side view; $b$ top view 


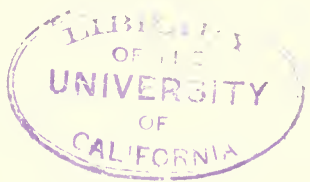



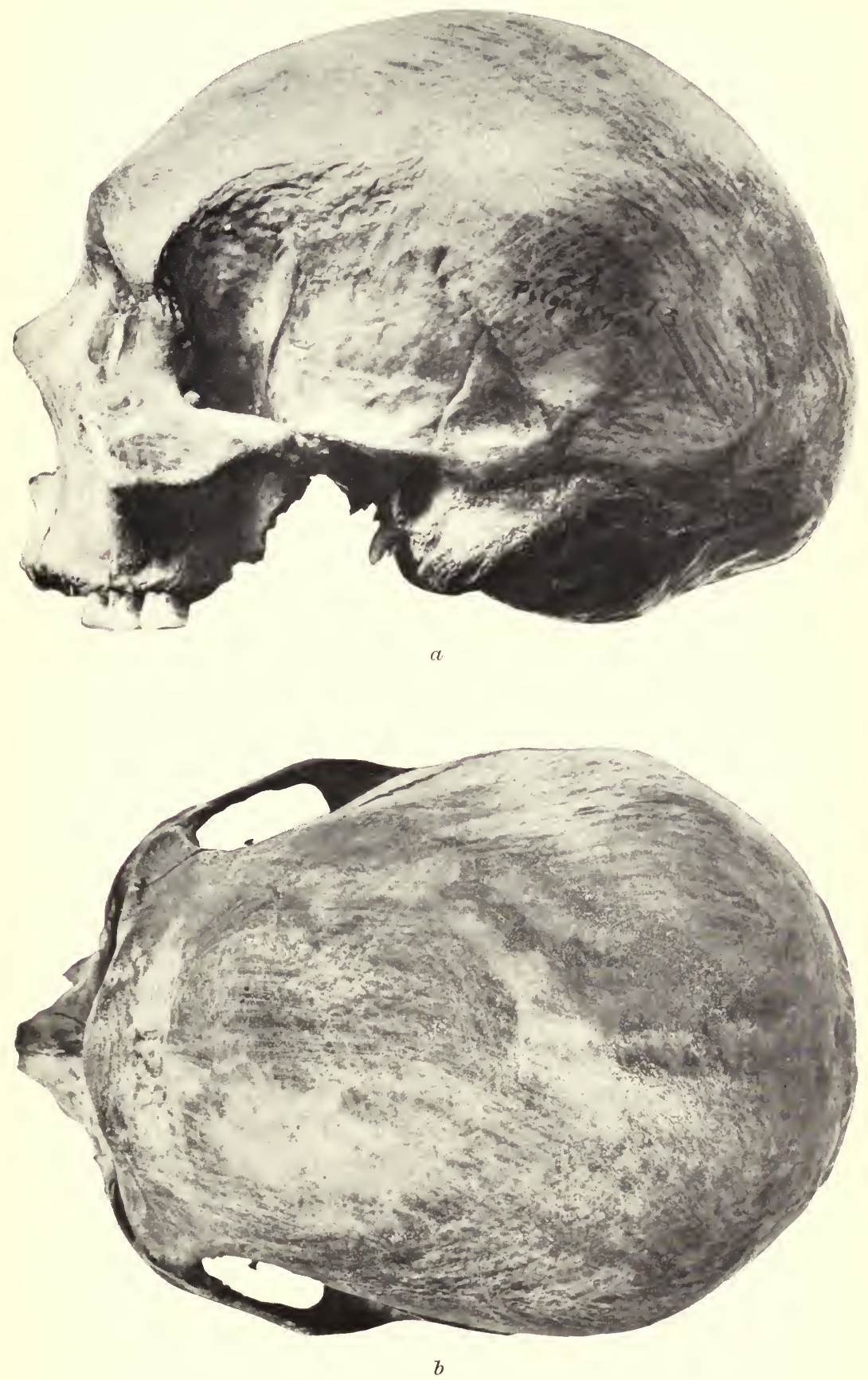

SKULL OF PIEGAN FROM MONTANA (U. S. NATIONAL MUSEUM NO. 243673)

$a$ Side view: $b$ top view 



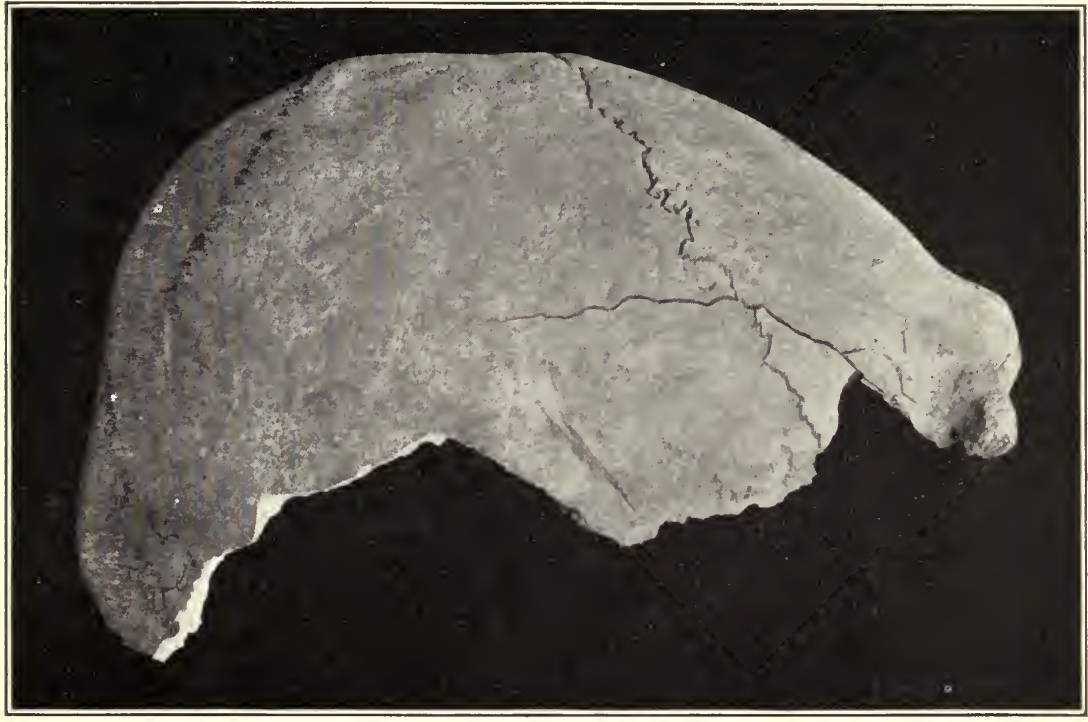

$a$

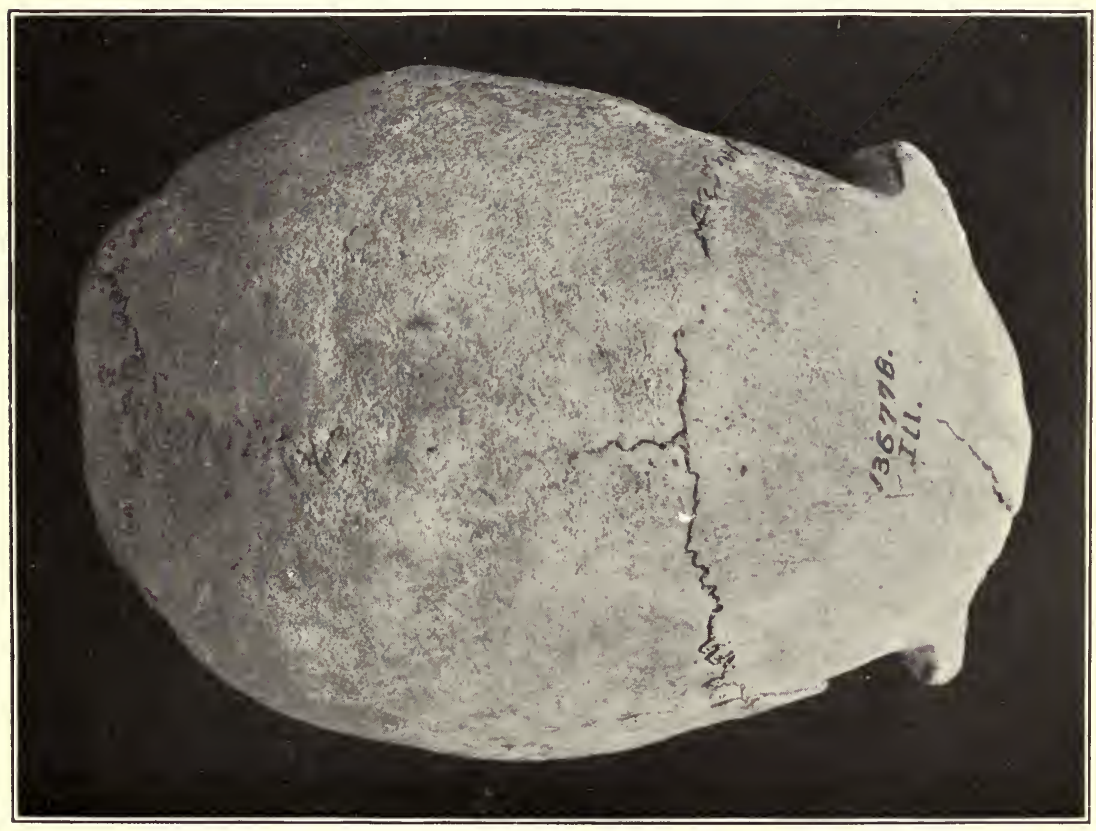

b

SKULL FROM MOUND NEAR BROWNING, SCHUYLER COUNTY, ILLINOIS (U. S. NATIONAL MUSEUM NO. 136778)

$a$ Side view; $b$ top view 


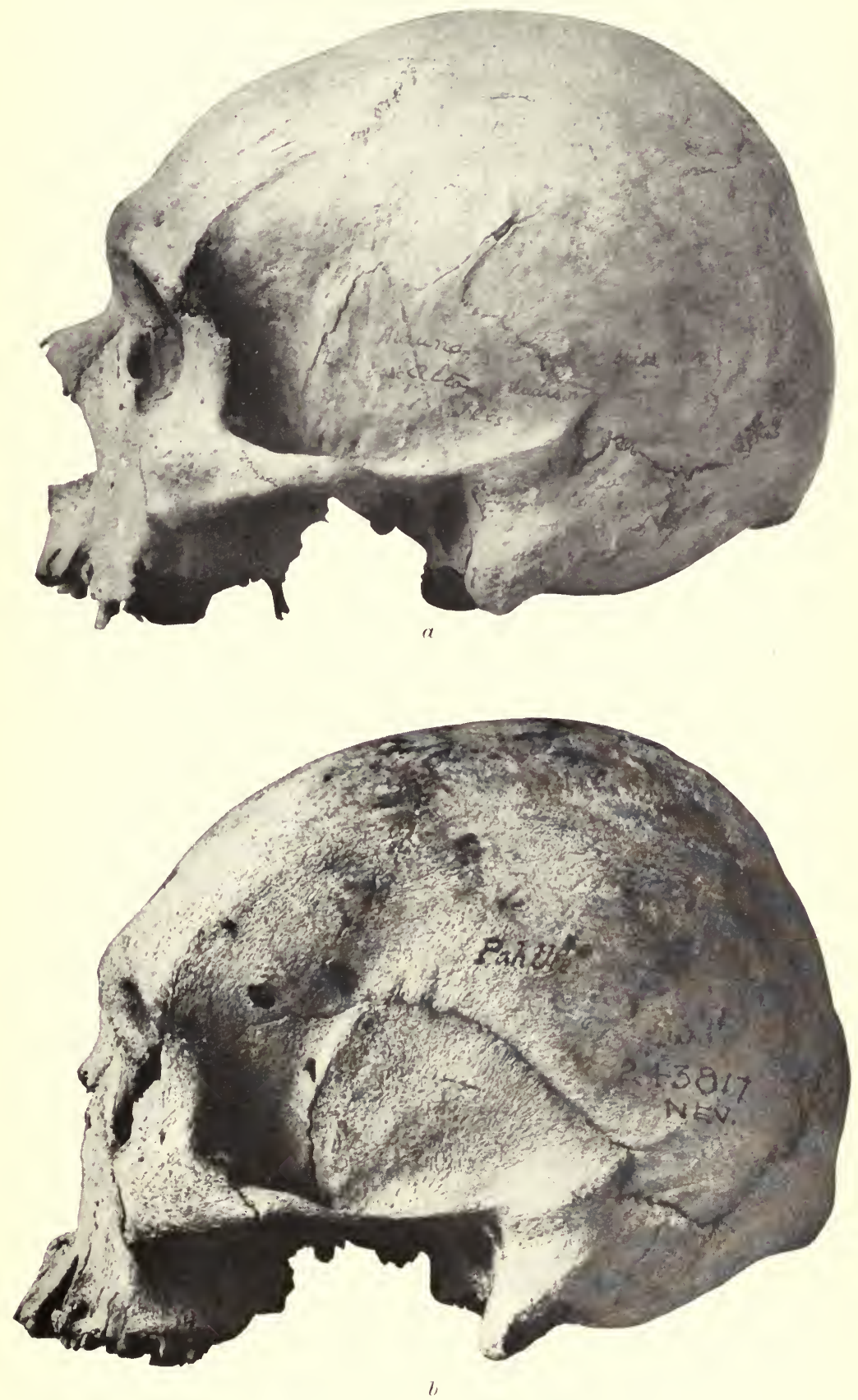

SKULLS WITH LOW FOREHEADS

a Side view of skull from mound near Alton, Illinois (U. S. National Museum no, 242982); $b$ side view of skull of Paiute, Nevada (U. S. National IIusemm no. 243817) 


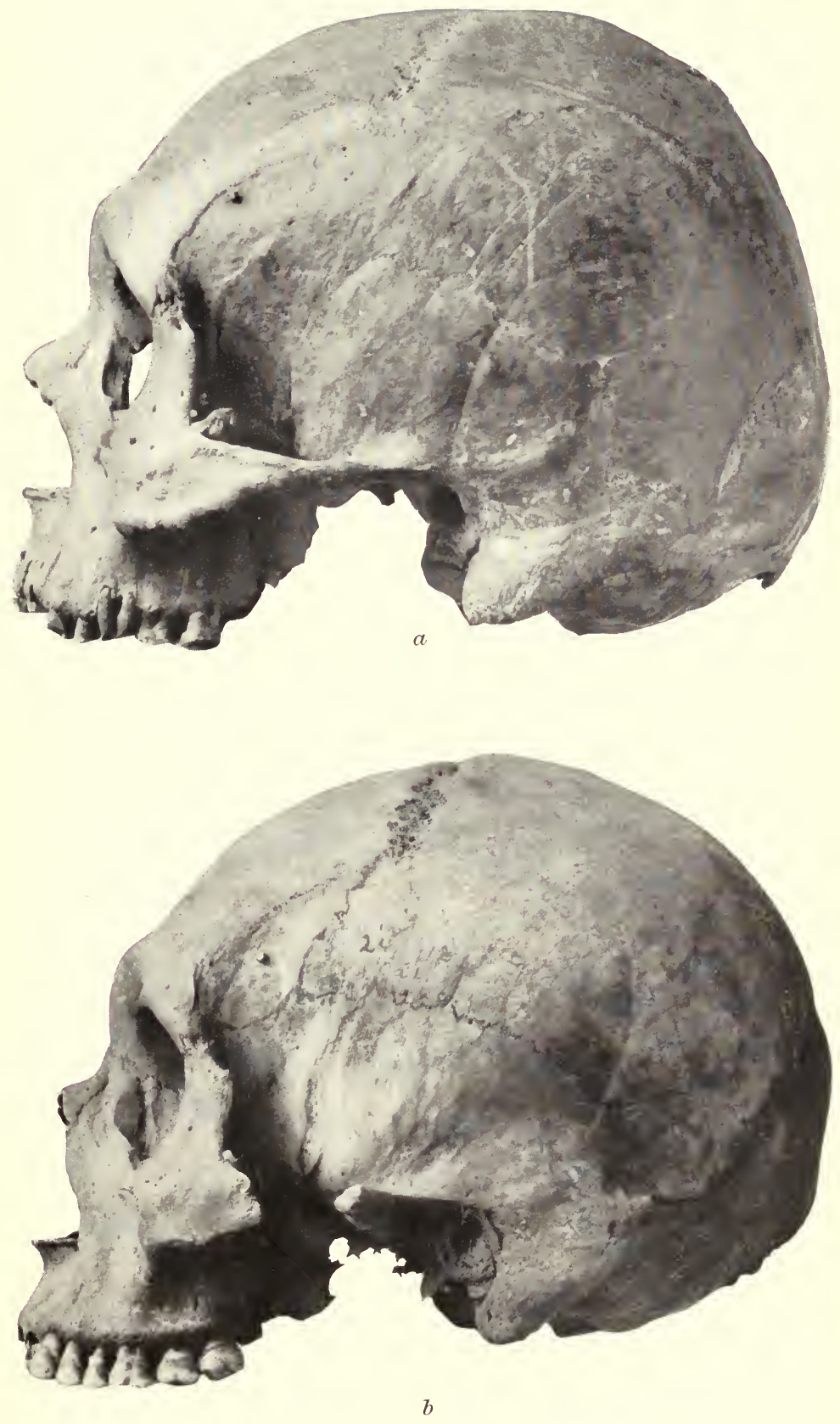

SKULLS WITH LOW FOREHEADS, FROM CALIFORNIA

$a$ Side view of skull from Calaveras county (C. S. National Museum no. 225173); $b$ side view of skull from Santa Barbara county (U. S. National Museum no, 211912) 


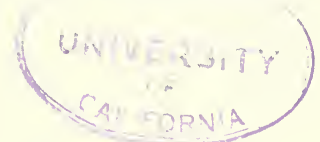



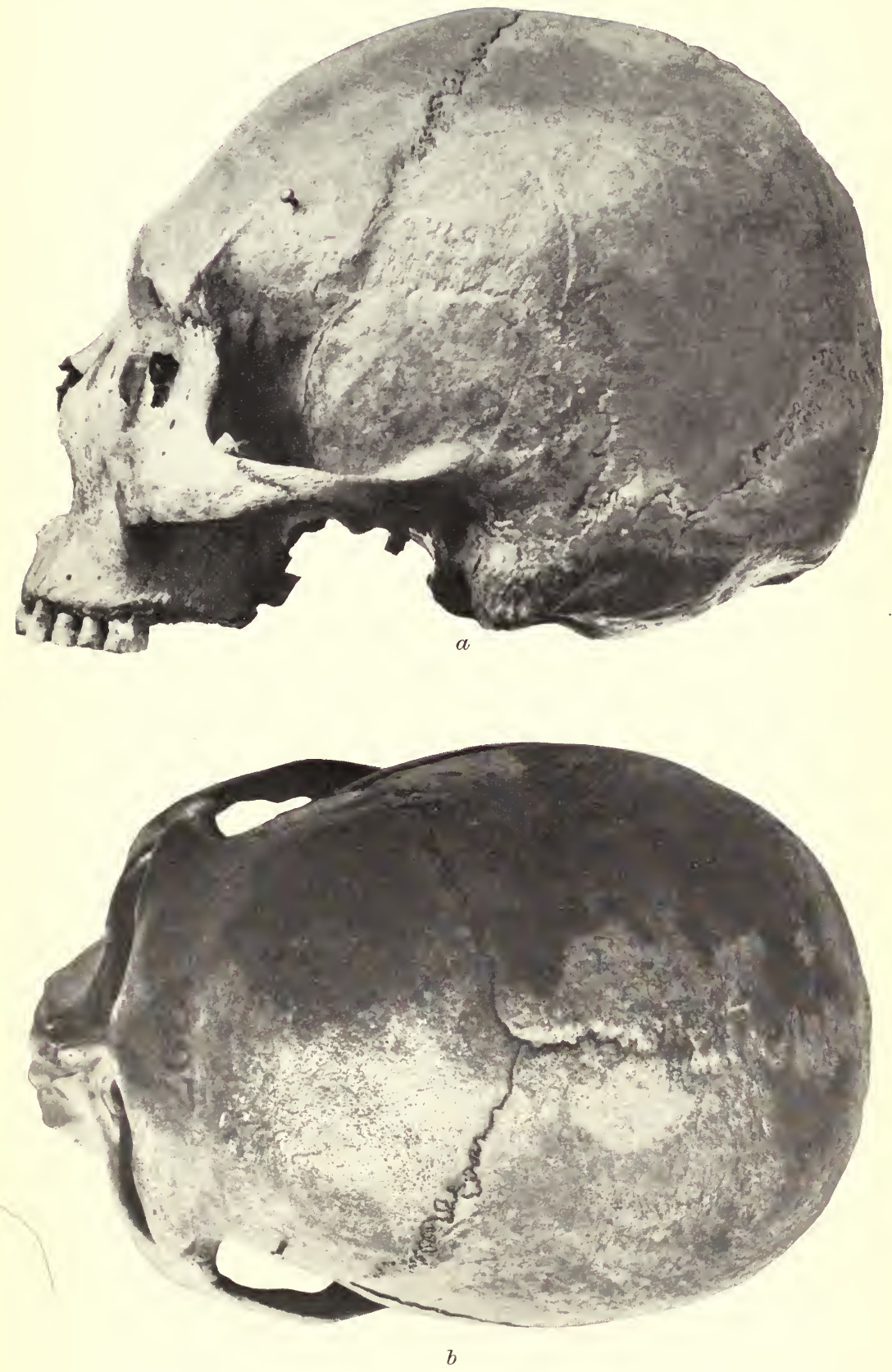

SKULL FROM SANTA CRUZ ISLAND, CALIFORNIA (U. S. NATIONAL MUSEUM NO. 241927)

$a$ Side view; $b$ top view 


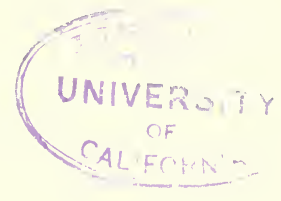




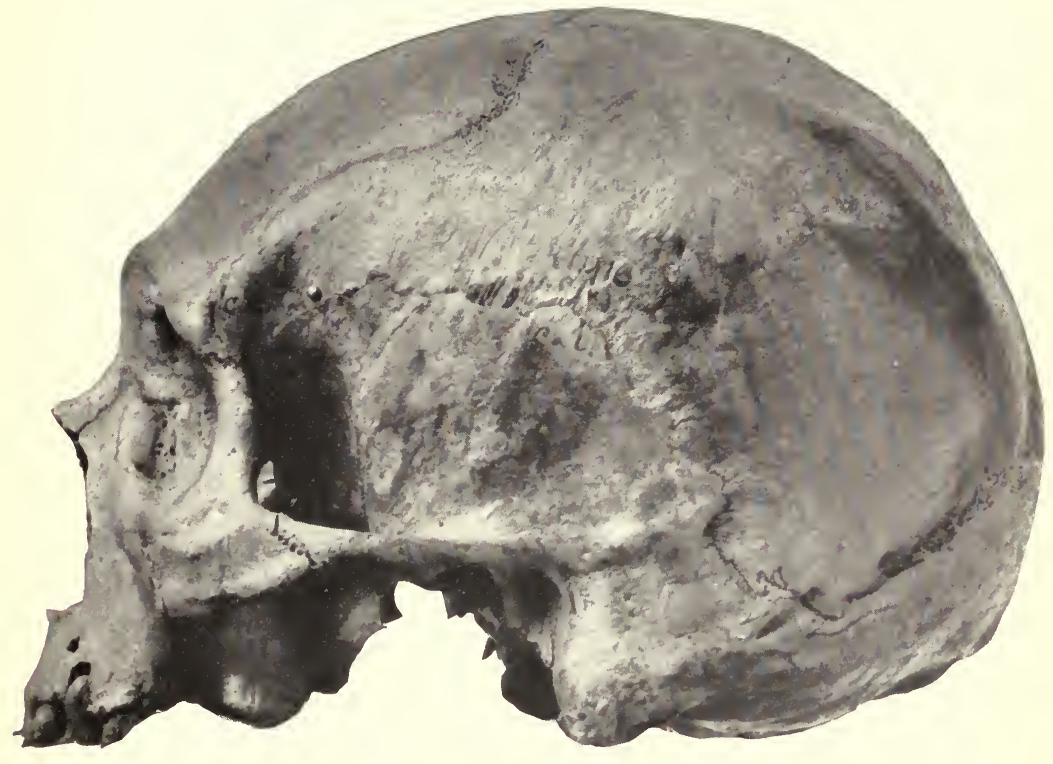

$a$

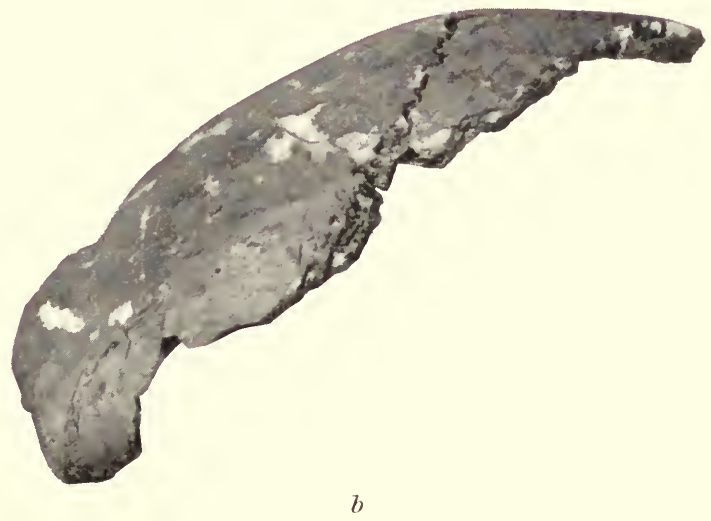

SKULLS WITH LOW FOREHEADS

a Side view of skull from Santa Cruz island, California (U. S. National Museum no. 241916); $b$ side view of skull from mound near Bagley, Wisconsin (U. S. National If useum no. 20787t) 


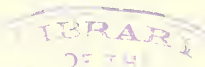

'NIVERSITY

○䛲

SAI IORNIA. 

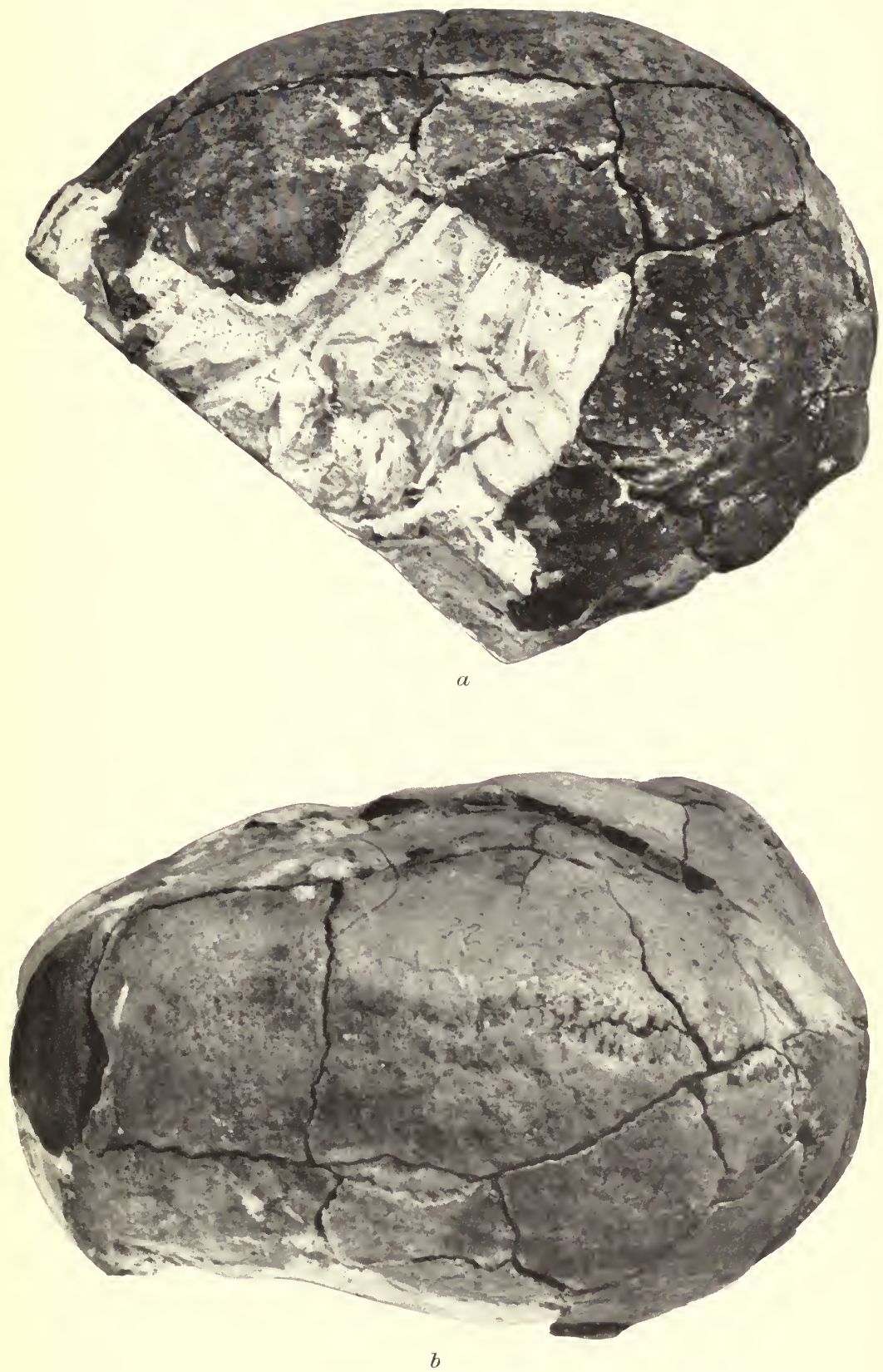

SKULL FROM MOUND IN ORANGE COUNTY, INDIANA (U. S. NATIONAL MUSEUM NO. 243855) $a$ side view; $b$ top view 



\section{XIX.-APPENDIX}

\section{Recent Indan Skullas of Low Type in the U. S. National Museual}

The preceding paper shows that in numerous cases great weight has been given to the low and sloping forehead, especially when accompanied by heary brows, as an index of low type and on occasion as evidence of antiquity.

The notion that the low forehead signifies low intelligence gainerl wide acceptance in the early part of the last century through the teachings of phrenology, while the connection of heary supraorbital arches and low front with human antiquity is prineipally due to the fact that these features in an exaggerated form characterize the crania of Neanderthal and spy (no. 1), the latter specimen, at least, being of undoubted geological antiquity. Subsequent to the discovery of these crania it became customary, even among men of science, to regard massive supraorbital ridges and low foreheads as necessary somatological accompaniments of antiquity in the human skull. This led to the rather premature acceptance of the view that early men in general were eharacterized by these features. that. in other words, these anatomical characters represent a developmental stage of man; and from this it was but a step to the acceptance of the notion that all occurrences not clearly pathological of similar formation are reversions-an impression which is prevalent to this day.

Following the intense interest produced in scientific circles by the discovery of the Neanderthal, Spy, Most (Bruex), Podbaba, and other skulls referred to the Quaternary period in Europe, there came in the course of time a number of reports by Busk. Davis, Blake, I'runerBey. Turner, Godron, and others, of nore or less recent crania with "neanderthaloid" features-that is, heary brows and low forehead-from different parts of Europe as well as from Asia and Australia. In account of most of these specimens will be found in Quatrefages and Hany's Crania Ethnica (I livraison, 27 et seq., Paris, 1876-7\%), and should be perused in this connection. The anomaly was unreservedly ascribed to atarism.

Nonpathological recent American crania with pronounced supraorbital ridges and low foreheads thus far have not been made the subject of a special report, yet such specimens are not very rare in our collections. The National Museum alone possesses a consider- 
able number (enumerated on page 96), and the writer will utilize this occasion to give a brief description, with illustrations, of the more remarkable of these specimens, without attempting to explain the cxact nature and cause of their peculiar features.

The whole subject of exceptionally large supraorbital arches and low foreheads deserves exhaustive anatomical study. A low sloping forehead does not oceur or has not yet been observed in the fetus and in infants and is extremely rare in the female sex. The same is true also of heavy supraorbital ridges. Hence both of these characters must he regarded as primarily ardult and sexual. Their relation is not constant. Most frequently heavy ridges and low forehead coexist and accentuate each other, but low front can be found, as will be seen in some of the specimens to be described, associated with only moderate ridges. and prominent brows are occasionally observed in skulls with good frontal arching. The ridges themselves offer sereral points for study. Ordinarily they form elevations which extend over from one-half to two-thirds of the median part of the supraorbital space, but in rare cases they extend along the whole supraorbital border. constituting an uninterrupted arch which may have a significance different from that possessed by the ridges of the more usual character. Ther are affected in volume by the frontal sinuses. but large ridges may coexist with relatively small sinuses and vice rersa, showing that some range of variation is inherent in the bony elevations themselves. The corrugator supercilii muscle attached to the glabella may also have some influence on the development of the parts of the ridges nearest to this attachment. I closer comparative anatomical study is necessary in this connection. IJeary supraorbital arches and sloping forehead are found in the adult male gorilla, but these features are much less apparent in the orang. chimpanzee, or gibbon, where we usially find a fairly well arched front, as well as in most of the lower primates.

The following descriptions and measurements of individual skull. show that in American crania low forehead and prominent supraorbital ridges are generally not associated with pathological conditions of the skull, or with premature occlusion of any of the sutures; where synostosis was observed, it was plainly senile in character. I number of the skulls show small size and according to the ordinary classification would be ranged as microcephals, but Indian skulls of these dimensions are not rare, and it is impossible to say that the small size of the brain of the individual is causally connected with the character of the front of any of the specimens. In two of the cases it will be seen that the cranial capacity is rely fair for Indians. It is an interesting fact that, with one not-very pronounced exception, all the low-front crania in the National Museum collection are dolichocephalic or mesocephalic, 
although the number of brachycephalic skulls examined was quite large. The writer is acquainted with only a single brachyceplialic skull that shows a low sloping forehead. This is the Indian cranium pictured in plate xur, $b$, of the preceding paper.

The antiquity of the specimens here described in no case is great. and several of the skulls are quite modern.

The cranial capacity was measured by the writer's methorl, explained in Srience, 1903 (page 1011 et seq.).

The illustrated skulls are placed in the alveolo-condylian plante.

\section{1.-SKTtL, FROM MOTND IX NORTI DAKOTA ( NO. .2.8876)}

\section{(I'late xir)}

A symmetrical and not diseased cranium of a man of about jos rears of age. The sagittal and coronal sutmes show adranced, the lambdoid slight, occlusion, which appears in no way premature.

The specimen is rather heary. Its low forehead is rery striking. The supraorbital ridges and glabella are very pronounced. The ridges are restricted to the median three-fifths of the supraorbital space; the remaining portion of the border above each orbit projects also forward, but is not massive, and is distinct from the ridge proper.

The slope of the forehead is uniform and the moderate convexity of the frontal bone presents no trace of the frontal eminences. From near the glabella to the vertex of the skull l'ums a median elevation, which is especially well marked bark of the bregma and gives the transverse plane of the skull in this region the outline of a pointed arch. The temporal ridges are well marked and reach on the right to within $2.2 \mathrm{~cm}$., on the left to within 1.f (m... of sagittal suture.

The face shows moderate prognathism, well-marked nasal gutters, and strong malars as well as zygome. The skull as a whole bears eridence of a strong musculature.

The teeth are of ordinary size and present no abnormality.

The base shows an anomalous fenestrum, formed by a process of bone passing from near the base of the external pterygoid plate to the sphenoid just outside of the foramen ovale.

Cuts in the rear of the foramen magnum and on the face indicate in all probability cleaning before a secondary burial.

\section{Measurements}

Diameter antero-posterior maximum ('entimeters.19. 1

Diameter antero-posterior from ophryon - do

Diameter lateral maximum dio_---

Basion-hregma height

('entimeters_-

Cranial module (mean diameter)

15. 53

Circumference above the ridges - centimeter's -52.0

Capacity. cubir contimeters_-

Thickness of left parietal above the squamous suture millimeters_-

Diameter frontal minimum _centimeters_-

Diameter frontal maximum (along coronal) do_--

Basion-nasion length (lo 


\section{B.-PIEGAN SKULL FROM MONTANA ( No. 243673)}

\section{(Plate xv)}

Skull of an aged male, without any sign of disease or deformation. The roronal, sagittal, and lambdoid sutures are, with most of the facial articulations, almost wholly occluded, but it does not appear that the shape of the skull on this account is in any way altered.

The supraorbital ridges and the glabella are voluminous (particularly the left ridge); the former are restricted to a little more than the median half of the supraorbital space. Above the ridges and along nearly the whole breadth of the frontal is a well-marked depression. The forehead is low and sloping. nerertheless it shows a distinct bend and small frontal eminences. There is a moderate, broad. median elevation of the region in front of the bregma and of a narrower ridge along the anterior fourth of the sagittal suture, giving to the anterior and posterior planes of the skull a pentagonal appearance. The parietal bosses are quite prominent.

The face is but slightly prognathic. The lower jaw is high; the chin prominent.

There is no indication of an extraordinary musculature.

The teeth are of average size. The denture shows the following anomalies: Congenital lack of all the third molars, and of the left lateral upper incisol: submedian size of the right upper lateral incisor and an anomaly of the median tooth; and a small supernumerary tooth between the right upper canine and the first bicuspial.

\section{lleasurements}

Diameter antero-posterior maximum centimeters_- 19.4

Diameter antero-posterior from ophryon (1) _- 18. ?

Diameter lateral maximum

Cephalic index

Basion-bregma height 72.9

Cranial module centimeters_-

Circumference

Capacity

Thickness of the left parietal

Diameter frontal minimum _centimeters__ 52. 2 cubic centimeters_- 1,470 millimeters_- $3-5$

Diameter frontal maximum centimeters__ 9.6

Basion-nasion length. do 11. 1

Facial height, total (teeth slightly woln) do_-_ 10.6

Facial height, upper__ _.

Facial breadth do_-_ 14. 3

\section{C.-SKILI, FROM MOUND NEAR BROWNING, SCHUYLER (OUNTY, ILIINOIS ( NO. 136778 )}

\section{(Plate xvi)}

This cranium shows the lowest natural forehead of any American skull with which the writer is acquainted.

It is regrettable that the specimen is very imperfect; the whole face and everything below the parietals, with a small portion of the occipital, are lacking. Further, this skull is not absolutely normal, for the surface of the upper part of the frontal and of the parietals shows several irregular depressions, which may be senile, or due to some old weakness or lesions of the bones. These 
depressions are not extensive; they do not extend to the inner table of the bones, and had only local effect on the shape of the skull and none perceptible on the lowness of the forehead. The extreme front of the skull is somewhat asymmetrical, the right side protruding forward more than the left. This asymmetry is also marked ventrally, but does not affect the rest of the skull.

The glabella is very prominent, and the same statement applies to the median extremities of the supraorbital ridges. The latter are limited to the median three-fifths of the supraorbital space, but owing to the small forward extension of the forehead, the remainder of the border on each side shows also a conspicuous projection. Abore the glabella and ridges is a depression, behind which rises the very limited arch of the forehead. The sagittal region is somewhat elevated. Between the vertex and inion the skull shows slight compression, due probably to cradle-board pressure.

The specimen is rather small (the greatest length measures about $18.4 \mathrm{~cm}$. ), but as the bones are not thick the capacity was probably in excess of $1,300 \mathrm{c} . \mathrm{c}$.

Ventrally the sutures are wholly obliterated, while dorsally most of the coronal, a part of the sagittal, and most of what is present of the lambdoid appear still open. There is no evidence that the state of the sutures has influenced in any way the shape of the skull.

The temporal ridges are only partially traceable, indicating no strong musculature.

The minimum frontal diameter in this skull amounts to only $8.7 \mathrm{~cm}$; the frontal maximum to $10.7 \mathrm{~cm}$.

\section{D.-SKULL FROM MOUND NEAR ALTON, ILliNOIS (NO. 242982)}

\section{(Plate xvir, a)}

The specimen is not deformed and, except in a part of the alveolar process, shows nothing pathological. It is plainly a masculine skull and belonged to an aging individual. The sagittal, median one-third of the lambdoid, and the coronal suture below the temporal ridges show, with some of the facial articulations, advanced senile occlusion.

It presents pronounced supraorbital ridges (restricted to the median threefifths of the supraorbital border), somewhat less voluminous glabella, and very low forehead, with but feeble frontal bend and but a trace of the eminences. The sagittal region is only slightly elevated. The ridges and other features indicate moderately strong musculature.

The face shows average (Indian) alveolar prognathism. The teeth are of ordinary size; third molars have never erupted (the skull is that of an individual at least 50 years of age; the lower jaw is missing).

The base shows the same anomaly as no. 228876 (page 101) - a fenestrum formed by a narrow bony septum, reaching from the lower part of the external pterygoid plate to the sphenoid, externally to the foramen ovale.

\section{Measurements}

Diameter antero-posterior maximum centimeters_- 
Circumference. centimeters

Capacity ('ubic rentimeter's 1. 255

'Thickness of the left parietal millimeters.

Diameter frontal minimum

Diameter frontal maximmm

Basion-nasion length do

10. 1

Facial height, upper

7..)

Facial breadth

14. 4

\section{E.-PAIUTE SKULL FROM NEVADA (NO. 243817)}

(Plate xir, b)

An undeformed and in no way diseased skull of an adult male. No trace remains of the basilar sutme, but the remaining cranial and facial sutures are all open.

The specimen is quite heavy and bears eridence of strong. though not excessive, musculature. It shows a prominent glabella; moderate masculine supraorbital ridges (limited to the median two-thirds of the supraorbital space); a gradually sloping. low forehead with only a trace of frontal bend and no sign of frontal eminences; and a median elevation which extends over the upper four-fifths of the frontal squama and up to obelion along the sagittal suture, wiving the top of the skull a scaphoid appearance.

The face presents a rather marked alveolar prognathism. The lower jaw shows no special features. The teeth were of ordinary size (all are now broken owing to exposure). The denture in the upper jaw is anomalous, there being three supernumerary teeth: one of these existed between the median incisors. and the second between the left lateral incisors and somewhat anterior thereto, while there is a socket on the left also for a somewhat diminutive extra tooth in the rear of the three molars. Notwithstanding the presence of 19 teeth in the upper jaw, the dental arch and palate are quite symmetrical, and there is nothing to correspond with the anomalies in the lower maxilla.

\section{Measurements}

Diameter antero-posterior maximum

Diameter antero-posterior from ophryon Diameter lateral maximum ..........

Cephalic index

liasion-bregma height

Cranial module

Circumference

Capacity

'Thickness of the left parietal

Diameter frontal minimum

Diameter frontal maximum .-

Basion-nasion length

Facial height, total (about)

Facial height, upper.--

Facial breadth... centimeters

18. 3

17.5

13. 4

do__._

7:3. 2

_centimeter's_- 13.0

14.90

_centimeters__ 50.7

(rubic centimeters_- 1, 290

_._millimeters__ $4-6$ _ontimeters_- 8.9 do__ 10.9

do__- 10.2

do___ 12.0

do

do_._ 14,0 


\section{F.-SKULL FROM CALAVERAS COUNTY, CALIFORNIA (NO. 225173)}

(Plate xvin, a)

The specimen, a skull of an aging male, is not deformed, and with the exception of an exostosis between the right mastoid and raginal processes shows nothing pathological. The various ridges and other features indicate strong though not excessive musculature. The sagittal suture is occluded, and the coronal, lambdoid, and several of the facial articulations show ndranced physiological synostosis.

The supraorbital ridges are pronounced, without exceeding the normal variation in this respect among male Indians; they extend over the median threefifths of the supraorbital space. The forehead is quite low and gradually slopes, presenting subaverage frontal bend and eminences. There is but a slight external metopic and sagittal crest, so that the outline of the transverse plane of the skull superiorly is but little pointed.

There is a moderate alveolar prognathism. The base presents several minor anomalies, and the exostosis above referred to, which is probably the result of a small tumor. The teeth are considerably worn off, but present nothing abnormal in size or number.

\section{Measurements}

Diametcr antero-posterior maximum centimeters_.

Diameter antero-posterior from ophryon

Diameter lateral maximum _..._........ _... Cephalic index _... 80.2

Basion-bregma lieight_..._._. Cranial module

Circumference _..... 50.5

Capacity _..._. cubic centimeters_- 1, 265

'Thickness of the left parietal___._.

Diameter frontal minimum________._. 9.2

Diameter frontal maximum _ _

Basion-nasion length _._._._._._._. 10.0

Facial height, total (teetl worn) 11.8

Facial leight, upper.

Facial breadth _...

(x.-SKCLL FROM SANTA BARBIR.I COLNTY, CALIFORNIA (NO. 241912)

$$
\text { (Plate xvili, } b \text { ) }
$$

A small, but plainly masculine, skull, from an aging, not very muscular individual. It is damaged, but in no way deformed or diseased. The sagittal suture is wholly occluded. a condition apparently somewhat premature, as the rest of the cranial and facial articulations are still patent; but this condition has not affected the shape of the skull.

The supraorbital ridges are pronounced, though not excessive for a male; they are limited to the median two-thirds of the supraorbital space. The forehead is very low and sloping, without distinct frontal bend or eminences. The upper part of the frontal squama shows a quite prominent median ridge, which broadens out as it proceeds backward and for a short distance is continuous 
along the sagittal suture. On account of this ridge the arch of the transverse plane of the skull is moderately pointed.

The temporal ridges are fairly well marked, but the muscular impressions and ridges on the occiput are weak.

The face shows a moderate grade of alveolar prognathism. The teeth are not large and present no anomaly.

The base show's on the left side one complete (proximal) and one slightly incomplete (distal) pterygo-spinous foramen or fenestrum, both formed on the median side of the foramen ovale.

\section{leasurements}

Diameter antero-posterior maximum _centimeters_- 17.1

Diameter antero-josterior from ophryon _do_-_- 16.6

Diameter lateral maximum do_-_- 13.4 Cephalic index 78. 4

Basion-bregma height 12.3 Cranial module 14.27

Circumference 47. 2

Capacity

Thickness of the left parietal

Diameter frontal minimum _millimeters_.

Diameter frontal maximum _centimeters_. do _._ 10.4

Basion-nasion length

Facial height, total 9. 7

Facial heiglit, upper 11. 8 Facial breadth, approximately

\section{H.-SKULL FROM SANTA CRUZ ISLAND, CALIFORNIA (NO. 241927)}

(Plate xix)

A symmetrical, nonpathological skull of a male of about 50 years of age. There is advanced occlusion in the sagittal, and some synostosis in the lambdoid suture, but all the other articulations are still patent. The condition of the teeth, which are somewhat worn, corresponds well to the state of the sutures, so that any premature ossification of the latter may be excluded.

The supraorbital ridges (limited to the median half of the supraorbital space) are of average masculine proportions and the same statement applies to the glabella, yet the forehead is low and sloping, presenting only a very moderate arching and no eminences. The region just anterior to the bregma and along the proximal half of the sagittal suture shows a well-marked elevation, which gives the skull a scaphoid appearance.

The face shows a medium grade of prognathism, and somewhat atypical, not very large nasal gutters. The zygomæ, with other features of the skull, indicate strong musculature. The teeth present nothing special. The base is free from anomalies of any importance.

\section{Measurements}

Diameter antero-posterior maximum centimeters_- 
Basion-bregma height centimeters..

Cranial module

Circumference centimeters_- 50.3

Capacity cubic centimeters_- 1, 365

Thickness of the left parietal millimeters_. $\quad 5-6$

Diameter frontal minimum centimeters_-

Diameter frontal maximum - _. do_-..-

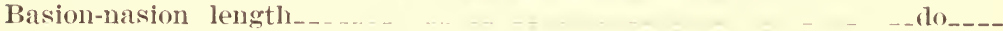

Facial height, total

Facial height, upper - $10+---$

Facial breatth

\section{T. - SIULI, FROM SANTA CRU\% ISLAND, CALIFORNA ( NO. 241916)}

(Plate $\mathrm{xx}, a)$

An undeformed masculine sinull. The sutures and teeth indicate a person 50 or somewhat more than 50 years of age. There is no trace of premature synostosis in any of the articulations.

The supraorbital ridges extend orer the median three-fifths of the supraorbital space and, while prominent, are not excessive. The glabella lies in a small depression between the ridges. The forehead, low and sloping, presents but moderate arching and mere traces of frontal eminences. The sagittal region anteriorly is slightly elevated.

The face shows a marked alveolar prognathism. The teeth are considerably worn off and several have been lost through disease, which affected to some extent also the left alveolar process, but there was apparently no anomaly of number or couformation.

\section{Heasurements}

Diameter antero-posterior maximum 18. 4

Diameter antero-posterior from ophryon Dianeter lateral maximum. 18. 1

Cephalic index do 13. 7

Basion-bregma height 74.5

Cranial module

15. 00

Circumference

Capacity

'Thickness of the left parietal

Diameter frontal minimum

Diameter frontal maximum -..

Basion-nasion length

Facial height, upper (lower jaw missing)

Facial breadth

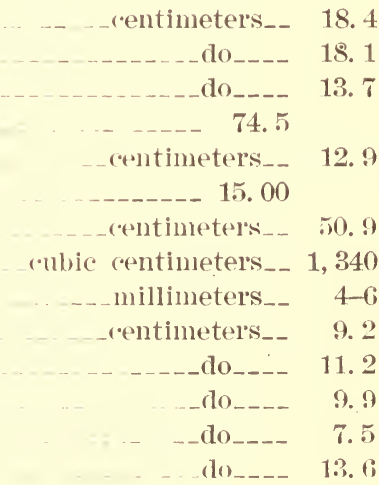

J.-SKULL, FROM MOUND NEAR BAGLEY. WISCONSIN (No. 207874)

(Plate $\mathrm{xx}, b)$

The only portions remaining of this specimen are the frontal bone and a small piece of each parietal. It was an adult masculine cranium. The sutures are patent dorsally but obliterated rentrally, pointing to an individual of more than 40 sears of age. 
The supraorbital ridges slow good but not extraordinary masculine development; they extend along the median three-fifths of the supraorbital space.

The forehead is low and very sloping. Its slight arching is gradual, showing no distinct frontal bend or eminences. A well-marked elevation is observed in the median line from above the ophryon to near the bregma. Sagittal elevation was not pronounced.

The skull was apparently of good size. The diameter frontal minimum measures $9.3 \mathrm{~cm}$.

K.-SKTLL FROM MOUNI) IN ORANGE (OUNTY, INDIANA (NO. 24:385.5)

\section{(Plate xxi)}

This specimen is reconstructed on a plaster base from pieces, and while in point of repair not perfect the main features of the rault are easily discernible. It is a long and narrow but not in any degree scaphocephalic or otherwise deformed skull, with a low, sloping, and but moderately arched forehead.

The supraorbital rilges and glabella are quite pronounced, lut their extent and volume are not clearly appreciable owing to the defective condition of the fragments. These features and the good-sized mastoids indicate a masculine cranium.

The sagittal region is quite elevated, giving the transverse plane above the shape of a pointed arch. The temporal ridges and occipital crests suggest strong musculature.

Occlusion is advanced in the sagittal and lambdoid sutures, and extends in some measure into the coronal, but there is no sign that the process in any place was premature.

The thickness of the skull is moderate and its capacity must have been good. 


\section{N D E X}

Abrott, Dr. Charles C., donor of Burlington County skull AFRICd, advent of man in

Agassiz, Professor, on lake Ionroe bones

AlBaNy MoUNDS, (rania from_ $31,75,93-9.7$

American Pleistocexe. (sec (ylacial period.)

AMERICA, peopled from Old World

ANTHROPOID SKULLS_.......... 31,100

ANTIQLITY OF M.AN-

general discussion

in I)elaware valley

in Florida

in North America

AlrikARA, arrival o: in ciilder iIound region .........

AKKANSAS MOUND SKULL

Asia, advent of man in

AISTRALIA NEgRO CRANIAL TYPL

IB.ArD, l'RoF. S. F., cited on locality of Rock Bluff skull _.

liaxkly, Ml., (xilder Mound remains. discovered by _.......-

BARBOER AND WARD, l'ROFEssors, on Nebraska "loess man" - $70-71$

barbotr, Prof. E. H.-

acknowledgments to

Filder Nound material furnished by _._.

on geological formation of Long's hill _._._._.

on human remains from Gilder mound _....... $78,8 \bar{\imath}, 97$

on Nebraska "loess man " ... 69-71.

$\tau 2,73-\tau+$

quoted on antiquity of man in North America _....... 98

somatological description of finds made by_ $81-8: 2,83,85,86$

BARCENA, MLARIANo, on Mitn of Peñon _.

BATAVIAN CRANIA_________- 42, 43

Berthocd, E. L., quoted on Soda Creek skeleton _._.-.--_

Blackmax, Irof. E. E., citerl on prehistoric man in Nebraska

BLAKr, cited on recent low-browed crania
BLEMENBACH-

Page

eited on suropean chamr-

cephals and Zuyder Ze:

Islands skulls_...... _ 42,43

Bog DEPosits, examination of 11

BотосUdo IxDIAxs, cranial type of $\quad 71$

BREMEN CIIAMACEPHALS _. _ _ . _ _ $43-46$

BRUEx (MOST) SFCLL____ 99

Bureau of American Ethnology, connection with-

Gilder Mound remains

60

IivRIALs, INTRESIVE - 11-1:

BLRLINGTON COIXTY SKTLL-

history _._.

physical (haracters ___ $37-38,39,41$

racial affinities

Busk, cited on recent low-browed crania__. 99

BUTLER, OMER, connection of with Gilder Mound explor: tion

BLTTs, E., locality of Lansing skeleton visited by .........

CALAVERAS (OTNTY LOW-BROWEI SKLLL__.

105

CALAVEKAS SKTLL-

comparisons with other crania_ $25-28$

history _...

physical characters___._._. 2-24, 30

preserved in I'eabody IIuseum _. 21

Calcareols coatiNg of osseots reMAINS____________ 27-28

CALIFORNIA INDIAX CRANA compared with Calaveras skull____ 25

CALIForia LOW-BRowed SKulls _ 105-117

Calvix, Professor, cited on Lansing skeleton

iase, Chinton A., connection of with Gilder Nound exploration

CASEY KEY BURIAL _._._._.

Caves, use of by primitive man _._ 11

Cexozolc era, divisions of ....... 9

('HAMACEPHALs, as a cranial type $-42-46$

('HAMBERLIN AND SALISBERY, cited on Glacial period....... 10

('HAMPLAIN EPOCH defined...... 17

CHAMPLAT LFOCTI defHed.

Charleston boxes _ _ 20-21

CHICKASAW MOUNDS_... 
Clark, George C., connection of with Gilder Mound exploration

Concannon, M., owner of site of Lansing skeleton

Condra, Doctor, connection of with Gilder Mound exploration

Cravia, comparison of undeveloped and developed

WALL, DR. WM. II.-

description of South Osprey remains received by _._._.-

usprey shells determined by ....

DAvis, cited on recent low-browed crania.

I ELAWARES, remains of in Helaware valley $35,36,+1-42$

DELAWARE VALLEY-

remains found in $35-36,+1-42$

settlement

(See also T'lenton crania, Trenton femur, Trenton gravels.)

Dei. (Astillo, Axtonio, on Man of l'eñon

IICKESON, 1)R. M. W., connection of with Natchez pelvic bone_ 16-19

DIGGERS, CRANIA OF

IORsey, Dr. GeOrge A.-

eited by W. II. Ilolmes on ('alaveras skull

quoted on Calaveras skull

Dowler. Dr. D. B., quoted on anti $i_{-}$ uity of man in Mississippi delta _..._._.....-

I)RAKF, l'rof. D., quoted on New Orleans skeleton

EAILY IAx, definition of term_...--

FGYPTAX CRANLA, ancient and modern_..............

EOCENE PERIOD defined

EskIMO CRANIA _........

Europe, advent of man in

WUROPEAN AXCIENT CRAXIA _..... 13, 7

chamæcephals

Flef, use of in mortuary mounds $--87-89$. $90,91,97$

FLorida-

antiquity of man in 19

bones of fossil mastodon in _..- 56,57

mound crania

(See also Hanson Landing remains, Lake Monroe bones, North Osprey bones, Osprey skull, South Osprey remains.)

Floy mot'xos

Fosstizition-

absent from Gilder Mound hones

character

90

ronditions

in Flolidil .

Fowke, G., cited on Lansing skeleton

"GASOMETER" SKULL 12,57
GEOLOGICAL TIME, classification of -Gildemeister, J., cited on Bremen chamæcephals

Gilder hound-

an Indian mortuary structure condition of bones in crania from, compared with Indian skulls

description

description of remains from distribution of remains in _.... human remains from vicinity -low-browed clania from _._._. type of long bones from _.__ 97-98 (See also Nebraska “ loess man.")

Gilloer, R. F--

acknowledgment to

74

cited on Nebraska "loess man"

finds made by. near Gilder mound _-_- 75, 82-83, 84-85, 86 on use of fire in Gilder mound__ $\quad 87$ quoted on exploration of (iilder mound

results of examination of finds made by $81,82,84-85,86$

GLACIAL GRAVELS_........ 10

llaworti, Prof. E., acknowledgments to

Heilpiin, Prof. Axgelo, on Hanson Landing remains_._.....

Hexis, Dr. E. C., cited on crania from Gllder mound .....

Hexky, Prof. Josepir, report on Osprey skull received by -.-

IFRrits, influence of on skeletal parts _.......

IIIS AND RUTIMEYER, cited on European chamæcephals _...-_

I!ItTell, J. S., donations by to National Museum _.____ 25-28

HOEvex, v. D., cited on European chamæcephals _.........

IIOLMES, Prof. F. S., Charleston bones discovered by _._. 20-21

age

$-10$

44

\section{8}

97

$7-76$
$6-82$

$7-89$

$-86$ 92

(n)

4

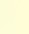

87

,

10

10
-10

HoLmes, Prof. WM. H.-

on Calaveras skull

on early man

on Lansing skeleton_______ 47,48

Human remaiss, general discussion of - 11-15. 
Huntington, Charles S.excavations near Gilder mound by

skulls found in Gilder mound by

ICE INVASIONS in North America.--

ILLINOIS L O W - B R O W E D MOUND SKULLS

$102-104$

ILLINOIS RIVER VALLEY-

crania from________ $31,32,93-94$ geology of ______ 28,29

INDIANA LOW-BROWED MOUND SKULL_ 108

INDIAN CRANIA-

compared with Burlington County and Riverview Cemetery skulls_........

from southern Florida

low-browed type-

general discussion.

$9 !-101$ specimens described

of Ilains tribes

secondary characteristies

thick types of moderite an

$$
\text { tiquity }
$$

INDIAN MOUNDS-

along Illinois river

29,31

use of fire in $\ldots \ldots \ldots . .89,90,91,97$

Indians, Nortil A Iraricanphysical characteristics present skeletal structure

49.50

INFILTRATION-

absent from Gilder Mound bones as a process in fossilization conditions of

INTRUSIVE BURIALS _. _. _ _ _. _ 11-12

Iows, arrival of in region east of ('ilder mound

Kollmas, .J.. cited on-

(ralaveras skull

Rock Bluff crinium

I,AKF MONROE BONES

IANSING SKELETIN-

accompanying remains

compared with Trenton crania

conclusion _.................

history

somatological characters

Leidy, Prof. Joseph-

on Charleston bones

21

on Hanson Landing remains _-_ 56,59

on Natchez pelvic bone_..._._. 18-19 on Osprey skull

$54,57,58$

I.ENAPE, remains of in Delaware valley _........ $35,36,41-4: 2$

LoNi, .I. C., cited in connection with Lansing skeleton

47,48

LONG'S HILL. (See Gilder mound.

Lyell, Sir Charles-

Lake Monroe bones mentioned by

on Natchez pelvic bone

Iyox, DR. M. W., identification of gopher's teeth by
MCCONNell, Mr., quoted on Rock Bluff skull__._.

MANDAN, arrival of in Gilder Mound region _.............

MIA OF PEX̃ON-

MAN OF SpY-

compared with Nebraska "loess man"

74

physical characters._._._._. 30,99

MARKEN ISLAND, skull from__.__ 43

MASTODON, bones of _._._._. 16, 17, 18, 21

Matrison, Mr., quoted by Whitney on Calaveras skull

22

MEGALONYX SKELETONS associated with human bones _- $16,17,18$

MIEIgs, J. AItken, on Rock Bluff cranium _........ 28

MIGRATIONS, IIUMAN _...

Miockene PERIOD defined

Montaxa low-browed I'iegan skull_- 102

MONTGOMery, I'ROFEssor, cited in connection with North Dakota mounds _.......

Morkis, WrLLiAn, excavations by in and near filder mound _. ti7, 82

Mertox, work of regarding antiq uity of man

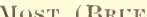

NOUND CRANIA-

artificial markings on _._._. 91

specimens described _._____ 101-104

witll low foreheads._._. 92

MISCTLAR ACTION, influence of on skeletal parts__._. 12

MYers, Chas. S., cited on ancient Egyptians

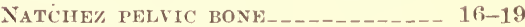

Nedinderthal skULL-

compared with Bremen chamæcephals _.............

compared with Iowa mound cranium -

compared with Nebraska "loess man" _._._. $71,74,80$

physical characters________ 30,99

NerRaska "LOeSS Max"-

bibliography _._.

conclusion as to antiquity $\quad 98$

history of finds_________ $67-70$

somatological description of remains-

from Gilder mound___._.- 76-82 from vicinity of Gilder mound _._._._-__-_- 82-86

views of men of science on _... $70 \ldots-74$

(see also Gilder mound.)

NeOlithic Max of Eriope_____ 71

Nerad LOW-Browfo PaIUTe SKulL 104

Newberry, Professor, cited on Man of I'eñon________ 32,33

16-18 New ORLEANS SKELETON _ _._. _ 14, 15

NORTH ПAKOTA LOW-BROWED MOUND SKULL. 




\section{DAY USE \\ RETURN TO DESK FROM WHICH BORROWED \\ LOAN DEPT.}

is due on the last date stamped below, or

on the date to which immediate recall.

Renewed books are su REC CIR DEC 121984

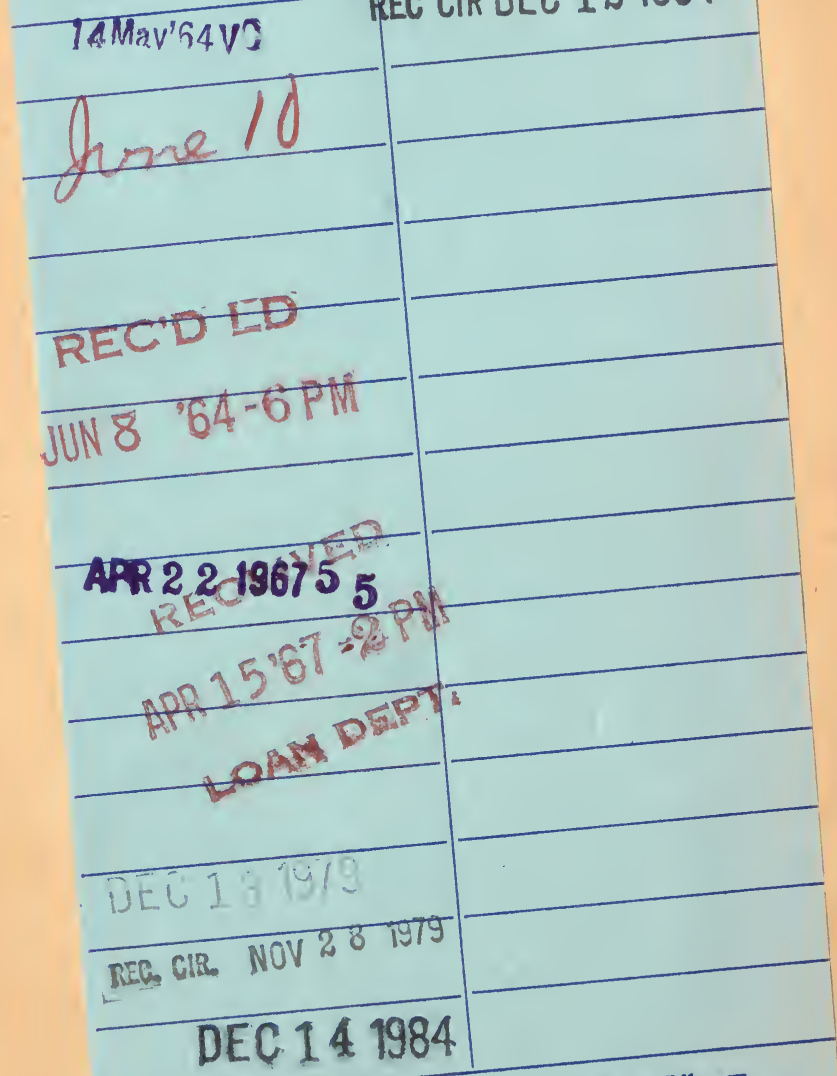

General Library

University of Californis

LD $21 \mathrm{~A}-40 \mathrm{~m}-11,{ }^{\prime} 63$

(E1602s10) 476 B 
GENEKAL LIBRARY - U.C. BERKELE B000723255

UNIVERSITY OF CALIFORNIA LIBRARY

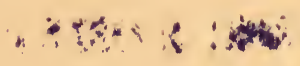


